\title{
Evaluation and Recommendation of Saltstone Mixer Auger/Paddles Materials of Construction for Improved Wear Resistance
}

J. I. Mickalonis

R. D. Torres

July 2012 
SRNL-STI-2012-00379

Revision 0

\section{DISCLAIMER}

This work was prepared under an agreement with and funded by the U.S. Government. Neither the U.S. Government or its employees, nor any of its contractors, subcontractors or their employees, makes any express or implied:

1. warranty or assumes any legal liability for the accuracy, completeness, or for the use or results of such use of any information, product, or process disclosed; or

2. representation that such use or results of such use would not infringe privately owned rights; or

3. endorsement or recommendation of any specifically identified commercial product, process, or service.

Any views and opinions of authors expressed in this work do not necessarily state or reflect those of the United States Government, or its contractors, or subcontractors.

\section{Printed in the United States of America}

Prepared for U.S. Department of Energy 
Keywords: Wear, Saltstone, slurry corrosion

Retention: Permanent

\section{Evaluation and Recommendation of Saltstone Mixer Auger/Paddles Materials of Construction for Improved Wear Resistance}

J. I. Mickalonis

R. D. Torres

July 2012

Savannah River National Laboratory Savannah River Nuclear Solutions, LLC Aiken, SC 29808

Prepared for the U.S. Department of Energy under contract number DE-AC09-08SR22470. 


\section{REVIEWS AND APPROVALS}

\section{AUTHORS:}

J. I. Mickalonis, Materials Science \& Technology

Date

R. D. Torres, Materials Science \& Technolog

Date

TECHNICAL REVIEW:

K. J. Imrich, Materials Science \& Technology

Date

APPROVAL:

K. E. Zeigler, Manager

Date

Materials Science \& Technology

K. M. Fox, Manager

Date

Environmental \& Chemical Process Technology Research Programs

J. E. Occhipinti, Manager

Date

SRR Engineering 


\section{ACKNOWLEDGEMENTS}

The authors wish to acknowledge Tracy Murphy for her diligence in conducting the corrosion testing and hardness measurements, to Jim Miller, WRES Inc., for expeditiously performing the wear testing in support of this task, and to Marissa Reigel for her helpful discussions and suggestions, as well as providing salt solution and dry feed components. The authors are indebted to Ken Imrich for sharing his knowledge on wear resistance materials and providing experimental assistance. The authors also want to acknowledge SRR Engineering for their support of this work. 


\section{EXECUTIVE SUMMARY}

Wear and corrosion testing were conducted to evaluate alternate materials of construction for the Saltstone mixer auger and paddles. These components have been degraded by wear from the slurry processed in the mixer. Material test options included PVD coatings (TiN, TiCN, and ZrN), weld overlays (Stellite 12 and Ultimet) and higher hardness steels and carbides (D2 and tungsten carbide). The corrosion testing demonstrated that the slurry is not detrimental to the current materials of construction or the new candidates. The ASTM G75 Miller wear test showed that the high hardness materials and the Stellite 12 weld overlay provide superior wear relative to the Astralloy and CF8M stainless steel, which are the current materials of construction, as well as the PVD coatings and Ultimet.

The following recommendations are made for selecting new material options and improving the overall wear resistance of the Saltstone mixer components:

- A Stellite 12 weld overlay or higher hardness steel (with toughness equivalent to Astralloy) be used to improve the wear resistance of the Saltstone mixer paddles; other manufacturing specifications for the mixer need to be considered in this selection.

- The current use of the Stellite 12 weld overlay be evaluated so that coverage of the 316 auger can be optimized for improved wear resistance of the auger.

- The wear surfaces of the Saltstone mixer auger and paddles be evaluated so that laboratory data can be better correlated to actual service.

- The 2-inch Saltstone mixer prototype be used to verify material performance. 


\section{TABLE OF CONTENTS}

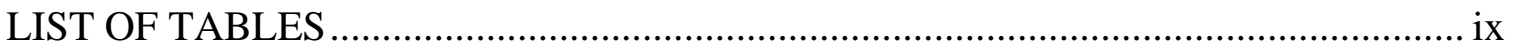

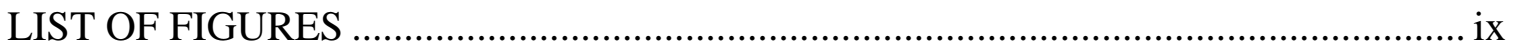

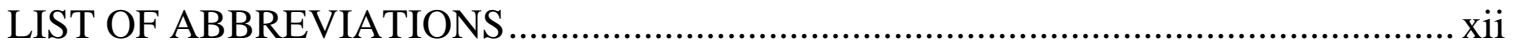

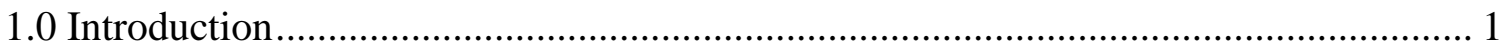

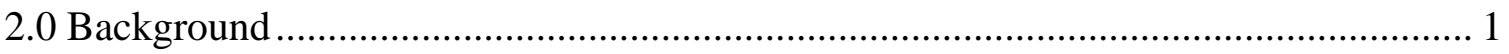

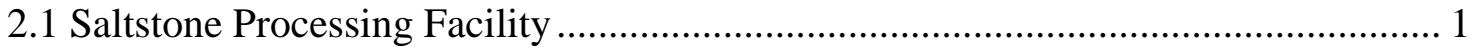

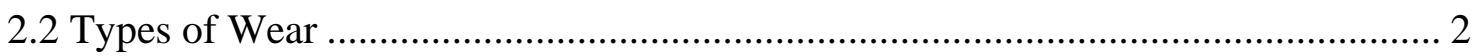

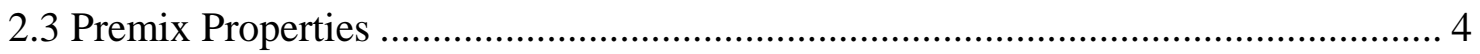

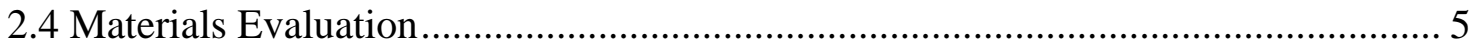

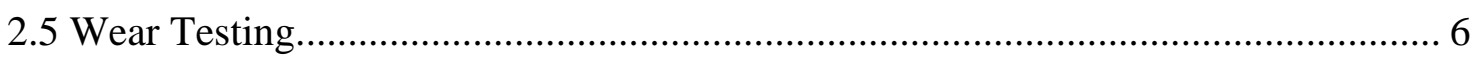

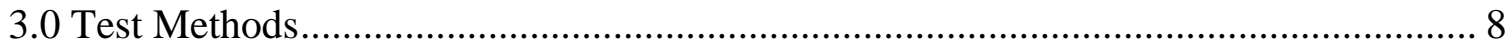

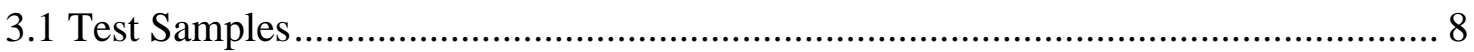

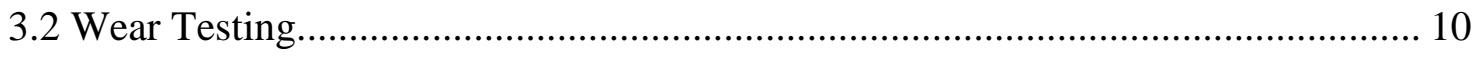

3.3 Electrochemical Corrosion Testing ................................................................... 11

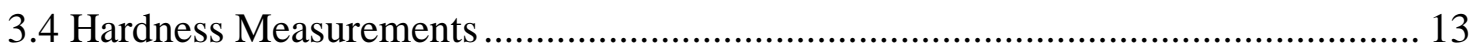

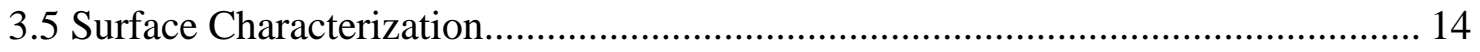

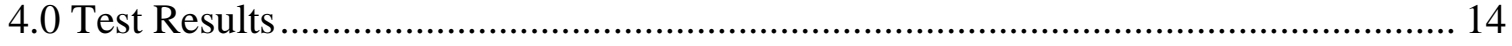

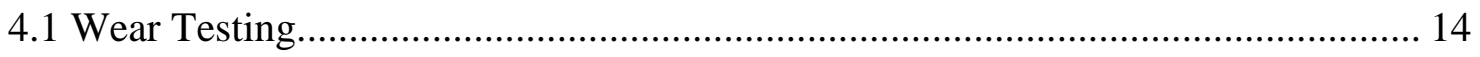

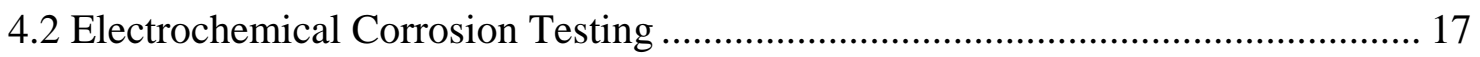

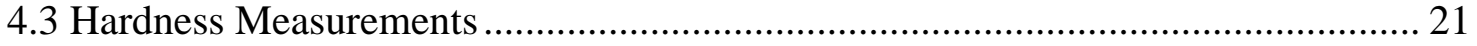

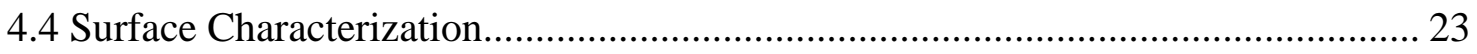

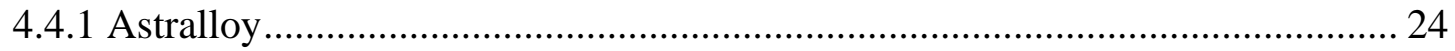

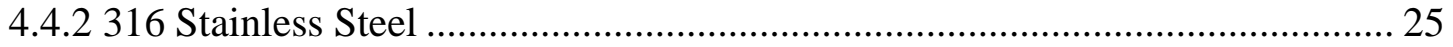

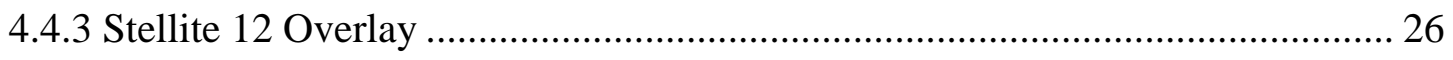

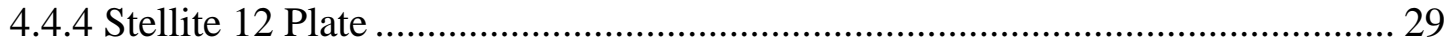

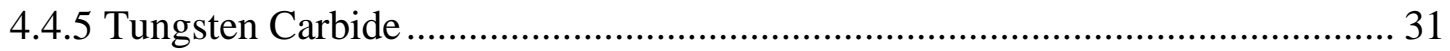

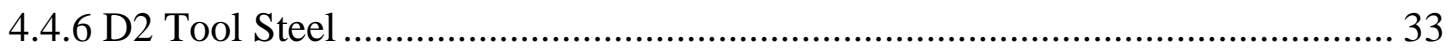

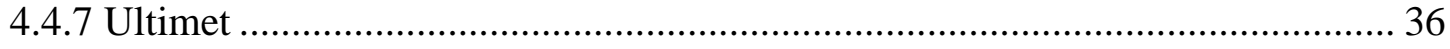

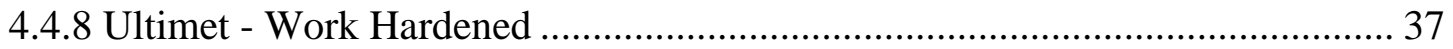

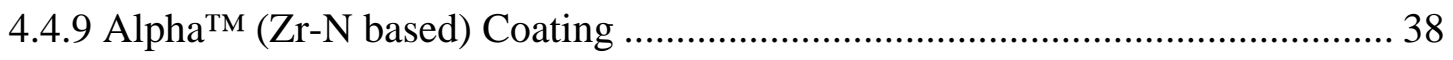




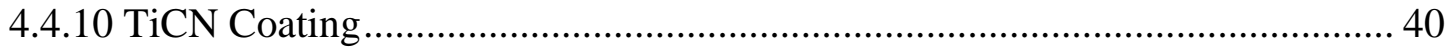

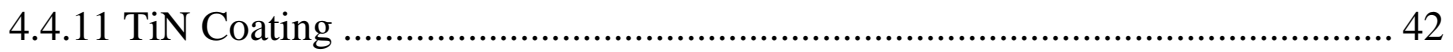

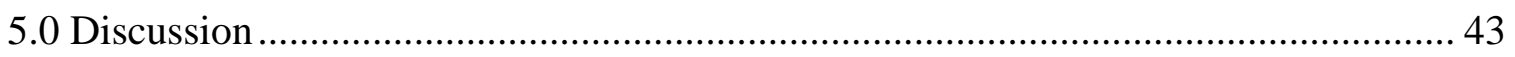

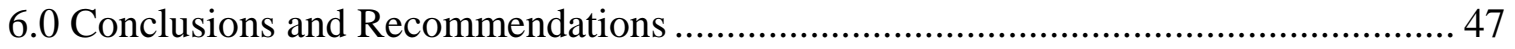

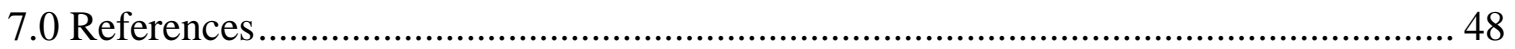

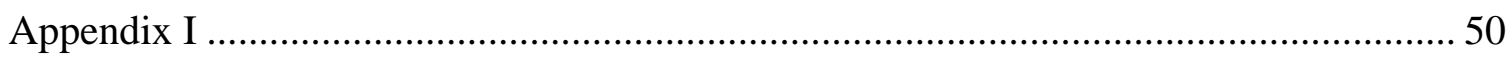

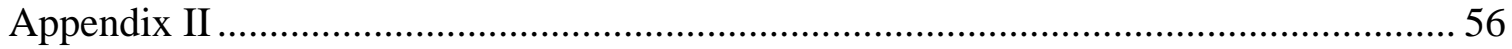




\section{LIST OF TABLES}

Table 2-1 Characteristics of the Saltstone Dry Feed Constituents ................................... 4

Table 2-2 ASTM Standard Wear Protocols Reviewed for Saltstone Mixer Wear Testing 7

Table 3-1 Nominal Chemical Composition (Wt \%) of the Candidate Materials of

Construction

Table 3-2 Material Values for Determining Corrosion Rate 12

Table 3-3 Salt Solution Composition Used in Corrosion Testing 13

Table 4-1 ASTM G5 Wear Test Results for Saltstone Mixer Candidate Materials of Construction 15

Table 4-2 Calculated Corrosion Rates and Open Circuit Potentials of the Candidate Materials of Construction in Slurry with Salt Solution 18

Table 4-3 Hardness Measurements of Candidate Materials of Construction 22

Table 4-4 Compositions (Wt\%) based on EDS Spectra for As-machined Wear Samples of Astralloy V, 316 Stainless Steel, and Stellite 12 Overlay.

Table 4-5 Compositions based on EDS Spectra for As-machined Wear Samples of Tungsten Carbide, D2 Tool Steel and Ultimet. 32

Table 4-6 EDS Compositions of PVD Coatings 39

Table 5-1 Comparison of Relative Wear and Average Hardness Values 44

\section{LIST OF FIGURES}

Figure 2-1 Schematic of Saltstone Processing Facility which shows the inputs into the Saltstone mixer. 2

Figure 2-2 Interior of Readco continuous mixer showing premix feed on the augers and the self-cleaning paddles 2

Figure 3-1 Saltsone mixer paddle used for testing: (A) before and (B) after sectioning.... 9

Figure 3-2 Wear Sample Dimensions 11

Figure 3-3 Locations of hardness measurements on the Astralloy and tungsten carbide samples

Figure 4-1 Mass losses during the ASTM G5 wear test for Saltstone mixer candidate materials of construction 15

Figure 4-2 Photomicrographs of dry feed constituent particles 16

Figure 4-3 OCP stabilization of the candidate materials of construction in slurry with salt solution 17

Figure 4-4 OCP stabilization of the TiCN and TiN coating in slurry with salt solution .. 18 Figure 4-5 CPP Scans for current materials of construction for the Saltstone mixer ....... 19 Figure 4-6 CPP scans for candidate PVD coatings for the Saltstone mixer..... 19 
Figure 4-7 CPP scans for candidate materials of construction for the Saltstone mixer.... 20

Figure 4-8 Stereomicroscope pictures of the candidate materials of construction after

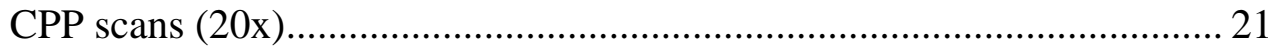

Figure 4-9 SEM micrograph and sum EDS spectrum of Astralloy wear specimens prior to

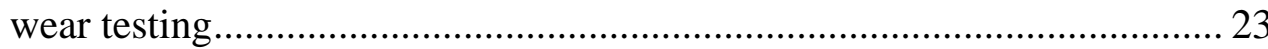

Figure 4-10 SEM micrographs of Astralloy V specimens after slurry/premix wear testing 24

Figure 4-11 Pits and filiform corrosion products observed in Astralloy specimens after slurry/premix wear testing.....

Figure 4-12 EDS mapping of corrosion products observed in the Astralloy surface after slurry/premix wear testing .................................................................. 25

Figure 4-13 SEM micrograph and sum EDS spectrum of 316 specimens prior to wear testing .

Figure 4.14 SEM micrographs of edges and surface of 316 specimens after slurry wear testing

Figure 4-15 Features on the 316 surface after wear testing: (A) metal fold; (B) surface particle

Figure 4-16 SEM micrograph and sum EDS spectra of as-received Stellite 12-overlay (on 316L stainless steel) prior to wear testing 27

Figure 4-17 Worn edges of Stellite 12-overlay specimens after wear testing 27

Figure 4-18 Stellite 12 overlay after wear test: (A) surface with less wear; (B) surface with more wear.

Figure 4-19 EDS compositional maps for high wear region from Stellite 12-overlay sample after wear testing 28

Figure 4-20 SEM micrographs of low (A) and high (B) abrasion regions in Stellite 12 overlay specimen tested under premix conditions

Figure 4-21 SEM micrographs of rounded edges and small gouging observed in Stellite 12 overlay specimen tested under premix conditions

Figure 4-22 SEM micrograph and sum EDS spectrum of EDM-cut Stellite 12 plate prior to wear testing 30

Figure 4-23 SEM micrographs of variable morphology lines/areas in Stellite 12 plate after premix wear testing.

Figure 4-24 SEM micrographs of Stellite 12 plate edge and high wear after premix wear testing

Figure 4-25 EDS compositional maps for high wear region from Stellite 12 plate after wear testing

Figure 4-26 SEM micrograph and sum EDS spectrum of surface of as-machined tungsten carbide wear specimen 
Figure 4-27 SEM micrographs of edge and surface of tungsten carbide samples following wear testing. 33

Figure 4-28 SEM micrographs of surface of as-received D2 tool steel wear specimens . 33

Figure 4-29 SEM micrograph and sum EDS spectrum of surface of as-received D2 tool steel wear specimen.

Figure 4-30 SEM micrographs of edges of D2 tool steel samples after wear testing....... 34

Figure 4-31 EDS compositional maps of dark (low secondary electron yield) features in surface of D2 tool steel specimen following wet slurry wear testing......... 35

Figure 4-32 EDS compositional maps of light (high secondary electron yield) features in surface of D2 tool steel specimen following wear testing. 35

Figure 4-33 EDS compositional maps of raised block features in surface of D2 tool steel specimen following wear testing. 36

Figure 4-34 EDS compositional maps of raised block features in surface of D2 tool steel specimen following wear testing ....................................................... 36

Figure 4-35 SEM micrograph and sum EDS spectrum of surface of as-machined Ultimet wear specimen

Figure 4-36 SEM micrographs of edge and representative surface of Ultimet steel specimens following wear testing

Figure 4-37 EDS compositional maps of material lodged at intersection of weld overlays in Ultimet steel specimens following wear testing. 38

Figure 4-38 Hardness values of common PVD coatings .............................................. 38

Figure 4-39 Sum EDS spectrum of surface of Alpha ${ }^{\mathrm{TM}}(\mathrm{ZrN})$ coated wear specimen..... 39

Figure 4-40 EDS compositional maps of surface of Alpha ${ }^{\mathrm{TM}}$ coated specimens following

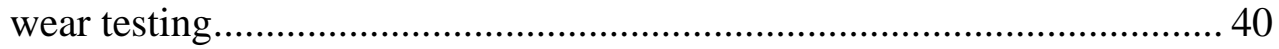

Figure 4-41 SEM micrographs of surface of TiCN coated wear specimens ................... 40

Figure 4-42 Sum EDS spectrum of surface of TiCN coated stainless steel wear specimen

Figure 4-43 SEM micrographs of TiCN coated stainless steel specimens following wear testing 41

Figure 4-44 EDS compositional maps of surface of TiCN coated stainless steel specimens following wear testing 42

Figure 4-45 SEM micrograph and sum EDS spectrum of surface of TiN coated stainless steel wear specimen.

Figure 4-46 SEM micrographs of TiN coated stainless steel specimens following wear testing . 43

Figure 5-1 Saltstone mixer with worn augur (circled). 45 


\section{LIST OF ABBREVIATIONS}

$\begin{array}{ll}\text { CF8M } & \text { Cast } 316 \text { stainless steel } \\ \text { CPP } & \text { Cyclic polarization resistance } \\ \text { CR } & \text { Corrosion rate } \\ \text { EDM } & \text { Electro-discharge machining } \\ \text { EDS } & \text { Electron dispersive spectroscopy } \\ \text { GBFS } & \text { Granulated blast furnace slag } \\ \text { HF } & \text { Hard facing } \\ \text { HV } & \text { Vickers hardness scale } \\ \text { KH } & \text { Knoop hardness scale } \\ \text { LPR } & \text { Linear polarization resistance } \\ \text { NHE } & \text { Normal hydrogen electrode } \\ \text { OCP } & \text { Open-circuit potential } \\ \text { PVD } & \text { Physical Vapor Deposition } \\ \text { R } & \text { Rockwell hardness B scale } \\ \text { R } & \text { Rockwell hardness C scale } \\ R_{\mathrm{p}} & \text { Polarization resistance } \\ \text { WC } & \text { Tungsten carbide } \\ \text { SAR } & \text { Slurry Abrasion Response } \\ \text { SEM } & \text { Scanning electron microscope } \\ \text { SPF } & \text { Saltstone processing facility } \\ \text { SRNL } & \text { Savannah River National Laboratory } \\ 30 N & \text { Rockwell superficial hardness }-30 \text { Kgf } \\ 316 & \text { 316 stainless steel }\end{array}$




\subsection{Introduction}

Wear on the Saltstone mixer has affected the process rate of grout which led to backups of premix in the mixer chute and subsequent shutdown of the facility.[1] Significant wear occurred on the mixer auger and the first set of mixing paddles. The paddle wear minimized the self-cleaning capability and allowed a buildup of grout and a reduced throughput flow. SRR Engineering initiated a request to SRNL for evaluating more wear resistant materials of construction for the auger and paddles as well as other paddle configurations to reduce wear.[2]

In March 2011, premix began backing up in the chute between the mixer and the weigh hopper, tripping the mixer chute 7-foot indicator, which requires the facility to be shutdown. [1] During troubleshooting of the mixer in May 2011, significant wear was found on the last flight of the mixer augers and the first two sets of mixing paddles, which are just upstream of the salt solution inlet. The wear on the paddles minimized the self-cleaning capability of the mixer, leading to a build-up of premix and reduced throughput. Currently, the Saltstone mixer uses Astralloy V steel for the paddles and for the auger CF8M, which is a cast stainless steel similar in composition to Type 316 stainless steel, as the base material for the auger with a Stellite 12 (Co-Cr alloy) weld overlay on the auger tips. This report discusses the investigation of wear resistant materials of construction only.

This task involved a literature review of applicable materials and wear tests, wear testing of materials according to ASTM G75, "Determination of Slurry Abrasivity (Miller Number) and Slurry Abrasion Response of Materials (SAR Number)," [3] and electrochemical corrosion testing. The ASTM G75 wear test is used to assess for abrasive wear, which is one of the hypothesized mechanisms occurring within the Saltstone mixer. The electrochemical corrosion testing was performed to assess if corrosion was a contributing factor to the observed wear.

\subsection{Background}

\subsection{Saltstone Processing Facility}

The Saltstone Processing Facility (SPF) immobilizes and disposes of low-level radioactive and hazardous liquid waste (salt solution) as Saltstone, a cementitious waste form (Figure 2-1). In the SPF, the salt solution is mixed with premix (45 wt\% slag, 45 wt \% fly ash, 10 wt \% cement) in a 10-inch Readco continuous mixer (Figure 2-2) to produce fresh (uncured) Saltstone slurry which is processed through the facility and permanently disposed of in Saltstone disposal units (or vaults). The previous Readco mixer, which was operated from 2003 to early 2012, processed approximately seven million gallons of salt solution. [2] 


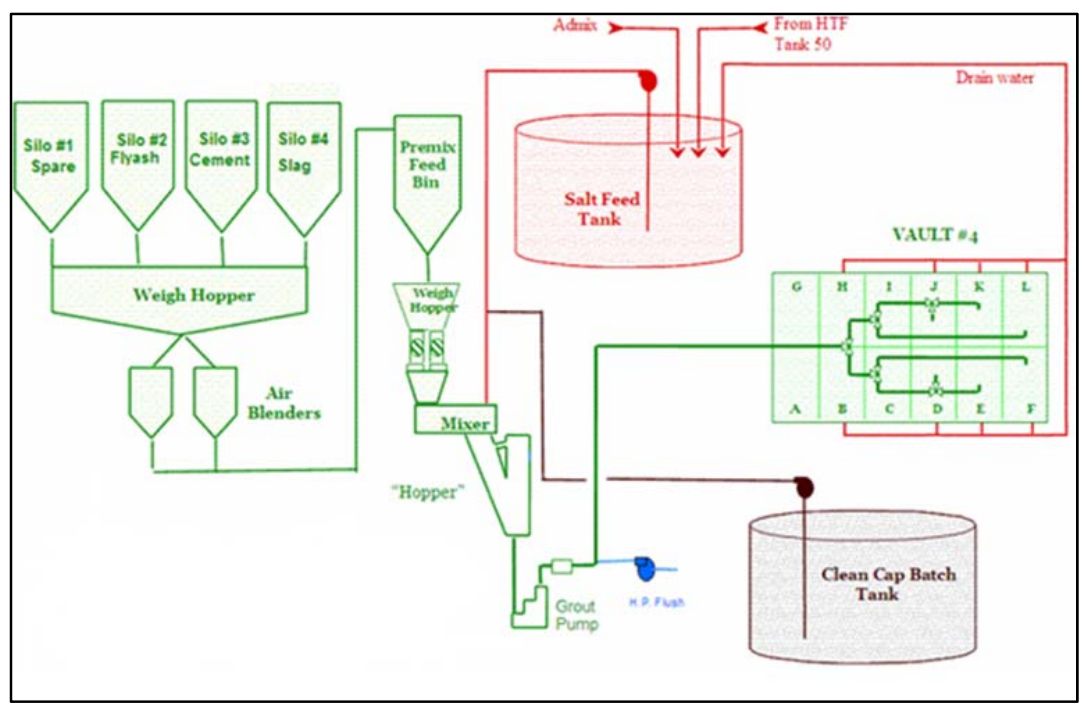

Figure 2-1. Schematic of Saltstone Processing Facility which shows the inputs into the Saltstone mixer

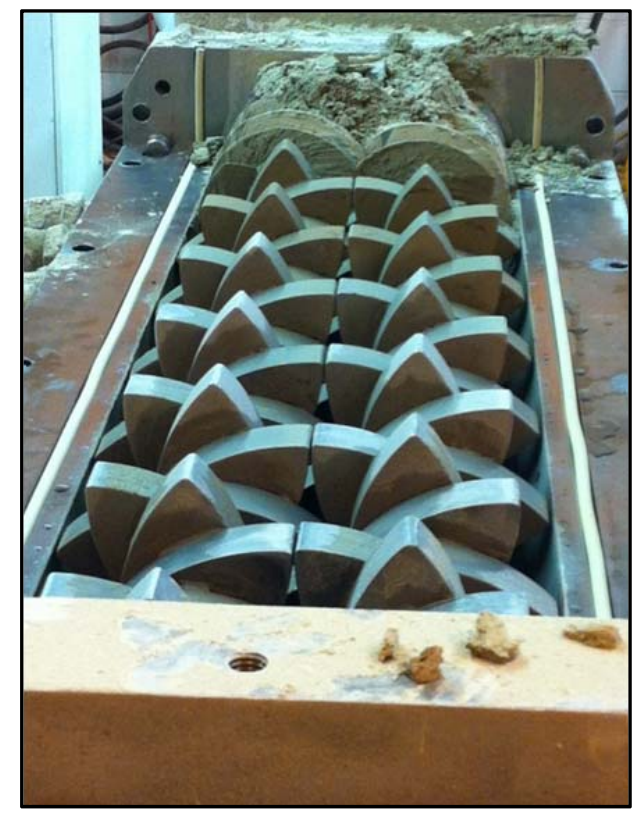

Figure 2-2. Interior of Readco continuous mixer showing premix feed on the augers and the self-cleaning paddles

\subsection{Types of Wear}

Identifying or analyzing the cause(s) of wear in the Saltstone mixer was important for choosing candidate materials of construction with improved wear resistance and for choosing an appropriate wear test. The causes of wear can be classified in several ways; one classification based on mechanism is as follows: abrasion, adhesion, corrosion, erosion, and fatigue. A situational classification, which might be easier for recognizing the wear, is as follows: sliding, fretting, abrasion (either three body or low stress), gouging, erosion, and corrosion. Erosion is actually a type of abrasion in which the 
impinging particle strikes the surface at an angle, while gouging is abrasion under a high load.

A review of these mechanisms shows that wear of a material is a complex phenomenon and affected by a number of factors: the direction and speed of motion between the two interacting bodies (e.g. specimen and slurry); the load applied between the two interacting bodies; and the environmental and chemical conditions between them. The observed wear will not only be dictated by the mechanism of mass loss within the material, but also by the attrition or degradation of the eroding or wear media.

The wear of the Saltstone mixer paddles, auger, and barrel has resulted from the dry feed and slurry movement through the mixer. A combination of wear situations can be identified: three-body abrasion between the tip and opposing paddle side or barrel as well as between the auger and barrel; erosion from dry feed and slurry against the paddle side due to the inlet of the waste stream at the auger/paddle transition point, and low stress abrasion along the auger due to the forward movement of the dry feed. An additional point of wear or three-body abrasion is the hardened slurry that starts to form at locations where the paddles, auger or barrel have worn down and are not sufficiently cleaned at the end of processing.

Corrosive wear could add an additional complication for determining the mechanism of wear if the environment is chemically active. If corrosive wear is occurring, degradation of the paddles and auger would be expected to increase because the abrasive material, in this case the dry feed, would abrade the protective oxide layer on the auger exposing fresh metal to aggressive slurry. The alkaline chemistry of the waste indicates that the corrosion should be minimal for the current materials of construction. Electrochemical corrosion testing was chosen to confirm this hypothesis since the test is quick (i.e. can be conducted before the slurry sets) and provides data for assessing both the corrosion rate and the susceptibility to localized corrosion.

The surface of the worn material can be a key factor in identifying the type of wear. In corrosive wear, the surface might not be bright from abrasion but obviously corroded. In erosion, the surface may be unevenly worn with wear areas showing a matte appearance. Since the actual wear surfaces could not be examined, identifying and testing for the wear in the Saltstone mixer becomes more challenging. Recommending effective new materials of construction or changes in process depends critically on the nature of the wear occurring.

For abrasive wear, the material property that primarily determines wear resistance is the material hardness, which can be thought of simply as the resistance to penetration. When wear particles are present, which for the Saltstone mixer, are the constituents of the premix feed, the material wear is determined by the ratio of the material hardness to that of the abrading particles. The wear resistance is also affected by the material toughness and structural strength and the size and shape of the wear particles. The impact of these other factors besides hardness depends on the type of abrasion as well as the material morphology. 
From a review of the Saltstone mixer wear inspections, the two principal wear mechanisms that lead to significant degradation and compromised mixer throughput are believed to be three body abrasion and erosion at the auger/paddle transition. Low stress abrasion may also be occurring on the 316 stainless steel body where the dry feed leaves the chute. This wear may not be sufficient to affect mixer operation. This type of wear was observed during the current testing on paddle configuration effects using the SRNL 2-inch prototype mixer.

\subsection{Premix Properties}

The premix properties including hardness, density, size and shape affect the observed wear in the Saltstone mixer. The premix consists of $45 \%$ granulated blast furnace slag, 45\% Class F fly ash from bituminous coal, and 10\% Portland cement. Their pertinent properties are given in Table 2-1.[4-6, 9]

Table 2-1. Characteristics of the Saltstone Dry Feed Constituents

\begin{tabular}{|c|c|c|c|c|}
\hline Constituent & Composition (\%) & $\begin{array}{c}\text { Mohs } \\
\text { Hardness }\end{array}$ & $\begin{array}{c}\begin{array}{c}\text { Particle Size* } \\
(\mu \mathrm{m})\end{array} \\
\end{array}$ & $\begin{array}{l}\text { Specific } \\
\text { Gravity }\end{array}$ \\
\hline GBFS & $\begin{array}{c}\mathrm{CaO}(34-43) \\
\mathrm{SiO}_{2}(27-38) \\
\mathrm{Al}_{2} \mathrm{O}_{3}(7-12) \\
\mathrm{MgO}(7-15) \\
\mathrm{Fe}_{2} \mathrm{O}_{3}(0.2-1.6) \\
\mathrm{MnO}(0.15-0.76) \\
\mathrm{S}(1-1.9) \\
\end{array}$ & $5-6$ & 10.97 & 2.7-3.1 \\
\hline Fly Ash & $\begin{array}{c}\mathrm{SiO}_{2} \text {, amorphous (41-58) } \\
\mathrm{SiO}_{2} \text {, crystalline (3-7) } \\
\mathrm{Al}_{2} \mathrm{O}_{3}(18.1-28.6) \\
\mathrm{Fe}_{2} \mathrm{O}_{3}(3.9-26) \\
\mathrm{CaO}(0.8-6.0) \\
\mathrm{MgO}_{(0.7-1.4)} \\
\mathrm{TiO}_{2}(1.0-1.9) \\
\end{array}$ & 7 & 33.15 & $2-3$ \\
\hline $\begin{array}{c}\text { Portland } \\
\text { Cement }\end{array}$ & $\begin{array}{c}3 \mathrm{CaO} \cdot \mathrm{SiO}_{2}(20-70) \\
2 \mathrm{CaO} \cdot \mathrm{SiO}_{2}(10-60) \\
\mathrm{Ca}_{2}(\mathrm{Al}, \mathrm{Fe})_{2} \mathrm{O}_{5}(5-15) \\
\mathrm{CaSO}_{4}(2-10) \\
3 \mathrm{CaO}^{\circ} \mathrm{Al}_{2} \mathrm{O}_{3}(1-15) \\
\mathrm{CaCO}_{3}(0-20) \\
\mathrm{MgO}(0-4)\end{array}$ & 9 & 19.42 & 3.15 \\
\hline
\end{tabular}

The average hardness is unknown but high hardness particles are present and would lead to greater abrasion. Particle sizes were quite small which would reduce the overall wear of the premix and slurry. The shape was unknown although photographs of the premix show most particles to be spheres, which again would reduce the overall abrasive effect. 
The constituents also had high specific gravities ranging from 2 to 3.15. These higher densities materials can lead to greater wear, especially in abrasion under low stresses.

\subsection{Material Evaluation}

Since the premix materials are not changing, the material hardness was used as the primary variable in choosing candidate materials of construction. This hardness is primarily effective if the value falls between about one-half to 1.3 times that of the abrasive particle.[7] A wide range of materials are available which include martensitic Cr-Mo steels, high $\mathrm{Cr}$ white cast iron, ceramics, as well as a range of coatings and hard facing materials.

Astralloy is reported to have a hardness value that ranges from 45 to $53 \mathrm{R}_{\mathrm{C}}$ and with continuous impact and abrasion can reach hardness of approximately $55 \mathrm{R}_{\mathrm{C}}$.[29] Astralloy also has moderate toughness with notch toughness at 26-40 ft-lbs. The Astralloy is the baseline material for comparison since it is the current material of construction for the paddles.

Candidate material selection used several approaches. One approach was to continue to make the paddle from a single metal as opposed to using a coating or hard facing to obtain the desired wear resistance, which could help keep the cost down. To obtain the higher hardness than Astralloy, tool steel, specifically D2, was chosen not only for the hardness $\left(R_{C} 60\right)$ but also because of ease of availability and of higher chromium concentration, which could provide a measure of corrosion resistance if corrosive wear is a factor. D2 has slightly lower toughness with a C-notch toughness of approximately 25 ft-lb.

Another metal with a higher hardness was initially planned using AISI 4140 steel $\left(\mathrm{R}_{\mathrm{C}} 68\right)$, which is also readily available. The high hardness, however, could not be obtained experimentally in the lab as will be discussed in the section Test Methods. Toughness was not considered for this material, which would be reduced by the heat treatments, since this testing was only to evaluate hardness effects on wear by dry feed and slurry.

Tungsten carbide, a widely used ceramic, was also chosen as a candidate material of construction for a monolith paddle. The high hardness of tungsten carbide (9 mohs) was believed to be sufficient to minimize the wear but suffers from low toughness and high cost. If improvement over Astralloy was sufficient, the cost might be amortized over an extended life for the mixer. This testing was not set up to establish whether tungsten carbide had sufficient toughness in the mixer application so further testing in the 2-inch scale mixer would be required to demonstrate that pieces of the paddle would not dislodge during service and impede the mixer operation.

The overlay of Stellite 12 on the CF8M auger was also another candidate. The wear resistance of Stellite is due mainly to the characteristics of the hard carbide phase dispersed in a Co-Cr alloy matrix. Stellite 12 is noted for withstanding both abrasion and corrosion. Some wear was apparent on the auger section located near the first paddle. Again, the details of the wear are unknown and may have resulted from incomplete 
coverage at this section of the auger and subsequent wear of the CF8M base material, which is quite soft $\left(R_{B} 90\right)$ in comparison to these other materials. The use of a Stellite 12 overcoat on the Astralloy paddle would keep the materials of construction the same and potentially provide sufficient wear resistance.

Another material that has seen use at SRS is Ultimet, which is a cobalt-based alloy noted for resistance to slurry erosion and abrasion as well as corrosive attack.[8, 28] The material was used to hard face the DWPF SME near the agitator to prevent abrasion by the frit. Although the hardness of Ultimet is relatively low initially $\left(R_{C} 20\right)$, the alloy quickly work hardens under loading conditions $\left(\mathrm{R}_{\mathrm{C}} 40\right)$. Ultimet performs well in low and high stress abrasions.[8]

A range of physical vapor deposited (PVD) coatings in the family of TiN were also considered due to their high hardness and thin coating thickness.[30] These coatings could be applied to the mixer paddle and not compromise the tight clearance between the paddles and the mixer body. These coatings have been used on tool steels to increase tool life from wear. The coatings have high hardness and adhesion, high chemical stability and toughness; all of these properties are potentially beneficial in the mixer. The new coating of TiCN and ZrN provide improved hardness and toughness over those of TiN.

\subsection{Wear Testing}

The appropriate selection of a wear test should be considered a representative simulation of the tribosystem of the application at issue, i.e. Saltstone mixer. The test selection involved three important factors, the use of representative slurry from the Saltstone mixer, an accelerated wear test that still produced valuable data about the Saltstone mixer wear, and duplication of results. Ideally, the test would exactly duplicate the Saltstone mixer wear, but this setup was unpractical since making paddles and augers from candidate materials would be costly. With accelerated testing as a requirement, consideration was also given to changes in the wear mechanism(s) during the test duration. In order to assess this change and potential wear rate changes, a test was necessary with data points at time intervals. Finally, an appropriate test would yield data on multiple (or at least duplicate) specimens to assess variations from sample to sample.

Detailed characterization of the worn surface, wear debris, and slurry properties from the actual system are useful for choosing a representative wear test. These include data on the morphology of the worn surface, the presence of any oxides or corrosion products, changes in the microstructure of the material, and slurry particle attrition across the mixer. This information was not available for the Saltstone mixer. Some visual information was obtained from images taken during a Saltstone mixer shutdown and small-scale testing performed at the Readco facilities.[1] Measurement data for the worn paddle to barrel clearances for the first three Astralloy $\mathrm{V}$ paddles of the mixer were evaluated during shutdowns but these measurements do not provide information about the wear mechanism(s).

ASTM G190, “Standard Guide for Developing and Selecting Wear Tests,” was used as the initial framework for determining the appropriate wear test for comparison of 
candidate materials of construction for the Saltstone mixer. [10] This document lists 33 ASTM standard protocols for the testing or the analysis of data obtained using different test configurations and various eroding/wearing agents. An ASTM protocol was preferred over an in-house designed method as it provided a peer-reviewed method with an established knowledge base.

Table 2-2 lists the wear testing protocols referenced by the ASTM G190 standard that (i) do not involve the use of greases or lubricants for testing, and (ii) were not designed for polymeric materials. The table also shows an assessment of whether the test was representative of the Saltstone mixer. Appendix I includes a fuller descriptions of each technique including the type of test results.

Table 2-2. ASTM Standard Wear Protocols Reviewed for Saltstone Mixer Wear Testing

\begin{tabular}{|l|l|}
\hline \multicolumn{1}{|c|}{ ASTM Standard } & $\begin{array}{l}\text { Representative } \\
\text { of Mixer Wear }\end{array}$ \\
\hline $\begin{array}{l}\text { ASTM D 2714: Calibration and Operation of the Falex Block-on-Ring } \\
\text { Friction and Wear Testing Machine }\end{array}$ & No \\
\hline $\begin{array}{l}\text { ASTM D 3702: Wear Rate and Coefficient of Friction of Materials in } \\
\text { Self-Lubricated Rubbing Contact Using a Thrust Washer Testing } \\
\text { Machine }\end{array}$ & No \\
\hline ASTM G32: Cavitation Erosion Using Vibratory Apparatus & No \\
\hline $\begin{array}{l}\text { ASTM G65: Measuring Abrasion Using the Dry Sand/Rubber Wheel } \\
\text { Apparatus }\end{array}$ & Yes \\
\hline ASTM G73: Liquid Impingement Erosion Using Rotating Apparatus & No \\
\hline $\begin{array}{l}\text { ASTM G75: Determination of Slurry Abrasivity (Miller Number) } \\
\text { and Slurry Abrasion Response of Materials (SAR Number) }\end{array}$ & Yes \\
\hline $\begin{array}{l}\text { ASTM G76: Conducting Erosion Tests by Solid Particle Impingement } \\
\text { Using Gas Jets }\end{array}$ & No \\
\hline $\begin{array}{l}\text { ASTM G77: Ranking Resistance of Materials to Sliding Wear Using } \\
\text { Block-on-Ring Wear Test }\end{array}$ & No \\
\hline ASTM G81: Jaw Crusher Gouging Abrasion Test & No \\
\hline ASTM G83: Wear Testing with a Crossed-Cylinder Apparatus & No \\
\hline ASTM G98: Galling Resistance of Materials & No \\
\hline ASTM G99: Wear Testing with a Pin-on-Disk Apparatus & No \\
\hline ASTM G105: Conducting Wet Sand/Rubber Wheel Abrasion Tests & Yes \\
\hline ASTM G132: Pin Abrasion Testing & No \\
\hline ASTM G133: Linearly Reciprocating Ball-on-Flat Sliding Wear & No \\
\hline ASTM G134: Erosion of Solid Materials by Cavitating Liquid Jet & No \\
\hline ASTM G171: Scratch Hardness of Materials Using a Diamond Stylus & No \\
\hline $\begin{array}{l}\text { ASTM G174: Measuring Abrasion Resistance of Materials by } \\
\text { Abrasive Loop Contact }\end{array}$ & No \\
\hline
\end{tabular}

Out of all the protocols listed in Table 2-2, three tests were representative of mixer wear. Procedures ASTM G65 and G105 are dry and wet variations of a sand/rubber wheel 
abrasion test. In these methods, the abrasive agent (sand grit) is introduced between the test specimen and a rotating wheel with a rubber tire or rim of a specified hardness. The test sample is pressed against the rotating wheel at a specified force by means of a lever arm. A controlled flow of abrasive is fed against the test surface. Abrasion is reported as volume loss, which allows for ranking the candidate materials. The principal issue with these two methods is that the wear rate of the specimens is dependent on the combined abrasion from the sand and a rotating rubber wheel, not solely from the grit. The tests could be modified to incorporate representative Saltstone premix as part of the tribosystem.

After analysis of the potential options, ASTM G75 was selected as the most representative wear test simulating wear in the Saltstone mixer. This test is used to calculate a number for a material which is related to the average rate of mass loss (converted to volume loss) of duplicate standard-shaped wear specimens run for a period of time in a slurry of interest. This is a conforming-contact test with beveled-edge flat samples, which minimize differences in stress behavior due to uneven surface contact. The test is designed to be performed with either standard (sand) or alternative slurry compositions. Moreover, the abrasion is a result of continuous contact of the sample with the slurry, eliminating any compounding abrasion effects from a rotating rubber backing.

From further discussions with the inventor and developer of the protocol, it was found that the method allowed for testing under wet and dry conditions.[11] This would provide valuable information on the effects of the liquid media on the wear for a same material. The test also provides data at multiple time intervals (2h, $4 \mathrm{~h}, 6 \mathrm{~h})$, which aids in assessing particle attrition, work-hardening or coating removal from a specimen surface. Finally, the calculate Surface Abrasivity Response (SAR) numbers would allow for ranking of the candidate materials.

\subsection{Test Methods}

The test methods chosen for evaluation of the materials of construction included wear testing following the ASTM G75 protocol, electrochemical corrosion tests, hardness measurements and surface characterization of wear surfaces.

\subsection{Test Samples}

The test samples for the materials of construction were obtained in several ways. A minimum of three samples were required, two duplicates for the wear testing and one for the corrosion testing. Hardness measurements were made on the corrosion test sample prior to corrosion testing. The nominal compositions of the candidate materials of construction are given in Table 3-1. The PVD coatings, TiN and $\mathrm{ZrN}$, are not included in the table since the manufacturer gave them as $100 \%$ of their respective compound. The TiCN is not listed since a nominal composition was not provided.

Astralloy samples were cut by electro-discharge machining (EDM) from a mixer paddle provided by Readco Kurimoto LLC (York, PA), vendor of the Saltstone mixer. Figure 31 shows the paddle before and after sectioning of the samples. Prior to sectioning the paddle, several hardness measurements were made around the sample to assess 
uniformity. The indents can be seen in the paddle shown in Figure 3-1 (B). These values showed that the hardness was fairly uniform on the sample, ranging from $R_{C} 41.7$ to 45 .

Table 3-1. Nominal Chemical Composition (Wt \%) of the Candidate Materials of Construction

\begin{tabular}{|l|c|c|c|c|c|c|c|c|c|}
\hline Material & $\mathbf{C}$ & $\mathbf{C r}$ & $\mathbf{N i}$ & $\mathbf{F e}$ & $\mathbf{M n}$ & $\mathbf{M o}$ & $\mathbf{S i}$ & $\mathbf{W}$ & Co \\
\hline Astralloy & $0.2-0.29$ & $1.25-2$. & $3.25-4.0$ & Bal & $0.8-1.2$ & $0.25-0.5$ & $0.2-0.4$ & & \\
\hline 316 & 0.08 & $16-18$ & $10-14$ & Bal & 2.0 & $2-3$ & 0.75 & & \\
\hline Stellite & $1.4-1.7$ & $27-32$ & & & & & & $7.5-9.5$ & Bal \\
\hline Ultimet & 0.06 & 26 & 9 & 3 & 0.8 & 5 & 0.3 & 2 & 54 \\
\hline D2 Tool & $1.4-1.6$ & $11-13$ & & & $0.1-0.6$ & $0.7-1.2$ & $0.1-0.6$ & & \\
\hline WC & 0.7 & 0.7 & & & & & & Bal & 10 \\
\hline
\end{tabular}

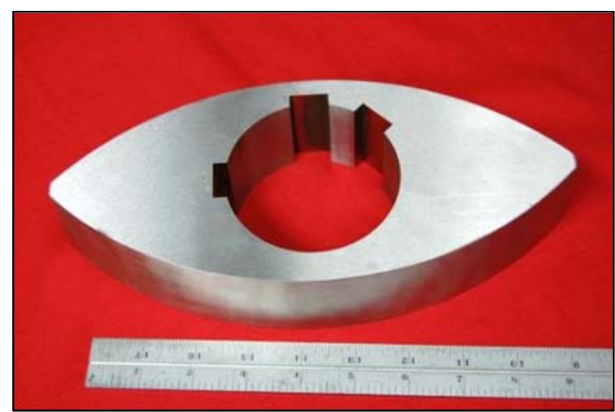

(A)

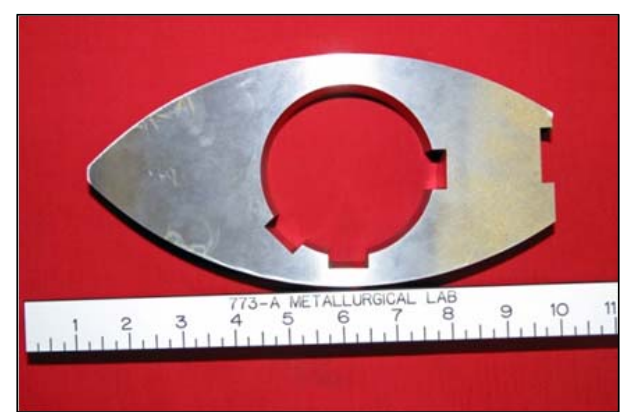

(B)

Figure 3-1. Saltsone mixer paddle used for testing: (A) before and (B) after sectioning

The 316 and Ultimet samples were sectioned by EDM from stock material at SRNL. The tungsten carbide samples were sectioned by EDM from an end mill bit manufactured by Imco Carbide Tool Inc. (Perrysburg, $\mathrm{OH}$ ). One set of Ultimet samples was needle peened to provide a work hardened layer on the surface. D2 tool steel samples were procured from Metal Samples (Munford, AL). The TiN, TiCN, and the ZrN coated samples were obtained from Surface Solutions Inc. (Fridley, MN). Coating thickness was nominally $5 \pm 1 \mu \mathrm{m}$. The coatings were put on 316 samples cut by EDM from SRNL stock material. The coatings were deposited by physical vapor deposition

The Stellite 12 samples were obtained from two sources. The first set was Stellite 12 weld overlay on a 316L stainless steel base from HFW Industries (Buffalo, NY), who also provided the weld overlay for the Saltstone mixer. The ' $L$ ' designation for 316 indicates a low-carbon composition (0.03\%). After a decision was made to test Stellite 12 in the dry condition an additional sample was sectioned from stock material of a Stellite 12 cast plate since there was insufficient time to procure additional samples.

The ASTM G75 calls for the sample surface to finished with 320-grit silicon carbide paper to remove machining damage. Samples that were EDM cut were prepared to that surface by the vendor except for the 316 which were finished at SRNL with 600-grit 
silicon paper. The PVD coatings and the Stellite weld overlay samples were tested as provided by those vendors. These details are discussed in the Results section.

Another material that was planned to be used was a low alloy steel, AISI 4140, which would be heat treated to several hardness values greater than that of Astralloy. Testing this material would have provided for an evaluation of Saltstone slurry abrasion as a function of steel hardness. Several attempts were made to heat treat the material to the maximum hardness of $\mathrm{R}_{\mathrm{C}} 65-68$. The maximum hardness obtained was approximately $R_{C} 60$, which is the hardness of the tool steel so 4140 was not used.

\subsection{Wear Testing}

The ASTM G75 wear test, commonly referred to as the Miller Test, is performed by moving a test sample through slurry with an applied standard load of 5 pounds. The mass loss of the sample is measured at 2 hour intervals up to a total time of 6 hours. The wear tester has a drive mechanism that provides a horizontal reciprocating harmonic motion to the wear block via a sample arm. The sample sits in a trough that contains the slurry. At each two-hour interval after the sample is weighed, the orientation of the sample is switched to provide an averaging of the wear pattern. The apparatus has two operating arms for duplicate samples which provide averaging and a check on the accuracy of measurements.

At the conclusion of the test, the cumulative wear or mass loss was fit by a least squares regression:

$\mathrm{M}=A \mathrm{t}^{\mathrm{B}}$

\{Equation 1$\}$

where $\mathrm{M}$ is the cumulative mass loss (mg), $\mathrm{t}$ is the time (hours), and $\mathrm{A}$ and $\mathrm{B}$ are the curve fit coefficients. The SAR number is related to the rate at which the wear sample loses mass at two hours into the test. The mass loss rate ( $\mathrm{m}$ in units of $\mathrm{mg} / \mathrm{hr}$ ) is calculated by taking the first derivative of Equation 1, which is the slope of the line tangent to the curve at the first two-hour point,

$m=A \times B \times t^{(B-1)}$

\{Equation 2\}

The SAR number is actually calculated from Equation 3 using the Miller Number, which normalizes the mass loss rate on a scale of 1 (soft, sulfur) to 1000 (hard, corundum) by using $18.18 \mathrm{hr} / \mathrm{mg}$, and a ratio of the specific gravity of the wear test material $\left(\mathrm{SG}_{\mathrm{wm}}\right)$ to that of the standard material $27 \%$ chrome iron (7.58).

$\mathrm{SAR}=18.18 \times \mathrm{m} \times\left(7.58 / \mathrm{SG}_{\mathrm{wm}}\right)$

\{Equation 3\}

A measure of the change in abrasivity is also calculated and is commonly referred to as the departure from the linear relationship (line tangent) at the first two-hour mark. In most cases the change in weight loss is not a linear relationship with time, but will either decrease or increase with time. The departure number is negative if the weight loss decreases with time indicating the abrasivity is decreasing, while a positive departure 
indicates the weight loss is increasing or the abrasivity is increasing. A negative departure may result from particle attrition or work hardening of the material surface, while a positive departure may occur from loss of a coating or release of hard abrasive particles from the material. Equation 4 shows the calculation for the Departure (D).

$$
\mathrm{D}=\frac{\mathrm{A} \times \mathrm{B} \times(\mathrm{B}-1) \times \mathrm{t}^{(\mathrm{B}-2)}}{\mathrm{A} \times \mathrm{B} \times \mathrm{t}^{(\mathrm{B}-1)}}
$$

\{Equation 4\}

Duplicate wear samples were fabricated to the specified dimensions as shown in Figure $3-2$. The slurry used in this testing was made from $50 \%$ Saltstone dry feed provided by SRNL, composed of $150 \mathrm{~g}$ dry feed, $150 \mathrm{~g}$ deionized water, and $0.3 \mathrm{ml}$ Daratard 17 . The Daratard 17 is used to delay the slurry from setting.

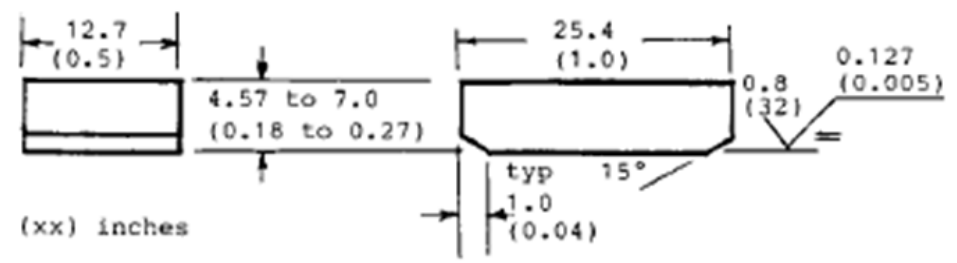

Figure 3-2. Wear Sample Dimensions [3]

Two tests were performed with the dry feed to determine the effect on the auger material from transporting the dry feed to the mixing paddles. Astralloy and Stellite 12 samples were tested in the dry feed. The Stellite 12 samples consisted of one sample with a Stellite overlay on 316 and the other was cut by EDM from a casting of Stellite 12. The use of two Stellite forms (cast and weld overlay) provided some information of notable differences in wear resistance of an overlay and a monolith.

\subsection{Electrochemical Corrosion Testing}

The electrochemical corrosion testing consisted of a series of three experiments. The first was open-circuit potential (OCP) monitoring which was used to follow the equilibration of the sample in the test solution. The OCP monitoring was performed for two hours. Immediately at the end of the OCP monitoring, linear polarization resistance (LPR) was performed to determine a general corrosion rate. This technique applies a scanning potential ramp ( $0.2 \mathrm{mV} / \mathrm{sec})$ over a range of $+/-20 \mathrm{mV}$ around the OCP. From the plot of the potential and resulting current, a polarization resistance value $\left(\mathrm{R}_{\mathrm{p}}\right)$ is calculated using Equation 5 which is related to the general corrosion rate (CR) of the material.

$\mathrm{CR}=3.2710^{3} \times \mathrm{B} \times \mathrm{EW} /\left(\mathrm{R}_{\mathrm{p}} \times \rho \times \mathrm{SA}\right)$

\{Equation 5$\}$

where $\mathrm{B}$ is a constant related to the electrochemical behavior of the material in the environment, 0.026 for this testing; $\mathrm{EW}$ is the equivalent weight (g); $\rho$ is the material density $\left(\mathrm{g} / \mathrm{cm}^{3}\right)$; and SA is the surface area of the sample $\left(\mathrm{cm}^{2}\right)$. The material values are given in Table 3-2. 
Table 3-2. Material Values for Determining Corrosion Rate

\begin{tabular}{|c|c|c|c|}
\hline Material & $\begin{array}{c}\text { Surface Area } \\
(\mathbf{c m} \wedge \mathbf{2})\end{array}$ & $\begin{array}{c}\text { Density } \\
(\mathbf{g} / \mathbf{c m} \wedge \mathbf{3})\end{array}$ & $\begin{array}{c}\text { Equivalent } \\
\text { Weight }\end{array}$ \\
\hline 316 & 1.97 & 7.98 & 25.50 \\
\hline Astralloy & 1.48 & 7.85 & 27.65 \\
\hline WC & 4.5 & 15.8 & 30.64 \\
\hline Stellite 12 & 3.03 & 8.53 & 24.37 \\
\hline D2 Steel & 3.2 & 7.7 & 26.02 \\
\hline TiCN & 1.19 & 5.4 & 23.95 \\
\hline TiN & 1.49 & 5.4 & 23.95 \\
\hline ZrN & 0.98 & 7.1 & 22.80 \\
\hline Ultimet & 1.55 & 8.47 & 24.97 \\
\hline
\end{tabular}

At the conclusion of the LPR, a cyclic potentiodynamic polarization (CPP) was performed to assess the susceptibility to localized corrosion. This technique applies a similar potential ramp as the LPR technique $(0.2 \mathrm{mV} / \mathrm{sec})$, but over a larger potential range away from the OCP $(+1.0 \mathrm{~V})$ along with a reverse scan back to the OCP. The potential/responding current plot provides data on the passivity and susceptibility to pitting, crevice corrosion and stress corrosion cracking.

The electrochemical tests were performed using an Ametek PAR Model 273A potentiostat/galvanostat in conjuction with a laptop computer and Scribner Associates Inc. CorrWare ${ }^{\circledR}$ software. The test cell consisted of a polyethylene beaker with a standard three-electrode set up: a reference, counter and working electrodes. The counter electrode was 0.25-inch diameter graphite rod, while the reference electrode was a $\mathrm{Ag} / \mathrm{AgCl}$ electrode $(+0.197 \mathrm{mV}$ vs NHE). All potentials in this report are given in reference to the $\mathrm{Ag} / \mathrm{AgCl}$ potential.

The working electrode was one of the candidate materials of construction. As can be seen in Table 3-2, different size pieces were used and depended on the initial configuration of the material. The sample had a Teflon-coated copper wire attached to the back with a conductive silver epoxy. The sample was then put in a metallurgical mount with fast-set epoxy. The mount exposed one surface of the sample for testing and facilitated surface preparation with 600 grit $\mathrm{SiC}$ paper prior to testing. The coated samples (TiN, TiCN, ZrN) were used in the as-coated condition without further surface preparation after mounting since abrading the surface could damage the coating.

The test solution was prepared immediately before testing. Solution volume was approximately $425 \mathrm{ml}$ and was sufficient to immerse the sample. The test solution was prepared to mimic the Saltstone formulation (0.6 water to premix ratio) processed through the mixer (laboratory ratio: $226.8 \mathrm{~g}$ of dry feed to $230 \mathrm{ml}$ of salt solution). The composition of the salt solution was based on recent Tank 50 slurry samples and is shown 
in Table 3-3.[12] Several tests were performed with water instead of the salt solution to provide some baseline information about the corrosivity of the premix.

The electrochemical testing took approximately eight hours to complete during which time the slurry thickened but remained sufficiently fluid. Slurry did cling to the exposed surface area of the samples, which lead to some noise in the acquired electrochemical data. In some cases the slurry was wiped from the surface of the sample before performing the LPR and CPP tests. This disturbance of the sample caused some shifts in the corrosion potential. Another source of noise was the stir plate, which was used to keep the feed constituents from settling excessively. Some tests needed to be performed without the stir plate in order to obtain useable data.

Table 3-3. Salt Solution Composition Used in Corrosion Testing

\begin{tabular}{|l|c|}
\hline Compound & Molarity \\
\hline $\mathrm{NaOH}$ & 1.55 \\
\hline $\mathrm{NaNO}_{3}$ & 2.12 \\
\hline $\mathrm{NaNO}_{2}$ & 0.34 \\
\hline $\mathrm{Na}_{2} \mathrm{CO}_{3}$ & 0.15 \\
\hline $\mathrm{Na}_{2} \mathrm{SO}_{4}$ & 0.06 \\
\hline $\mathrm{AlNO}_{3}\left(9 \mathrm{H}_{2} \mathrm{O}\right)$ & 0.11 \\
\hline
\end{tabular}

\subsection{Hardness Measurements}

Hardness measurements were made on samples of the candidate materials of construction. Initial or pre-test measurements were made on the corrosion test samples prior to mounting except for the Stellite coated sample used in the premix wear test. This sample was initially planned for use in the corrosion test, but after hardness measurements were made a decision was made to perform some premix test and the sample was needed for that testing. The post-test measurements were made on the actual wear surface of the sample.

These measurements were made on either a Wilson Instruments Series B2000 for Rockwell B and C hardness values or a Wilson Instruments Tukon 2100B for Knoop and Vickers hardness values. The values for the coated samples do not represent just the coating but both the coating and the softer 316 or 316L base material. Multiple measurements were made on each sample around the surface of the sample as shown in Figure 3-3. Prior to each series of measurements the instrument was calibrated using standard reference blocks for each hardness scale. 
Astralloy

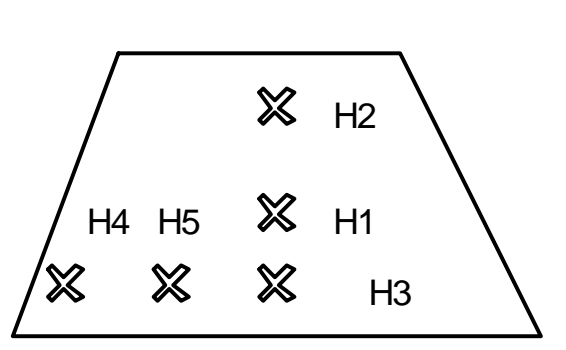

Tungsten Carbide

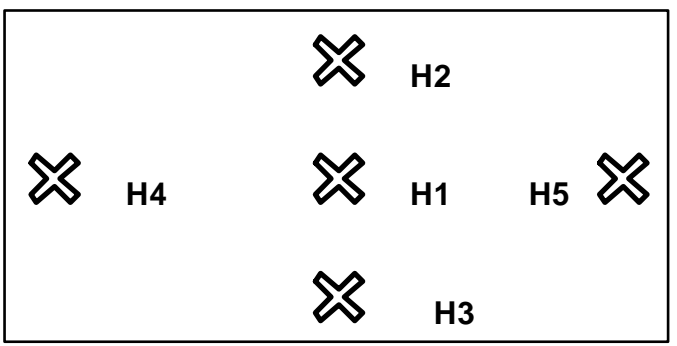

Figure 3-3. Locations of hardness measurements on the Astralloy and tungsten carbide samples

\subsection{Surface Characterization}

Scanning electron microscopy (SEM) and energy dispersive spectroscopy (EDS) was used to characterize the surface of all wear specimens, as-received or as-made and following ASTM G5 testing. All SEM images were obtained on secondary electron mode with a Hitachi S-3600N Variable Pressure SEM. EDS, an x-ray fluorescence technique, was used to obtain elemental analysis based on the emission of characteristic secondary $\mathrm{x}$-rays following bombardment of the sample with the SEM electron beam. The EDS was an Oxford INCA X-sight Energy Dispersive X-ray System. All reported compositions based on EDS spectra are semi-quantitative, with an absolute error of $\pm 5 \%$. EDS spectra used for determining the material composition were obtained from a raster or area scan.

Observations with a stereomicroscope were also made of the post-corrosion test surfaces to determine if localized corrosion had occurred and on post-test wear samples to assess large scale wear characteristics of the surface.

\subsection{Test Results}

The test results are presented herein for the ASTM G5 wear testing, the electrochemical corrosion testing, the hardness measurements, and the surface characterization of the wear samples.

\subsection{Wear Testing}

The candidate materials of construction did not perform unexpectedly as shown by the data presented in Table 4-1. The data in the table include the mass losses measured at the first and last two hours of the six-hour test, the calculated SAR number, the relative wear to the material with the best wear rate, and the departure. The data has been divided into three categories for discussion purposes: slurry, premix, and coatings. The first and last two hour mass losses are also shown graphically in Figure 4-1. Photographs of samples before and after wear testing are given in Appendix II. 
Table 4-1. ASTM G5 Wear Test Results for Saltstone Mixer Candidate Materials of Construction

\begin{tabular}{|c|c|c|c|c|c|c|}
\hline \multirow{2}{*}{ Material } & \multirow{2}{*}{$\begin{array}{c}\text { Test } \\
\text { Category }\end{array}$} & \multicolumn{2}{|c|}{ Losses (mg) } & \multirow{2}{*}{$\begin{array}{c}\text { SAR } \\
\text { Number }\end{array}$} & \multirow{2}{*}{$\begin{array}{c}\text { Relative } \\
\text { Wear }\end{array}$} & \multirow{2}{*}{$\begin{array}{c}\text { Departure } \\
(\%)\end{array}$} \\
\hline & & 2- Hour & Final & & & \\
\hline WC & Slurry & 5 & 2.3 & 13 & 1.00 & -19 \\
\hline Stellite 12 & Slurry & 2.6 & 2.1 & 23 & 1.69 & -5 \\
\hline D2 Tool Steel & Slurry & 5.9 & 4.5 & 46 & 3.39 & -7 \\
\hline Ultimet & Slurry & 16.1 & 10.1 & 100 & 7.45 & -11 \\
\hline Astralloy & Slurry & 15.9 & 13.4 & 127 & 9.43 & -4 \\
\hline Ultimet - WH & Slurry & 25.6 & 17.8 & 184 & 13.66 & -6 \\
\hline 316 & Slurry & 60.4 & 23.8 & 292 & 21.67 & -22 \\
\hline $\begin{array}{l}\text { Stellite } 12, \\
\text { Dry }\end{array}$ & Premix & 6.4 & 6.4 & 54 & 4.03 & 3 \\
\hline Astralloy, Dry & Premix & 19.9 & 18.7 & 187 & 13.91 & 4 \\
\hline TiN & Coating & 1.7 & 4.3 & 24 & 1.78 & 12 \\
\hline TiCN & Coating & 4.4 & 10.773 & 5.4 & 0 & \\
\hline ZrN & Coating & 8.3 & 18.1 & 88 & 6.5 & 11 \\
\hline
\end{tabular}

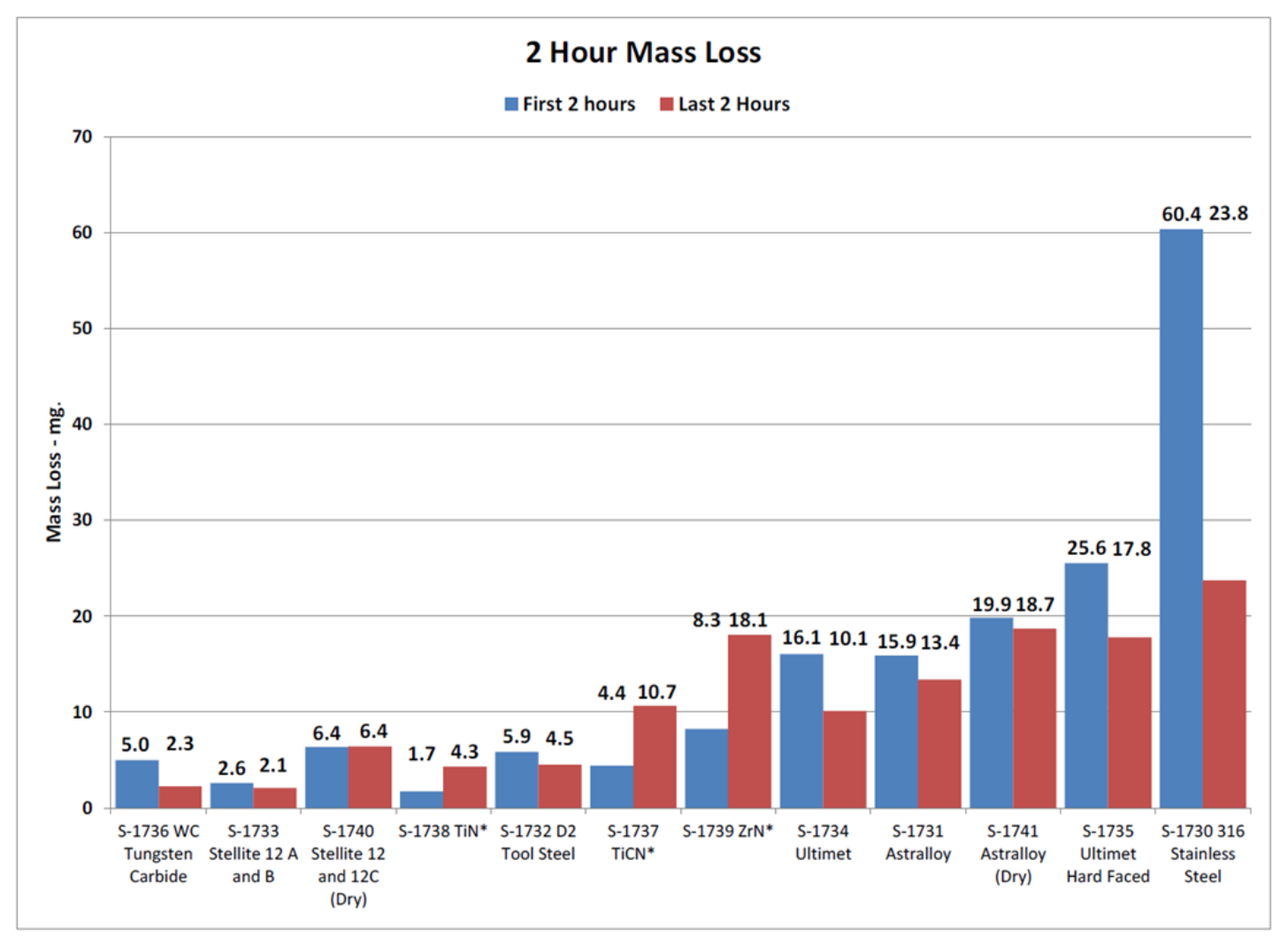

Figure 4-1. Mass losses during the ASTM G5 wear test for Saltstone mixer candidate materials of construction 
As can be seen in the table, the tungsten carbide had the lowest SAR number indicating the smallest volume loss. However, note in Figure 4-1 that tungsten carbide had a higher mass loss than Stellite 12. The lower SAR number results from the higher specific gravity for the tungsten carbide. The difference among the top three performers, tungsten carbide, Stellite 12, and D2 tool, is not large and as a group performed better than the Astralloy. Ultimet samples had a similar performance, although work hardening (WH) prior to testing to increase the sample hardness appeared to decrease resistance. The Ultimet WH samples were also from a different lot but this fact may be circumstantial. The 316 had the highest mass and volume losses. In the wet testing, all materials experienced a negative departure indicating the abrasivity of the test decreased with time, which could be associated with either work hardening of the sample or particle attrition.

For the Stellite 12 and Astralloy test in dry feed, SAR numbers increased due to the more abrasive nature of the dry feed. The departure was positive as opposed to negative for the slurry test indicating the abrasivity of the testing increased with time. This increase may have resulted from fracture of the dry feed, pullout of abrasive particulate, and formation of metallic grinding particulate.

The PVD coatings also showed a positive departure with low SAR numbers and good relative wear performance. The positive departure is a result of the thin coatings not lasting throughout the test. The positive departure is an indication of the coatings wearing away and exposing the softer 316 based metal. As can be seen in the table the final two-hour loss is greater than the first two-hour loss. A visual examination of the wear samples showed the loss of coating and will be discussed in more detail in the Surface Characterization section.

Prior to the wear testing the premix was characterized for particle size and shape. The premix had a very high concentration $(91 \%)$ of fine particulate $(<45 \mu \mathrm{m})$, which agreed with the results obtained at SRNL (Table 2-1).[9] The particles were essentially spherical with few sharp edges as shown in Figure 4-2.
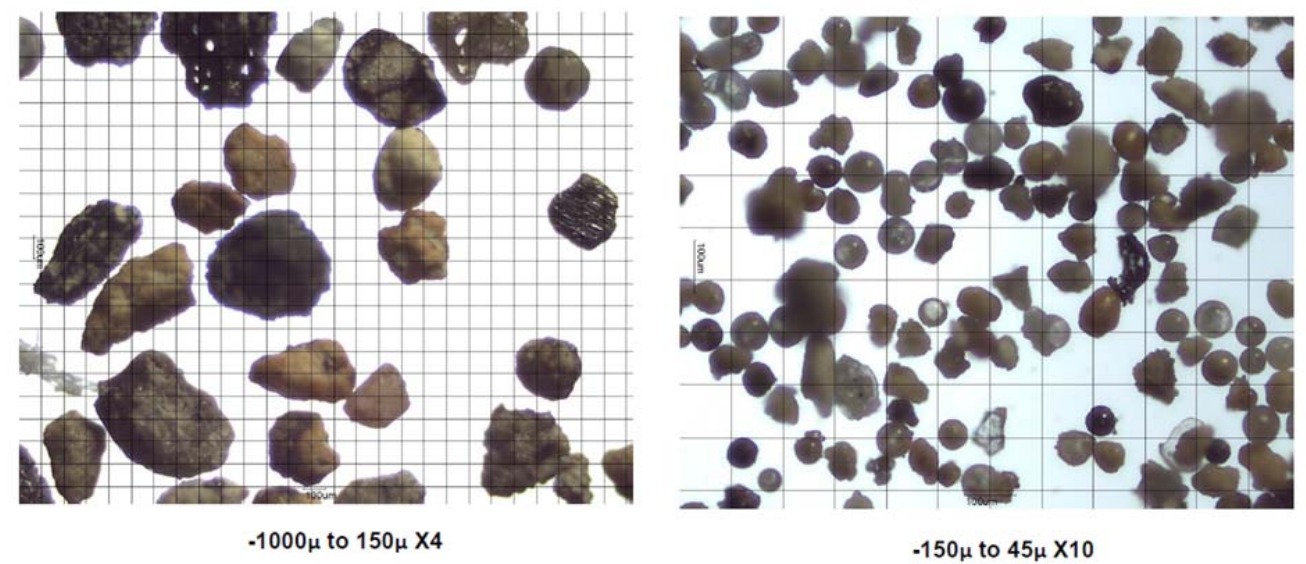

Figure 4-2. Photomicrographs of dry feed constituent particles 
The size and shape of the dry feed are favorable for a low wear rate.[27] The abrasive nature of the slurry was not expected to change during the testing based on the experience of the wear test vendor.[11]

\subsection{Electrochemical Corrosion Testing}

The materials of construction showed a broad range of OCP values after the two hours of equilibration as shown by the data in Figure 4-3. The OCP values all became more electropositive, which coincided with the formation of slurry deposits on the sample surface. These deposits made performing the scanned potential techniques difficult.

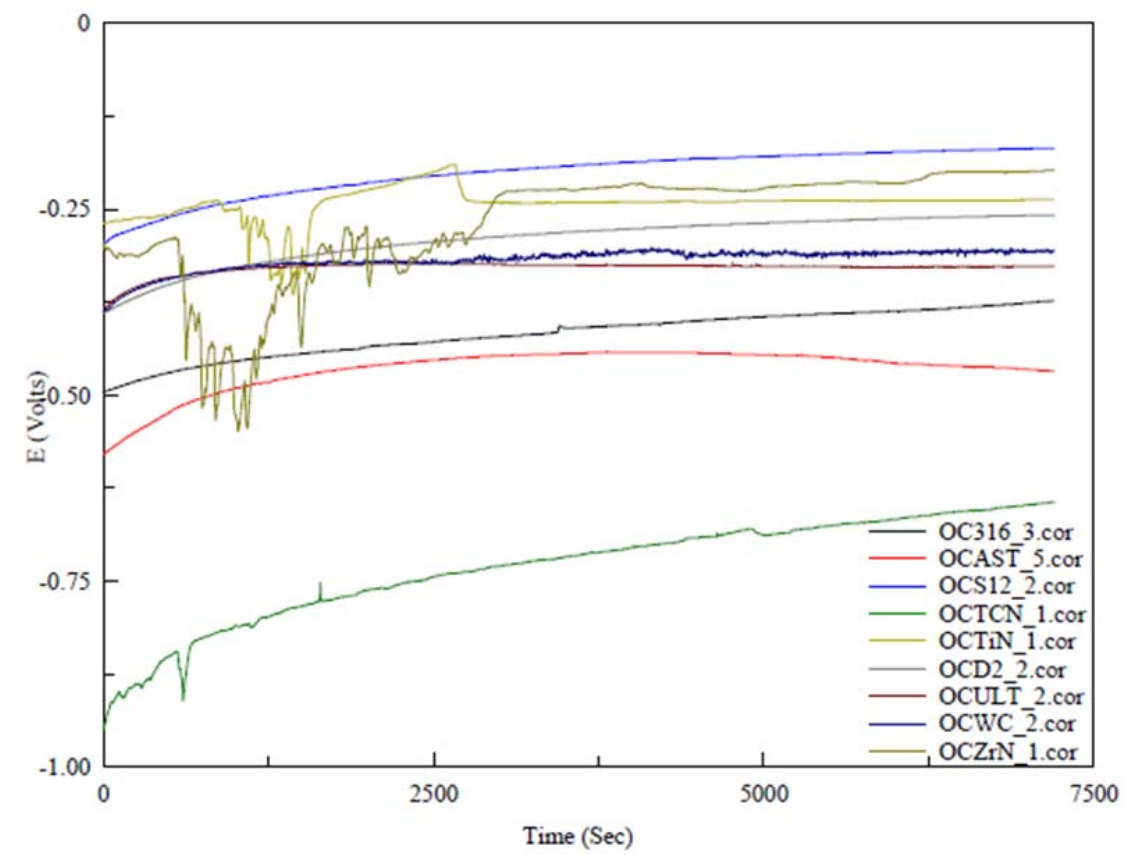

Figure 4-3. OCP stabilization of the candidate materials of construction in slurry with salt solution

Removal of the slurry by gently scraping with a plastic implement affected the OCP value in some cases as shown by the data in Figure 4-4 for the TiN and TiCN coatings. In the figure, the XXX_1.cor data files are for the samples with the slurry in place and the XXX_1a.cor data files are after removal of the slurry. The removal of the slurry was only required for the PVD coatings. The size of the potential shift may be associated with the thickness of the slurry layer.

The corrosion rates as measured by LPR were extremely low as shown in Table 4-2. Corrosion rates below 2 mils per year are generally accepted as excellent. Corrosion rates were not measureable for the TiN and TCN samples due to excessive noise during the measurements. Based on literature results these coatings would be expected to have similar low corrosion rates in alkaline solutions as the other candidate materials of construction. [12] Ultimet was found to have the highest corrosion rate at $0.3 \mathrm{mpy}$ and the $\mathrm{ZrN}$ the lowest rate at $0.02 \mathrm{mpy}$. 


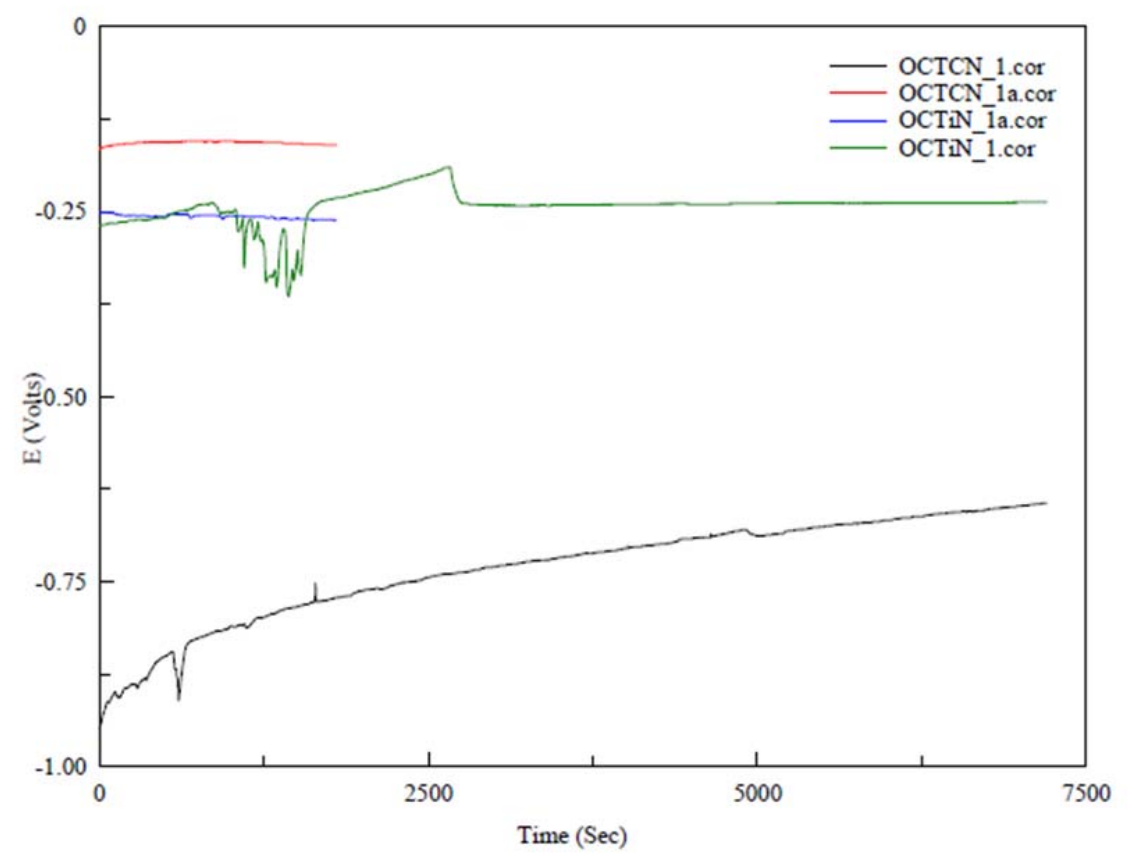

Figure 4-4. OCP stabilization of the TiCN and TiN coating in slurry with salt solution

Table 4-2. Calculated Corrosion Rates and Open Circuit Potentials of the Candidate Materials of Construction in Slurry with Salt Solution

\begin{tabular}{|c|c|c|}
\hline Material & $\begin{array}{c}\text { OCP } \\
\text { (V, Ag/AgCl) }\end{array}$ & $\begin{array}{c}\text { Corrosion Rate } \\
\text { (mpy) }\end{array}$ \\
\hline Astralloy & -0.474 & 0.04 \\
\hline Stellite 12 & -0.397 & 0.03 \\
\hline 316 & -0.368 & 0.05 \\
\hline D2 tool steel & -0.286 & 0.18 \\
\hline WC & -0.536 & 0.07 \\
\hline Ultimet & -0.305 & 0.3 \\
\hline TiN & -0.246 & ND \\
\hline TiCN & -0.254 & ND \\
\hline ZrN & -0.222 & 0.02 \\
\hline
\end{tabular}

The CPP curves are shown in Figure 4-5 for the current materials of construction, in Figure 4-6 for the PVD coatings and in Figure 4-7 for the remaining materials of construction. All figures have been plotted on the same axes for ease of comparison. The reverse portions of the curves have been truncated for ease of viewing. None of the materials displayed a higher current on the reverse scan than the forward scan, indicating the unlikelihood of pitting. Most of the samples showed passive behaviors with significant polarization or low current densities $\left(10^{-6}\right.$ to $\left.10^{-4} \mathrm{~A} / \mathrm{cm}^{2}\right)$ over a broad range of potentials. During the polarization, the passive nature of the oxide appears to have changed as shown by the nose in most of the curves. These curves are in general 
agreement with literature data for the candidate materials of construction exposed to alkaline solutions. [14-17, 26]

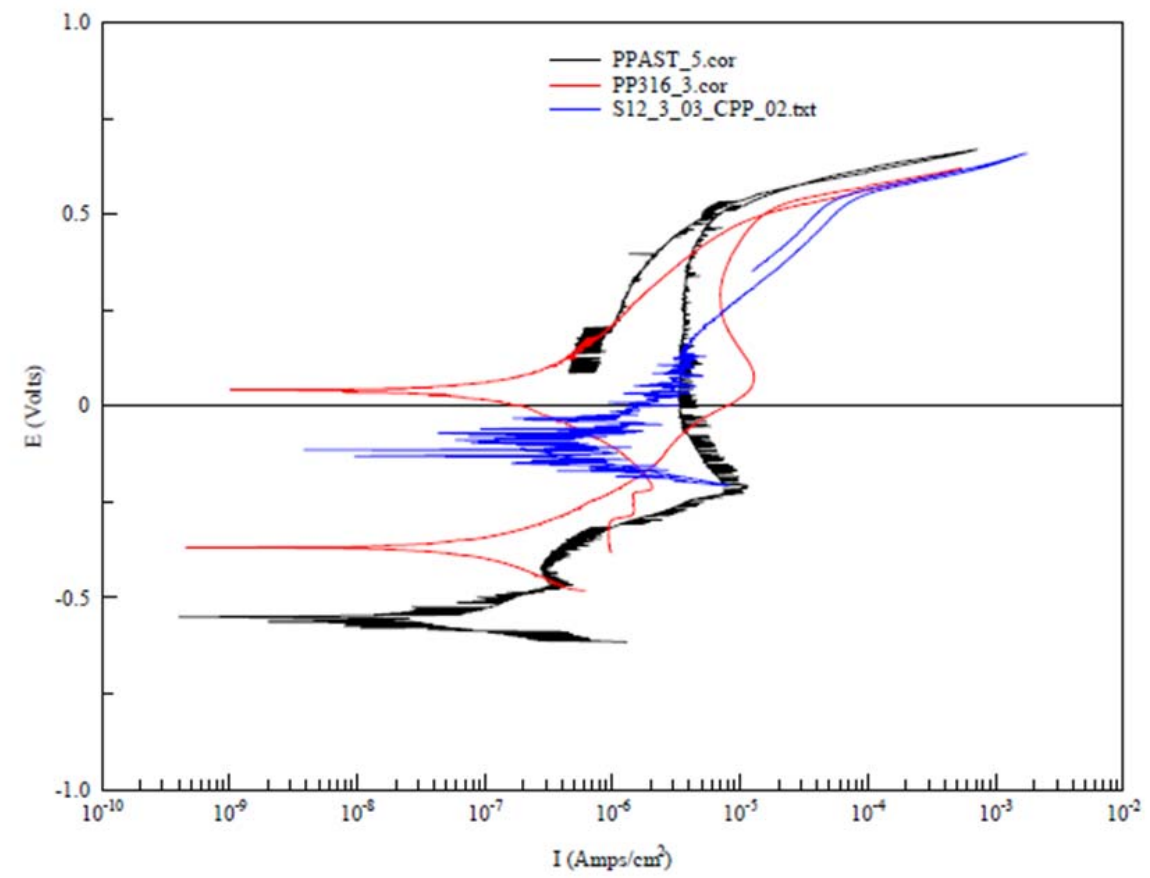

Figure 4-5. CPP Scans for current materials of construction for the Saltstone mixer

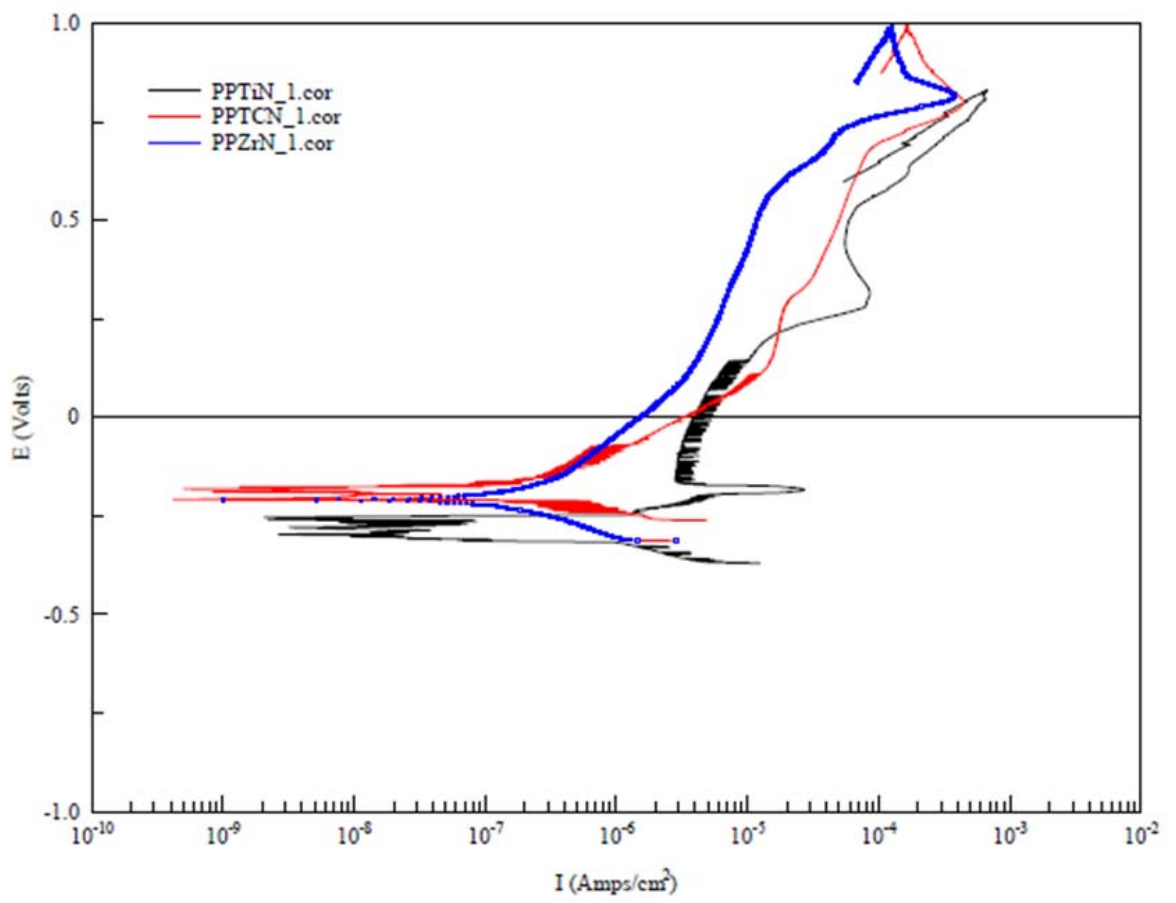

Figure 4-6. CPP scans for candidate PVD coatings for the Saltstone mixer 


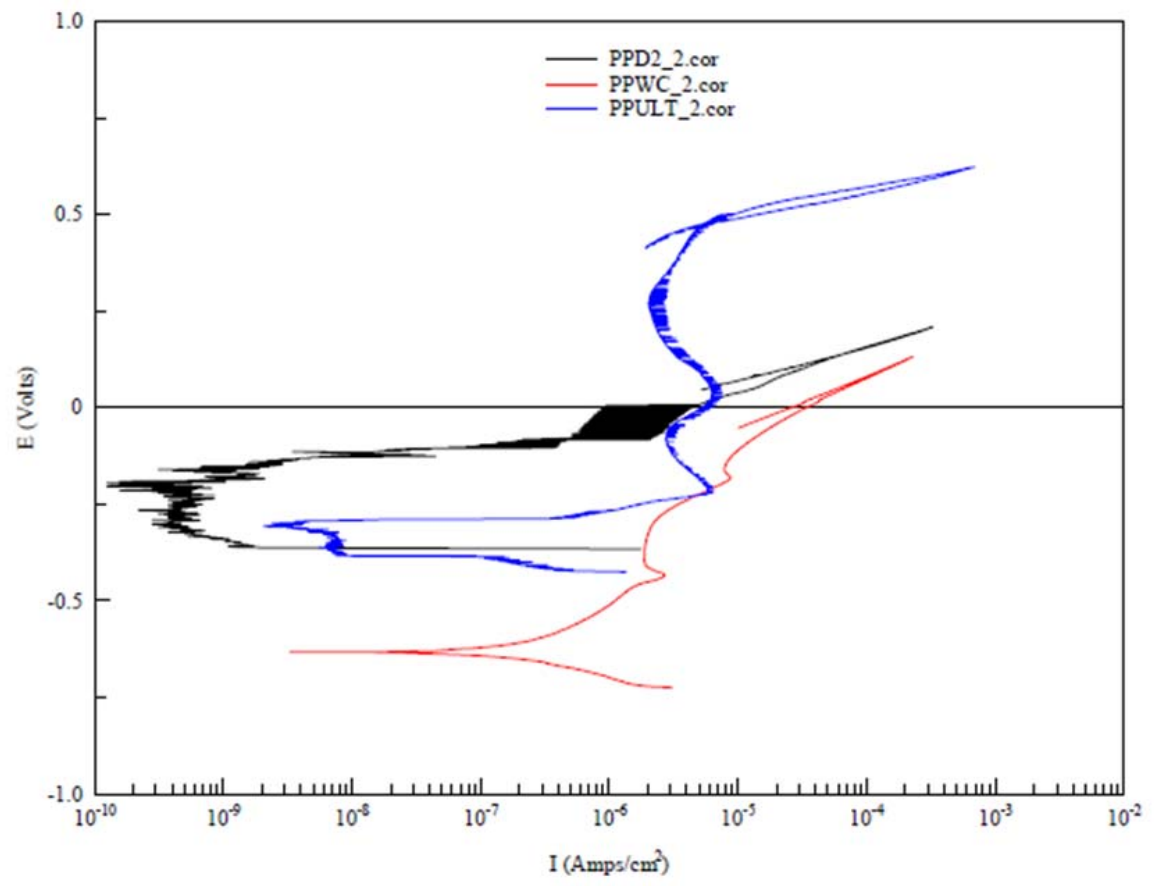

\section{Figure 4-7. CPP scans for candidate materials of construction for the Saltstone mixer}

A visual evaluation of the samples after testing also showed no pitting as shown by the stereo-micrographs in Figure 4-8. For 316, Astralloy, Stellite 12, Ultimet, and D2 tool steel, the initial grinding marks from sample preparation are clearly evident. In the tungsten carbide sample the porosity from incomplete compaction during fabrication of the drill bit is seen. For the TiCN and the ZrN coatings, the initial grinding marks of the base 316 coupon can be seen, although this is not observable in TiN coating, which appears to have highlighted the coating microstructure similar to electrochemical etching.

When water was used in place of the salt solution, the OCP values for the samples became more active or electropositive. For example, 316 had an OCP of approximately $-0.24 \mathrm{~V}$ in slurry made with water as compared to an OCP of $-0.37 \mathrm{~V}$ in a slurry made with the salt solution. This more active OCP in the slurry with salt solution indicates that the salt solution slurry is more corrosive. Additionally the cyclic polarization curve is shifted to slightly higher current densities; another result that the salt solution is more corrosive. The PVD coatings were not tested in slurry made with water. 


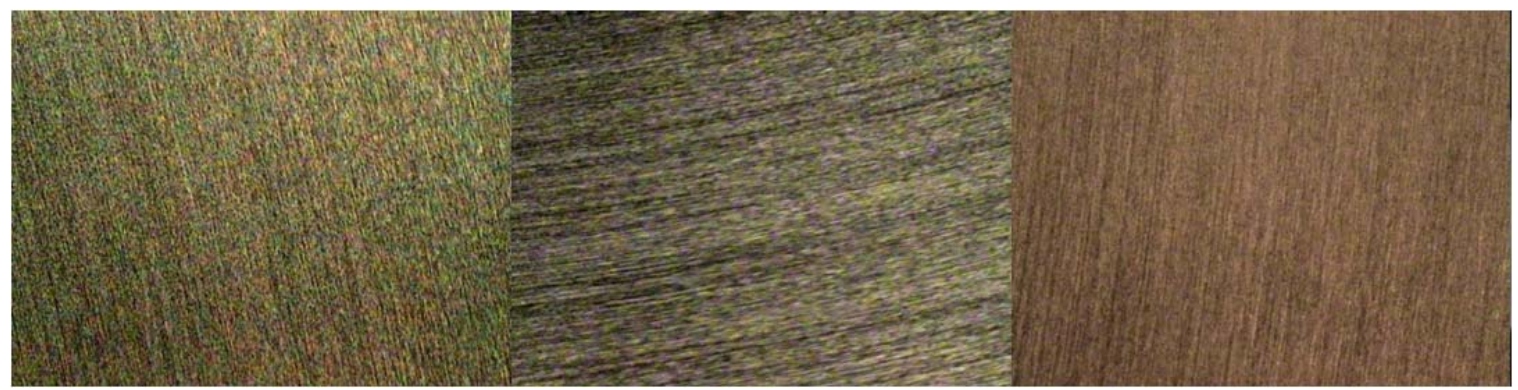

Astralloy

Stellite 12

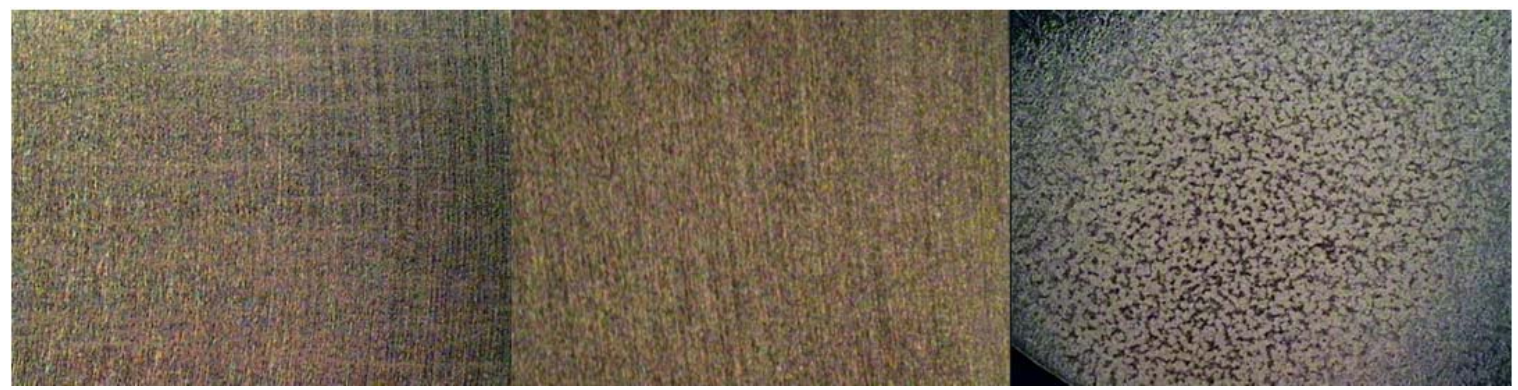

D2 Tool Steel

Ultimet

Tungsten Carbide

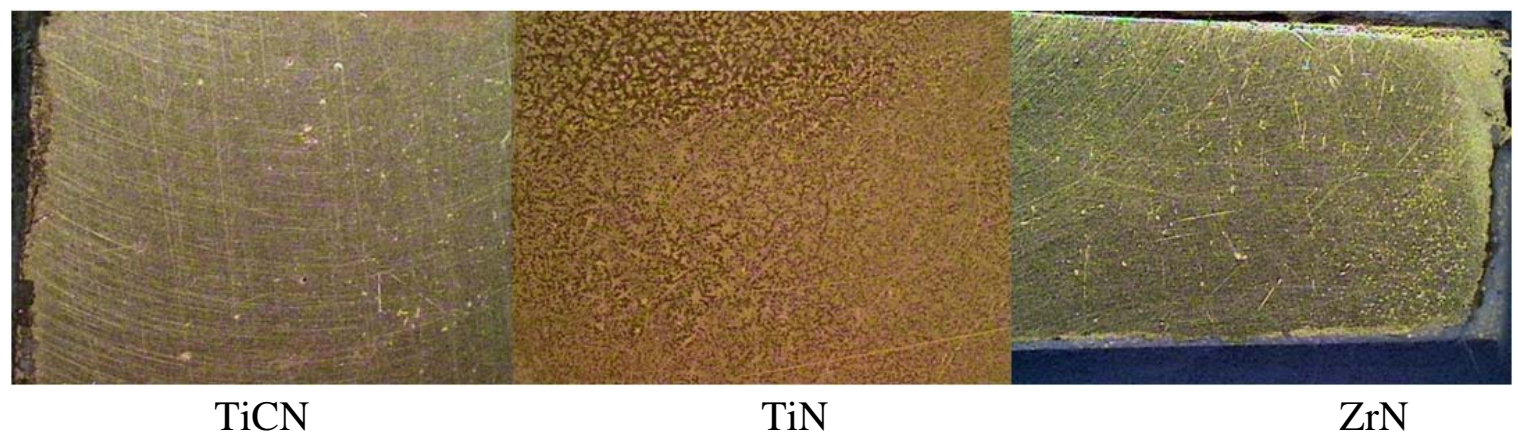

Figure 4-8. Stereomicroscope pictures of the candidate materials of construction after CPP scans (20x)

\subsection{Hardness Measurements}

The prime material property that is indicative of the wear resistance is the material hardness. The measured values for the test materials are given in Table 4-3. The table gives the hardness scale used for the particular material, the range of pre-test hardness measurements and the pre- and post-test average hardness. The pre-test hardness measurements are provided to show the range of hardness measured for the various samples. A difference in hardness of less than 2-3 on the $\mathrm{R}_{\mathrm{C}}$ scale is not considered significant (for Vickers scale a difference of 10).

The commercial literature for Astralloy gives hardness values of approximately 43-54 $\mathrm{R}_{\mathrm{C}}$. The certified material test reports for the plates used in making the lot of paddles from which the test paddle was taken had Brinell hardness values of 444 and 429 . These values correspond to $\mathrm{R}_{\mathrm{C}}$ values of approximately 46-47. The values measured on the paddle test sample averaged approximately $R_{C} 43.5$, which indicates some reduction due to the fabrication of the paddles. The wear surface of the Astralloy sample may have had 
some work hardening as indicated by the higher hardness measurement after wear testing, although the increase is not considered significant.

The base material of construction for the auger is 316, which is soft in comparison to most of the other materials tested. The average measured value of 77.7 is lower than values considered typical for 316 plate material $\left(R_{B} 90\right)$. The grain size of the 316 test samples may have been larger than the typical plate so hardness would be lower. Hardness for the 316 wear samples was essentially constant.

Table 4-3. Hardness Measurements of Candidate Materials of Construction*

\begin{tabular}{|c|c|c|c|c|c|c|c|c|}
\hline \multirow{2}{*}{ Material } & \multirow{2}{*}{ Scale } & \multicolumn{9}{|c|}{ Pre- Test Hardness } & \multicolumn{2}{c|}{ Average } \\
\cline { 3 - 9 } & & $\mathbf{\# 1}$ & $\mathbf{\# 2}$ & $\mathbf{\# 3}$ & $\mathbf{\# 4}$ & $\mathbf{\# 5}$ & Pre & Post \\
\hline Astralloy & $\mathrm{R}_{\mathrm{C}}$ & 43.4 & 43.7 & 43.9 & 42.8 & 43.7 & 43.5 & 44.5 \\
\hline 316 & $\mathrm{R}_{\mathrm{B}}$ & 77.9 & 78 & 77.8 & 77.1 & 77.7 & 77.7 & 76.8 \\
\hline Stellite 12 Cast & $\mathrm{R}_{\mathrm{C}}$ & 49.0 & 49.4 & 49.6 & 48.4 & 48.9 & 49.1 & 46.8 \\
\hline Stellite 12 HF & $\mathrm{R}_{\mathrm{C}}$ & 39.8 & 44.4 & 44.3 & 46.4 & 40.4 & 43.1 & 46.6 \\
\hline D2 Tool Steel & $\mathrm{R}_{\mathrm{C}}$ & 60.1 & 60.1 & 60.1 & 60.1 & 60.1 & 60.1 & 59.7 \\
\hline Ultimet & $30 \mathrm{~N}$ & 49.3 & 48.7 & 48.7 & 46.8 & 47.1 & 48.1 & 44.6 \\
\hline Ultimet WH & $\mathrm{R}_{\mathrm{C}}$ & 45.7 & 44.6 & 46.9 & 42.1 & 47.1 & 45.3 & 28.9 \\
\hline WC & $\mathrm{HV}$ & 1753 & 1873 & 1723 & & & 1783 & 1608 \\
\hline TiN Coating & $\mathrm{Kn}$ & 1692 & 1721 & 1952 & & & 1788 & $\mathrm{ND}$ \\
\hline TiCN Coating & $\mathrm{Kn}$ & 1054 & 1006 & 1155 & & & 1072 & $\mathrm{ND}$ \\
\hline ZrN Coating & $\mathrm{Kn}$ & 1272 & 1020 & 945 & & & 1079 & ND \\
\hline
\end{tabular}

* $\mathrm{R}_{\mathrm{C}}$ - Rockwell C, $\mathrm{R}_{\mathrm{B}}$ - Rockwell B, 30N - Rockwell superficial $30 \mathrm{Kgf}$ load, HV Vickers, Kn - Knoop (superficial)

Stellite 12 overlay (HF), which is used as an overlay for the 316 auger, had an initial hardness of 43.1. This value is below literature values of 45-51. [16, 24] Since the wear samples were quite small, the lower hardness may have resulted from dilution of the Stellite overlay with iron and the loss of carbon to the 316 base metal or a difference in grain size. The Stellite $12 \mathrm{HF}$ sample appeared to have work hardened during the test as demonstrated by the increase in hardness to $\mathrm{R}_{\mathrm{C}}$ 46.6. The Stellite 12 cast plate, however saw a decrease in hardness from the wear testing with values changing from $R_{C} 49.1$ to 46.8. Literature values for the cast Stellite 12 range from $R_{C} 45.1$ to 54.1. [16]

For the candidate materials of construction, D2 tool steel showed no change in hardness resulting from the wear testing and was in agreement with literature values. Tungsten carbide (WC) saw a slight decrease (1783 to $1608 \mathrm{HV}$ ). This decrease may be associated with the variability observed in the sample microstructure.

The Ultimet sample did not perform as expected since work hardening was not observed, but rather quite the opposite. The Ultimet wear sample showed a drop from 48.1 to 44.6 $30 \mathrm{~N}$ (on the $\mathrm{R}_{\mathrm{C}}$ scale this change would be from approximately 27.5 to 23.5). The Ultimet samples that were work hardened (WH) prior to testing showed a drop from 45.3 to $28.9 \mathrm{R}_{\mathrm{C}}$. Rockwell $\mathrm{C}$ values of 30 and 43 correspond to conditions of mill annealed 
and $20 \%$ cold work, respectively, indicating the initial degree of working for the $\mathrm{WH}$ surface. The Ultimet samples did show lack of fusion between different weld overlays which may have impacted performance.

\subsection{Surface Characterization}

The alloy surface characteristics before and after wear testing were investigated. The results are discussed for each alloy herein.

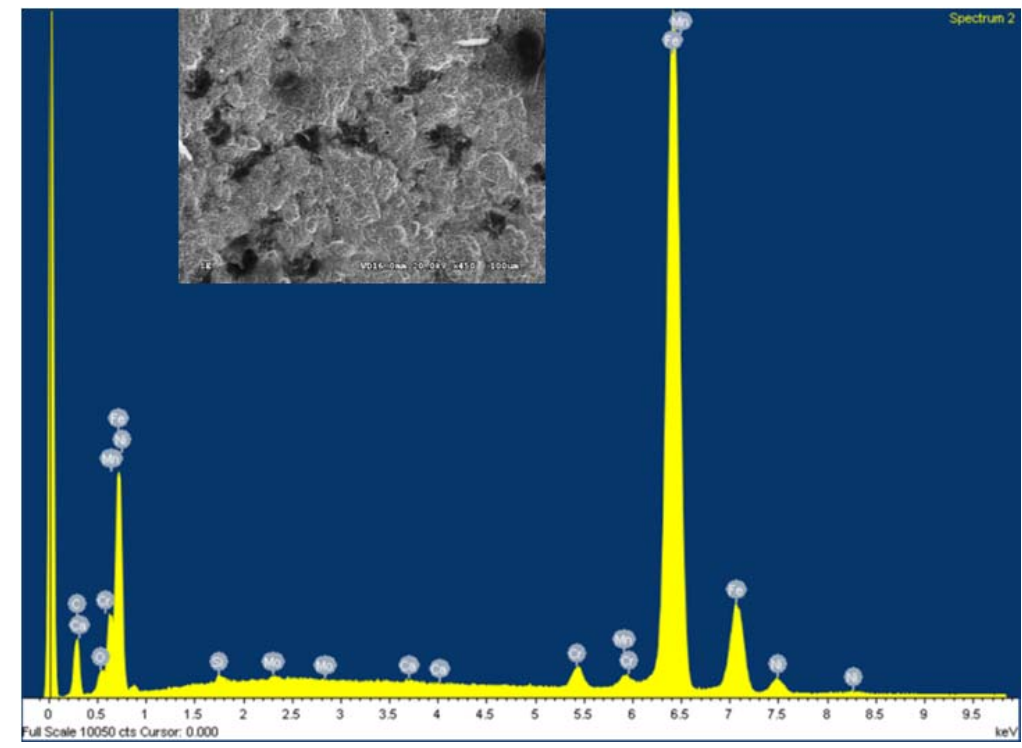

Figure 4-9. SEM micrograph and sum EDS spectrum of Astralloy wear specimens prior to wear testing

Table 4-4. Compositions (Wt\%) based on EDS Spectra for As-machined Wear Samples of Astralloy V, 316 Stainless Steel, and Stellite 12 Overlay and Plate

\begin{tabular}{|c|c|c|c|c|c|c|c|}
\hline \multirow{2}{*}{$\begin{array}{c}\text { Element } \\
\text { /Spectra } \\
\text { Line } \\
\end{array}$} & \multicolumn{2}{|c|}{ Astralloy } & \multicolumn{2}{|c|}{316 Stainless Steel } & \multicolumn{3}{|c|}{ Stellite 12} \\
\hline & $\begin{array}{c}\text { Expected } \\
\text { (max.) }\end{array}$ & $\begin{array}{c}\text { Measured } \\
\text { Wt } \%\end{array}$ & $\begin{array}{c}\text { Expected } \\
\text { (max.) }\end{array}$ & $\begin{array}{c}\text { Measured } \\
\text { Wt \% }\end{array}$ & $\begin{array}{c}\text { Expected } \\
\text { (max.) }\end{array}$ & $\begin{array}{l}\text { Plate } \\
\text { Wt \% }\end{array}$ & $\begin{array}{c}\text { Overlay } \\
\text { Wt \% }\end{array}$ \\
\hline $\mathrm{C} \mathrm{K}$ & 0.29 & 13.59 & 0.08 & 2.67 & $1.4-1.85$ & 16.8 & 5.88 \\
\hline Si K & 0.40 & 0.24 & 0.75 & 0.5 & 1.5 & 0.74 & 1.05 \\
\hline Cr K & 2.00 & 1.41 & $16-18$ & 16.03 & 29.5 & 26.58 & 30.81 \\
\hline Mn K & 1.20 & 0.90 & 2 & 1.88 & 1 & 0.41 & 0.28 \\
\hline Fe K & Bal. & 81.08 & Bal & 66.19 & 2.5 & 2.22 & 3.23 \\
\hline $\mathrm{Ni} \mathrm{K}$ & 4.00 & 2.79 & $10-14$ & 10.3 & 3 & 1.25 & 2.08 \\
\hline Mo L & 0.50 & 0.00 & $2-3$ & 1.91 & NA & NA & NA \\
\hline $\mathrm{P} \mathrm{K}$ & 0.015 & 0.00 & 0.045 & 0.0 & NA & NA & NA \\
\hline S K & 0.010 & 0.00 & 0.03 & 0.0 & NA & NA & NA \\
\hline $\mathrm{Co}$ & NA & NA & NA & NA & Bal & 44.98 & 48.61 \\
\hline $\mathrm{W}$ & NA & NA & NA & NA & 8.5 & 7.01 & 8.06 \\
\hline
\end{tabular}




\subsubsection{Astralloy}

As-machined wear specimens obtained from a Readco wear paddle were cut by EDM. Figure 4-9 shows the surface of these specimens as characterized by SEM and a sum EDS spectrum with the expected X-ray lines. Darker regions in Figure 4-9, which are potentially carbon-rich, can be observed throughout the surface. Carbides are typical for these types of alloys and provide some of the desired properties, including strength and hardness. A semi-quantitative composition is given in Table 4-4 (Note: carbon values are high due to surface contamination).

Post-wear testing (slurry followed by premix) SEM micrographs of the Astralloy wear specimens show a fairly smooth surface with mostly unidirectional abrasion lines, with some areas showing varying wear patterns (Figure 4-10). Some deep random scratches were observed and attributed to some of the harder components of the dry feed. The leading edges of the specimen appear rounded and highly worn with some areas showing removed material, which is consistent with the high SAR numbers (SAR=127, wet; $\mathrm{SAR}=187$, dry) for these specimens. Some features resembling filiform corrosion were observed (Figure 4-11) and EDS mapping was performed. The localized oxygen concentrations verified the formation of an iron oxide (Figure 4-12), although when these formed is uncertain.
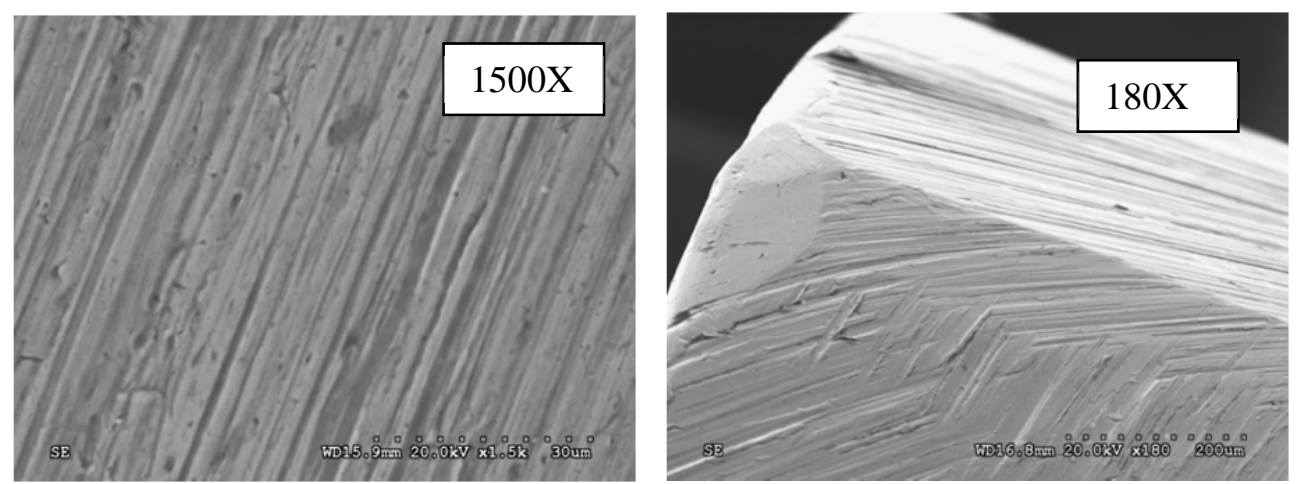

Figure 4-10. SEM micrographs of Astralloy $\mathrm{V}$ specimens after slurry premix wear testing

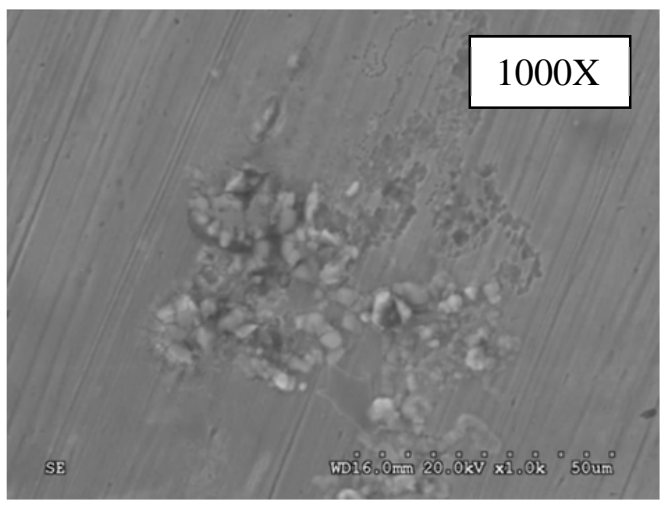

Figure 4-11. Pits and filiform corrosion products observed in Astralloy specimens after slurry/premix wear testing 


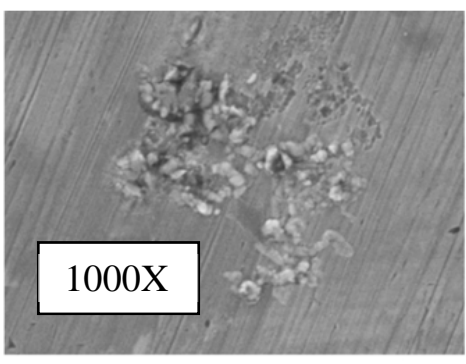

Electron Image 1

(A)

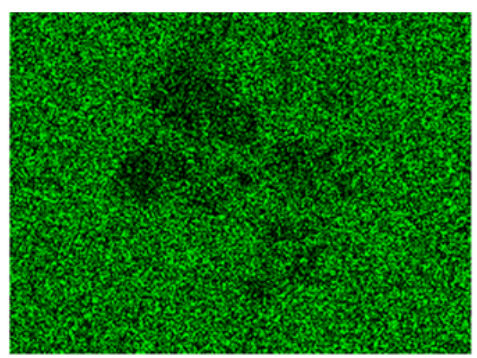

(B)

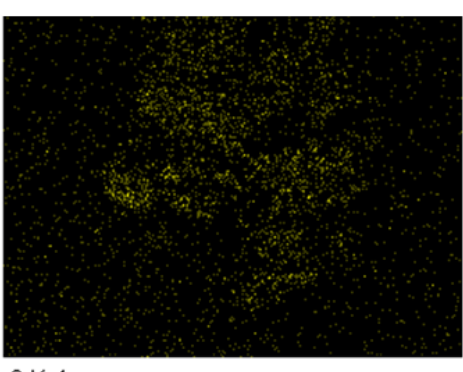

(C)

Figure 4-12. EDS mapping of corrosion products observed in the Astralloy surface after slurry/premix wear testing: (A) Secondary electron image; (B) Fe K $\alpha$ line map; and (C) $\mathrm{O} \mathrm{K} \alpha$ line may

\subsubsection{Stainless Steel}

SEM micrographs of the as-machined specimens showed very smooth surfaces with unidirectional scratch lines and an average width well below $0.5 \mu \mathrm{m}$ (Figure 4.13). Small pits $(\sim 5-10 \mu \mathrm{m})$ could be observed throughout the specimen. The sum EDS spectrum of the surface shows all expected spectral lines for the 316 composition (Table 4-4).

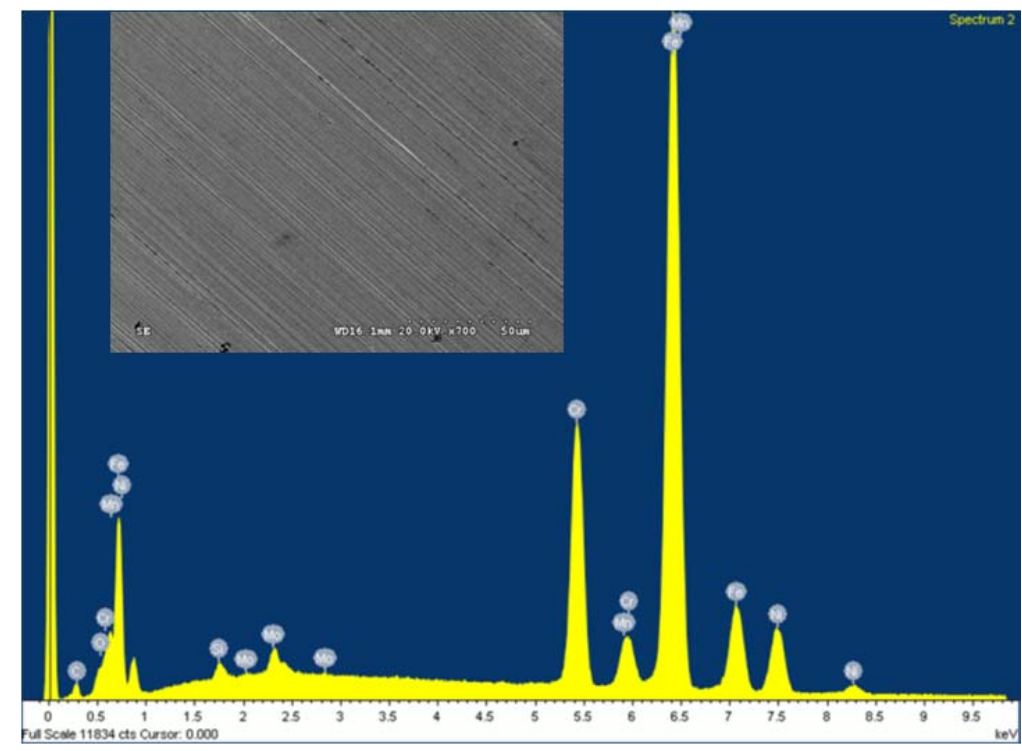

Figure 4-13. SEM micrograph and sum EDS spectrum of 316 specimens prior to wear testing

SEM analysis after slurry abrasion revealed deep gouging and material plowing/removal from the edges of the 316 specimens (Figure 4-14), all consistent with the very high SAR number for these specimens ( $\mathrm{SAR}=292$ ). Moving away from the edges, the samples showed random deep scratches, although the directionality of the wear test could still be observed. Some features observed, as shown in Figure 4-15, were the shaving-like curl of the base metal and salt residues from the testing. The curl appears to have been torn. These observed features are consistent with the low hardness and high ductility of 316. 

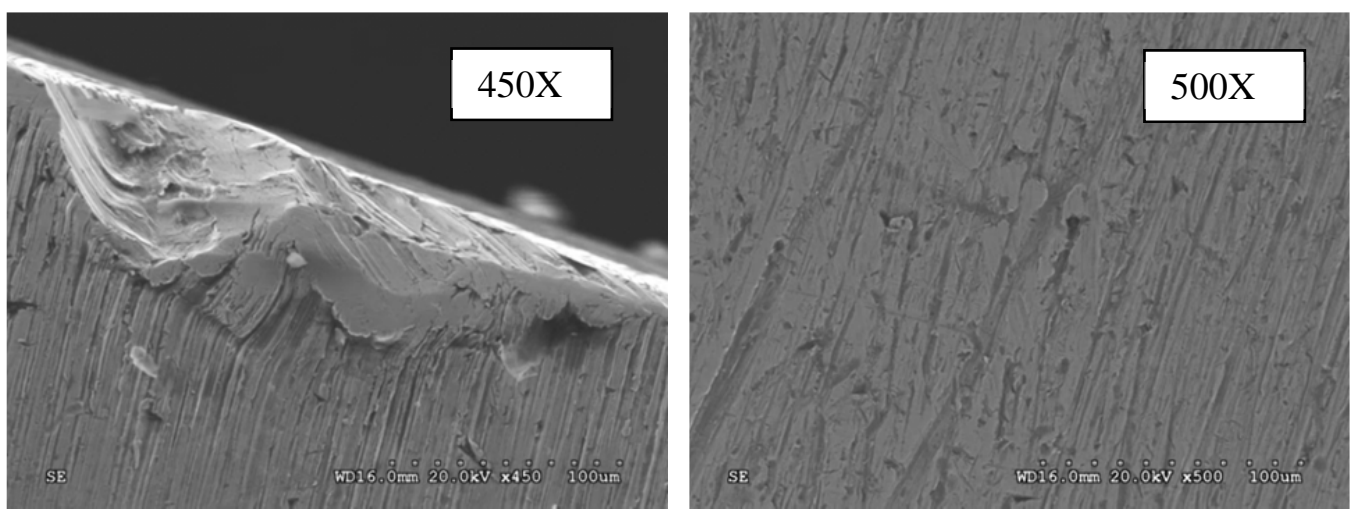

Figure 4-14. SEM micrographs of edge and surface of 316 specimens after slurry wear testing

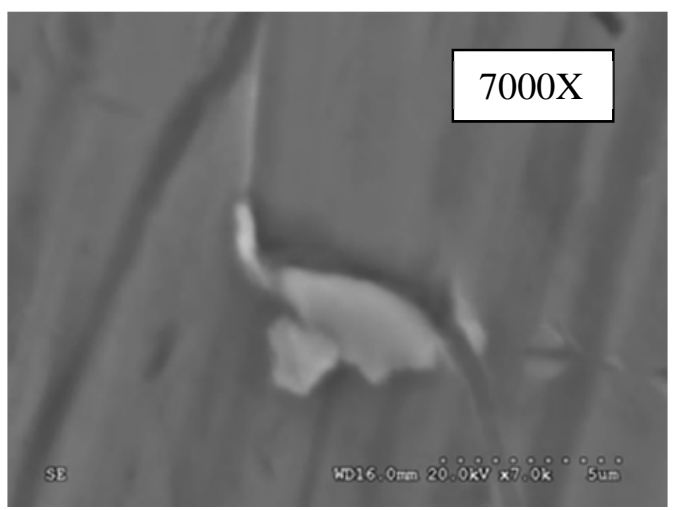

(A)

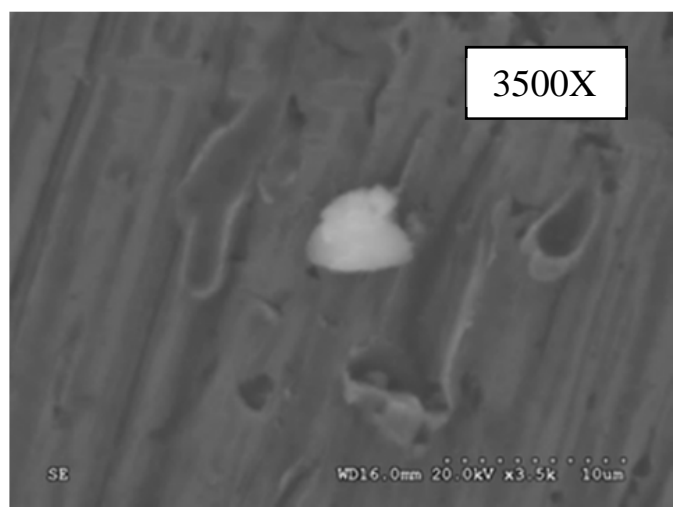

(B)

Figure 4-15. Features on the 316 surface after wear testing: (A) metal fold; (B) surface particle

\subsubsection{Stellite 12 Overlay}

Stellite overlay samples were received from HFW industries and had a consistent appearance. Relatively unidirectional grinding lines could be observed, ranging from 1-3 $\mu \mathrm{m}$ width (Figure 4-16). Surface roughness of the procured specimens was smooth and stated as 32AA or 0.8 Ra. The sum EDS spectra of the surface (Figure 4-16) showed all the expected X-ray lines and semi-quantitative compositions were within the expected composition considering the error of the measurement (Table 4-4).

After the wear testing in the slurry, the edges were sharp with some spots of wear, showing heavy gouging and material lifting or removal (Figure 4-17). Wear was not uniform throughout the sample, with some areas exhibiting more aggressive wear from the slurry ( $\sim 50 \%$ and $\sim 75 \%$ of total surface area for the two samples). Figure 14-18 shows a comparison of the two distinct regions. Figure 14-18 (A) shows mostly unidirectional surface lines consistent with the starting material (Figure 4-16). Figure 1418 (B) shows a dendritic and rougher appearance representative of higher worn areas. The revelation of the dendritic microstructure is attributed a differential wear rate between the dendritic (Co-rich alloy) and the interdendritic (carbides) regions, although which has the higher wear rate was not discernible in the microstructural examination. 


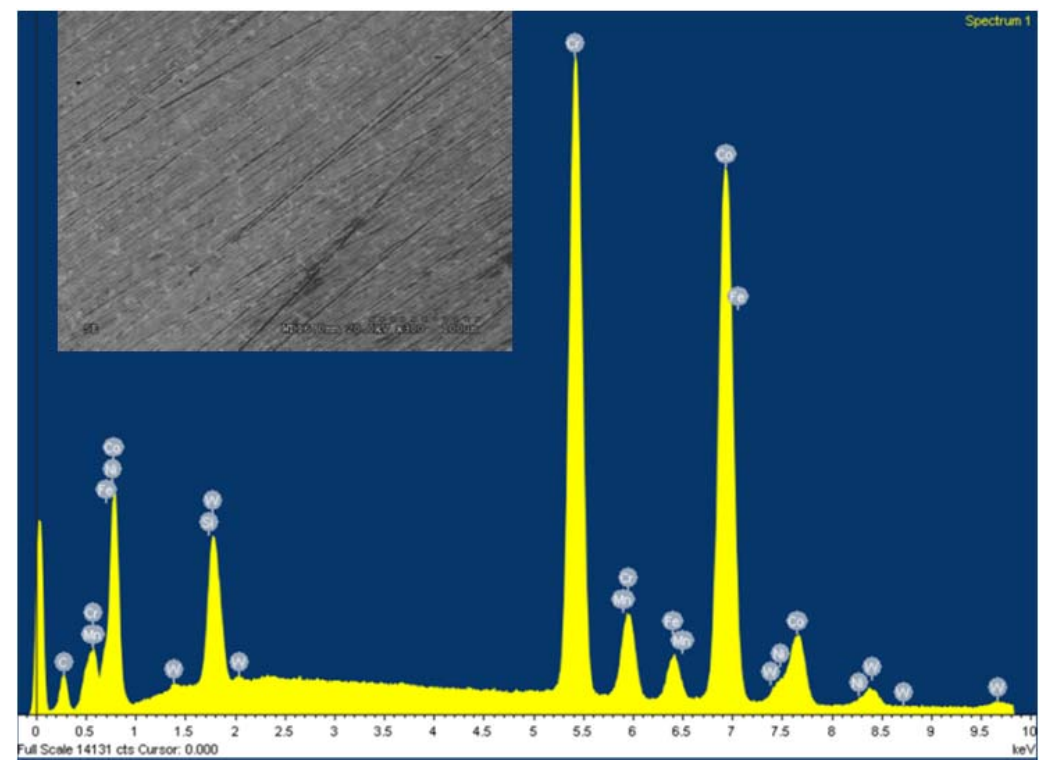

Figure 4-16. SEM micrograph and sum EDS spectra of as-received Stellite 12overlay (on 316L stainless steel) prior to wear testing
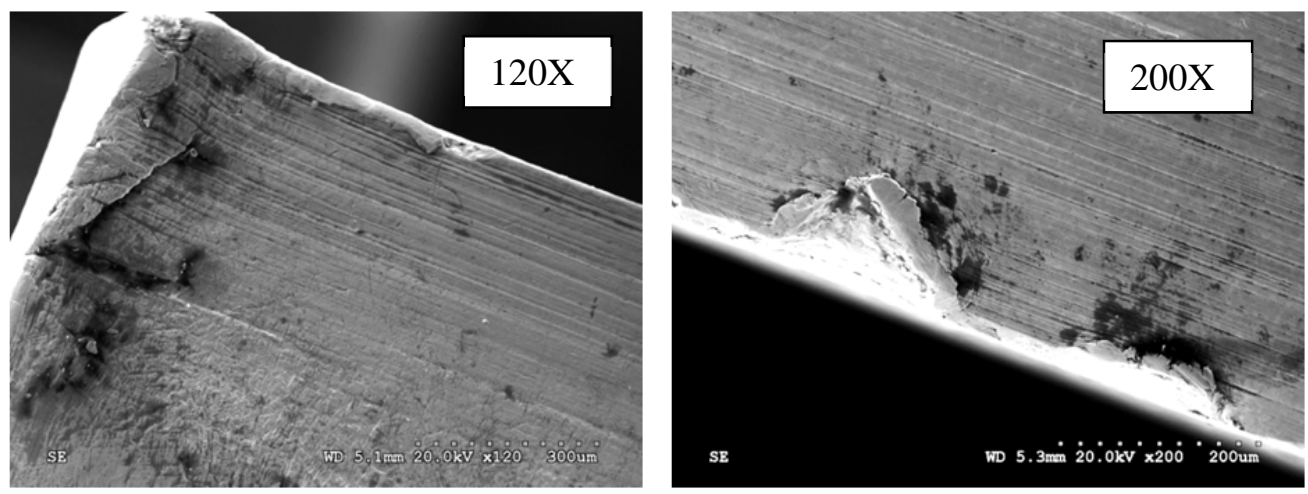

Figure 4-17. Worn edges of Stellite 12-overlay specimens after wear testing

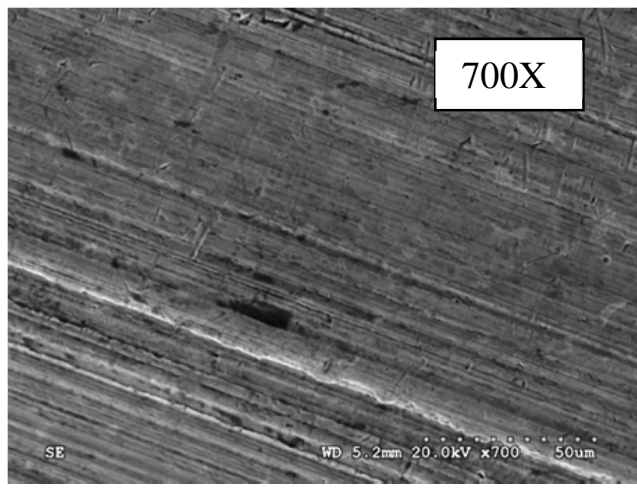

(A)

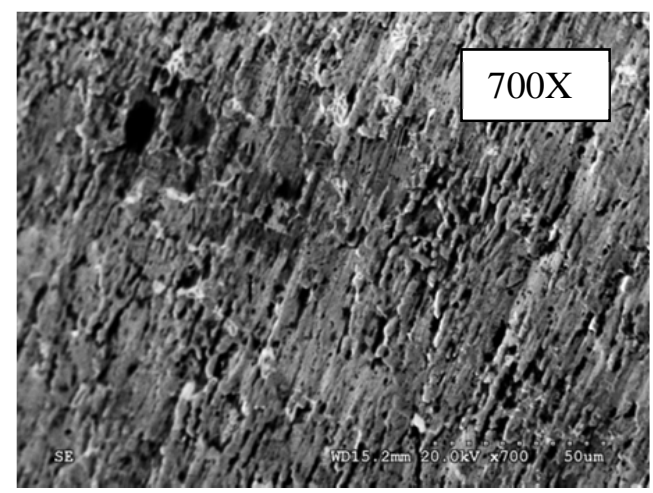

(B)

Figure 4-18. Stellite 12 overlay after wear test: (A) surface with less wear; (B) surface with more wear 
EDS mapping was performed in some of the higher-wear and dendritic-appearing regions (Figure 4-19). The Stellite hardfacing alloys typically solidify by dendritic growth of a Co-rich composition and the formation of various metal carbides in the interdendritic regions. [22-24] The $\mathrm{Fe}, \mathrm{C}, \mathrm{Mn}$ and Ni maps (not shown) indicated homogeneous surface compositions for these elements. By contrast, the Si and W maps showed segregation, with higher concentrations corresponding to the lighter features in the micrograph (i.e. features with higher secondary electron yields). This could be attributed to the retention of slurry Si particles on the surface. Cr and Co also appear segregated in these dendritic regions as would be expected from the dendritic solidification. Their compositional maps indicate that Co rich areas are highly $\mathrm{Cr}$ deficient, and vice-versa, which is in agreement with literature for Stellite alloy solidification [21].
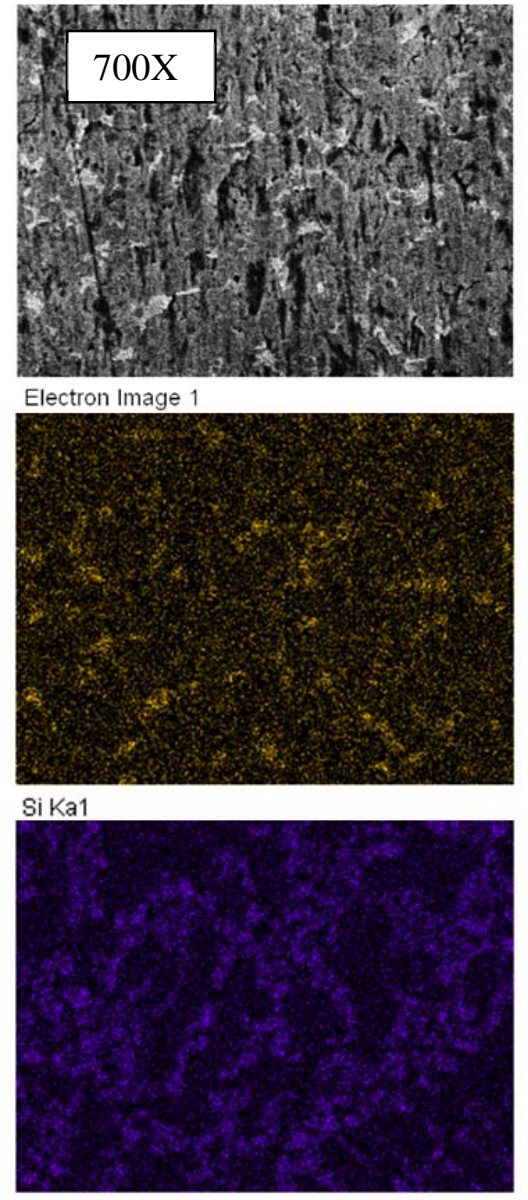

Cr Ka1

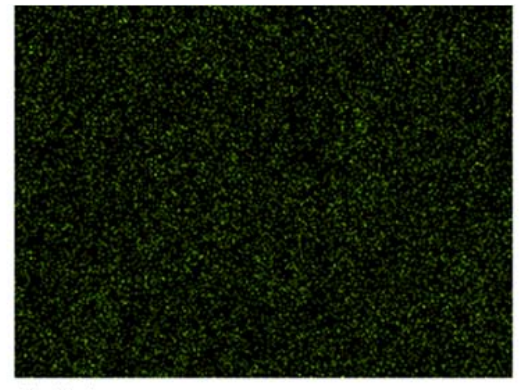

Fe Ka1

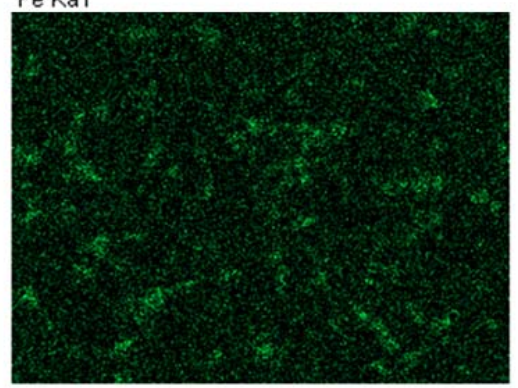

WMa1

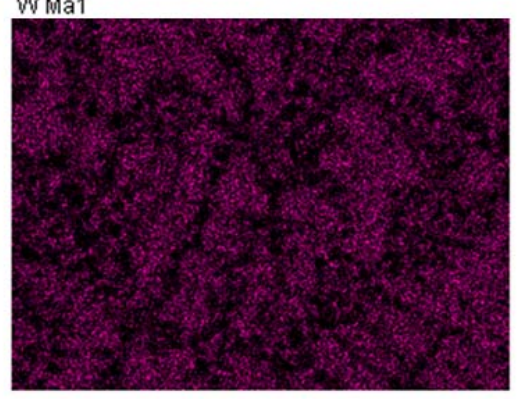

Co Ka1

Figure 4-19. EDS compositional maps for high wear region from Stellite 12-overlay sample after wear testing

An additional specimen with the same surface characteristics as Figure 4-16 was tested with premix only but identical ASTM G75 test conditions. This sample exhibited a large dull area ( $30 \%$ of total sample surface) corresponding to higher wear, as confirmed by SEM. This area appears to be a combination of high amounts of abrasion lines within smoother areas. Figure 4-20 shows higher magnification images of both low and high 
wear regions. The edges of these samples appeared rounded and small gouges/pits could be observed ( 5-30 $\mu \mathrm{m})$ (Figure 4-21). Similar to the Stellite 12 plate (Section 4.4.4), the higher SAR number (SAR=54) of this sample relative to that tested in a wet slurry seems to indicate that the dry premix appears to act as a polishing media enhancing material loss or conversely the liquid in the wet slurry acts as a lubricant.

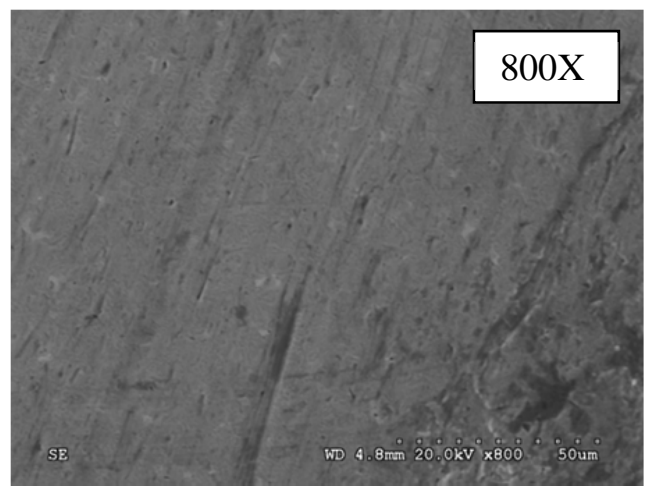

(A)

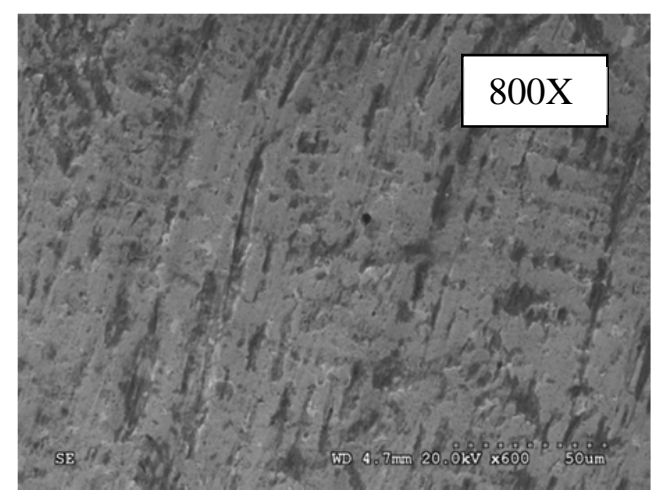

(B)

Figure 4-20. SEM micrographs of low (A) and high (B) abrasion regions in Stellite 12 overlay specimen tested under premix conditions
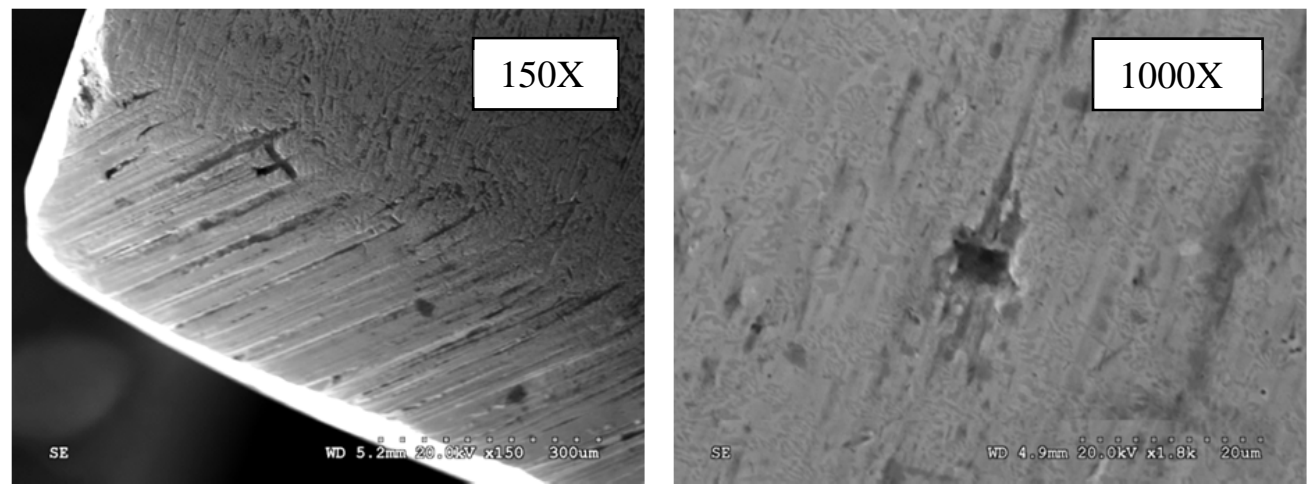

Figure 4-21. SEM micrographs of rounded edges and small gouging observed in Stellite 12 overlay specimen tested under premix conditions

\subsubsection{Stellite 12 Plate}

A Stellite 12 plate wear specimen was prepared by electric discharge machining (EDM) for premix abrasion testing. Figure 4-22 shows an SEM micrograph of the specimen after sectioning by EDM. A sum EDS spectra was obtained for a selected area, which showed all expected X-ray lines, with the additional presence of $\mathrm{Cu}$ and $\mathrm{Zn}$ resultant from residue of the EDM wire. The EDS composition is given in Table 4-4.

The EDM-cut Stellite 12 plate sample was polished with 320-grit silicon carbide paper to remove machining features prior to premix abrasion testing per ASTM G75 process conditions. The post-test sample exhibited a large dull area ( $30 \%$ of total sample surface) corresponding to higher wear, as confirmed by SEM. This area appears to be a combination of smooth and rough lines, the latter with a rougher appearance (Figure 4- 
23). Abrasion can be seen in one phase. In Figure 4-23, there is also an indication of possible cracking as shown by the white arrow. Some areas (e.g. close to the sample edge - Figure 4-24), show more prominent interdendritic features, suggesting a localized abrasion that removed the Co-rich alloy or the carbide interdendritic region. A higher SAR number $(\mathrm{SAR}=54)$ was obtained for this specimen relative to the Stellite 12 overlay sample tested with a wet slurry. Since the plate showed a smoother morphology relative to the latter, the premix may act as a polishing media that enhances material loss or conversely the liquid in the wet slurry acts as a lubricant.

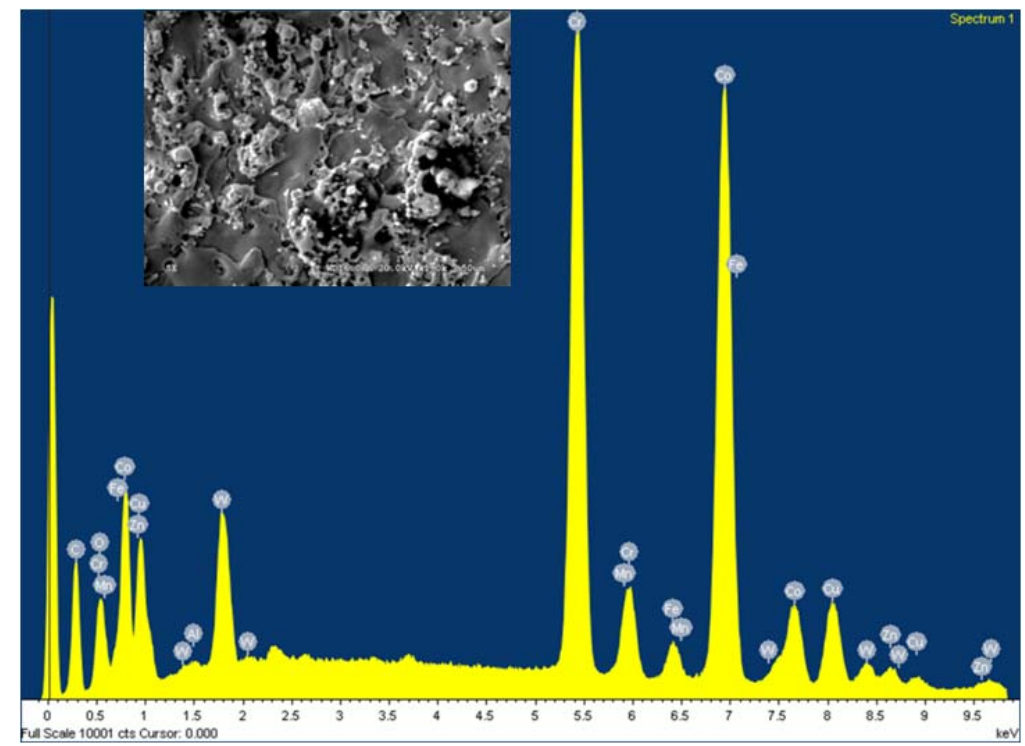

Figure 4-22. SEM micrograph and sum EDS spectrum of EDM-cut Stellite 12 plate prior to wear testing
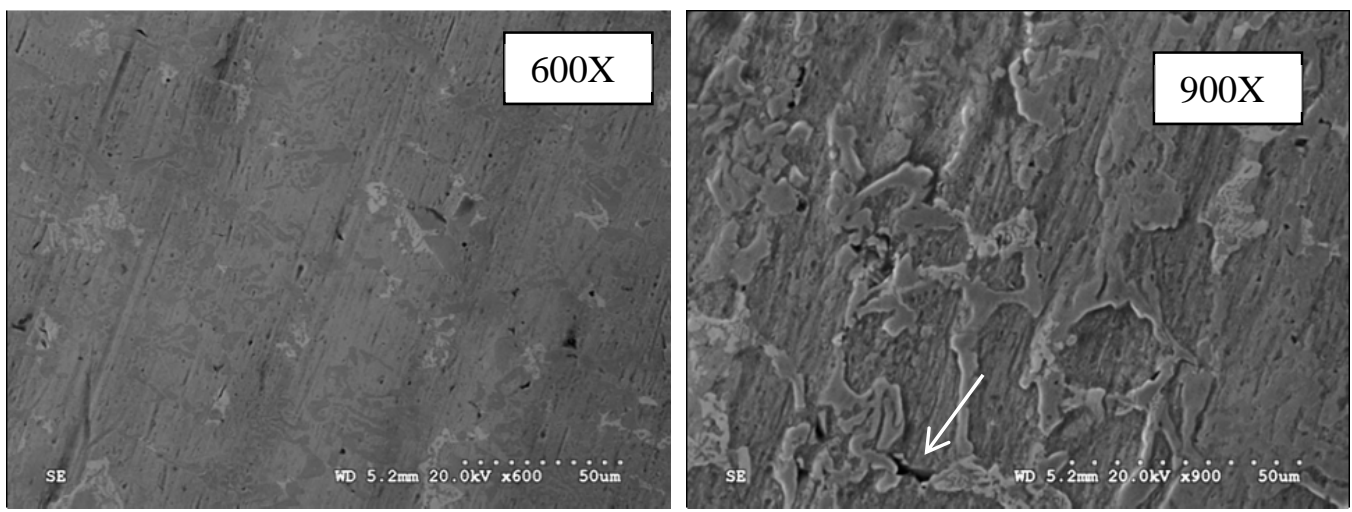

Figure 4-23. SEM micrographs of variable morphology lines/areas in Stellite 12 plate after premix wear testing

EDS mapping was performed in the rougher-appearing regions of the sample (Figure 425). The Fe, C, and Ni maps (not shown) indicated homogeneous surface compositions for these elements. Similar to the Stellite 12 overlay tested under wet slurry conditions, the Si and W maps showed segregation, with higher concentrations corresponding to the 
lighter (higher secondary electron yield) features in the micrograph. This could be the result of Si particles from the slurry retained on the surface. The maps for $\mathrm{Mn}, \mathrm{W}$ and $\mathrm{Cr}$ indicate these elements have high concentrations where Co is deficient, i.e. interdendritic carbides. These are the regions that show less wear in the SEM micrograph of Figure 423. These results are consistent with expected microstructure for Stellite alloys. [21] The wear of these alloys is dependent on the size and distribution of the carbides.
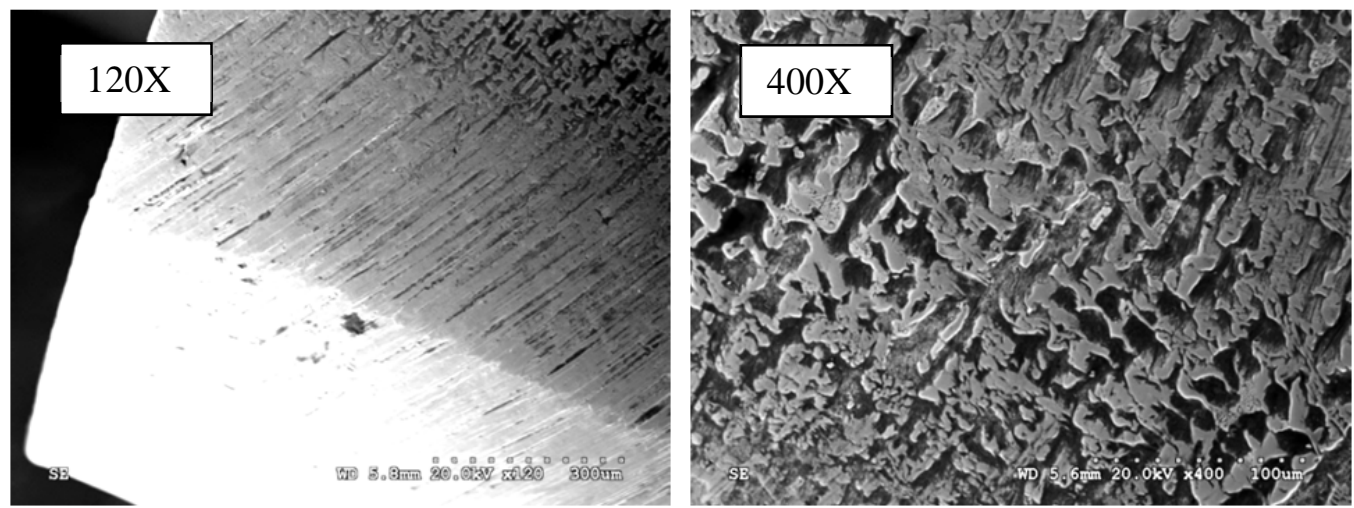

Figure 4-24. SEM micrographs of Stellite 12 plate edge and high wear after premix wear testing

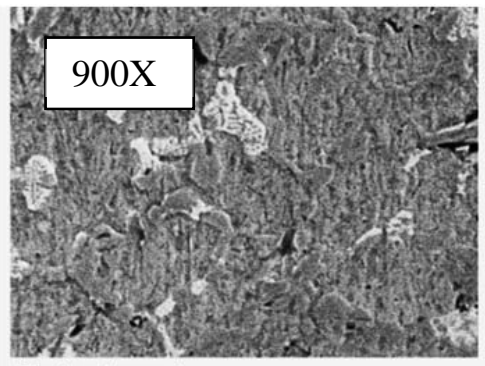

Electron Image 1

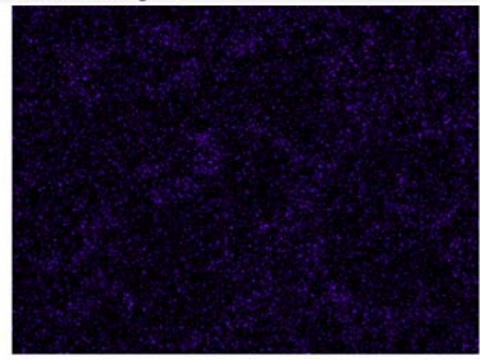

Mn Ka1

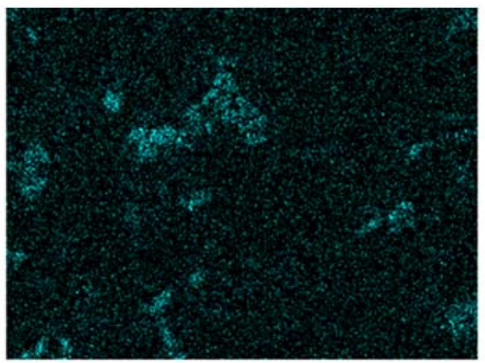

WMa1

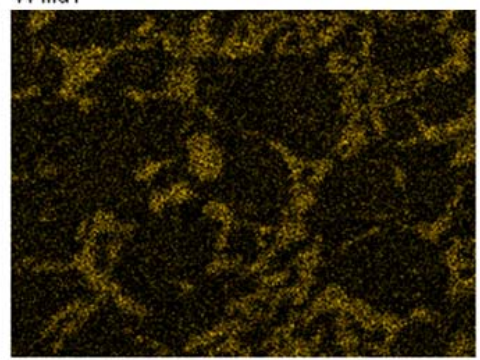

Cr Ka1

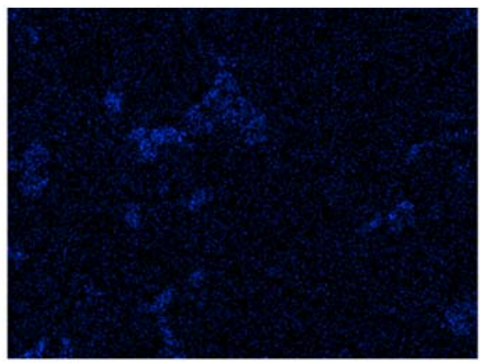

Si Ka1

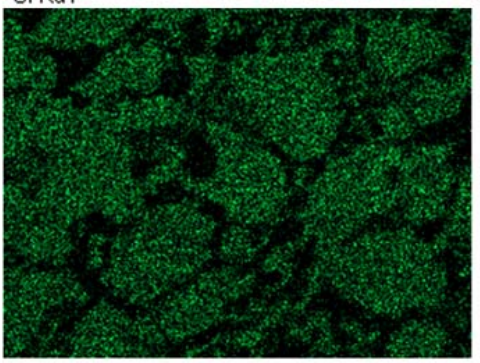

Co Ka1

Figure 4-25. EDS compositional maps for high wear region from Stellite 12 plate after wear testing

\subsubsection{Tungsten Carbide}

Tungsten carbide wear specimens were prepared by EDM from an end mill bit manufactured by Imco Carbide Tool, Inc. A specification sheet provided by the manufacturer stated a composition of 10 wt.\% Co and 0.7 wt.\% $\mathrm{Cr}_{\mathrm{x}} \mathrm{C}_{\mathrm{y}}$. SEM micrographs of the EDM as-machined surface showed morphology consistent with the instantaneous melting due to the sparking from the sides of the wire to the work piece. A 
sum EDS spectra was obtained for a selected area (Figure 4-26), which showed all expected X-ray lines, and is in reasonable agreement with the specification sheet composition. The presence of copper is from the residue of the EDM wire. Table 4-5 listed the EDS composition excluding the $\mathrm{Cu}$ and $\mathrm{O}$ lines.

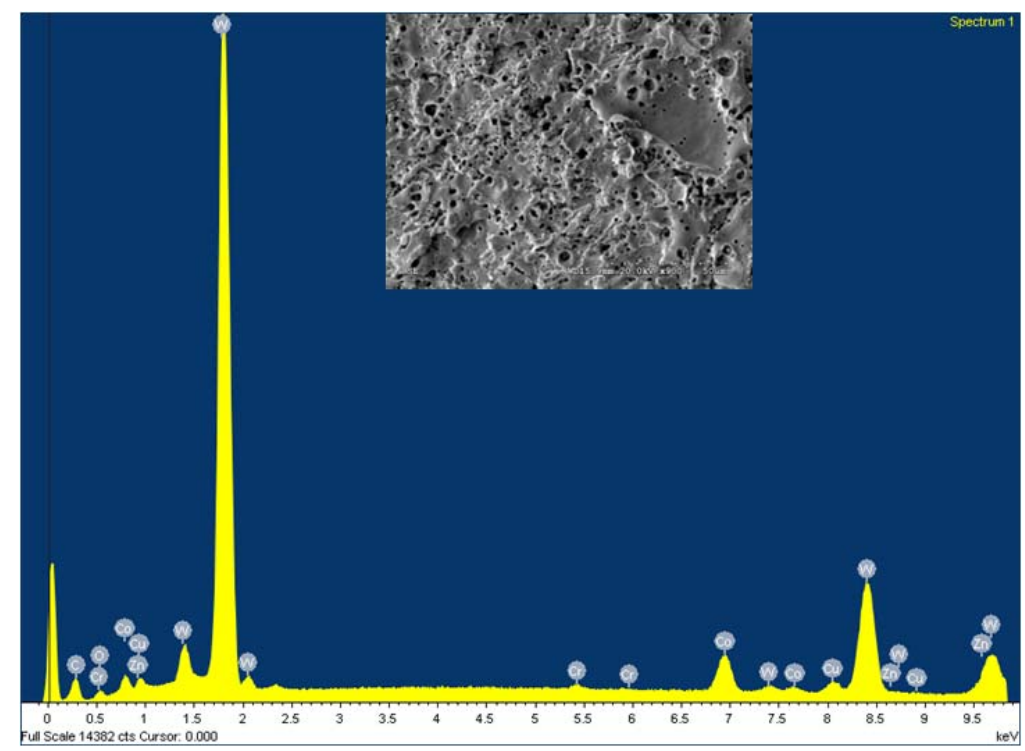

Figure 4-26. SEM micrograph and sum EDS spectrum of surface of as-machined tungsten carbide wear specimen

Table 4-5. Compositions based on EDS Spectra for As-machined Wear Samples of Tungsten Carbide, D2 Tool Steel and Ultimet

\begin{tabular}{|c|c|c|c|c|c|}
\hline & $\begin{array}{c}\text { Tungsten } \\
\text { Carbide }\end{array}$ & \multicolumn{2}{|c|}{ D2 Tool Steel } & \multicolumn{2}{c|}{ Ultimet } \\
\hline Element & $\begin{array}{c}\text { Measured } \\
\text { Wt \% } \\
\text { (max.) }\end{array}$ & $\begin{array}{c}\text { Expected } \\
\text { Wt \% } \\
\text { (max.) }\end{array}$ & $\begin{array}{c}\text { Measured } \\
\text { Wt \% }\end{array}$ & $\begin{array}{c}\text { Expected } \\
\text { Wt \% } \\
\text { (max.) }\end{array}$ & $\begin{array}{c}\text { Measured } \\
\text { Wt \% }\end{array}$ \\
\hline C K & 8.84 & 1.46 & 8.32 & NA & NA \\
\hline Si K & NA & 0.42 & 0.39 & NA & NA \\
\hline Cr K & 0.59 & 11.74 & 18.4 & 26 & 27.97 \\
\hline Mn K & NA & 0.39 & 0.0 & NA & NA \\
\hline Fe K & NA & Bal & 69.79 & 3 & 3.15 \\
\hline Ni K & NA & 0.11 & 0.06 & 9 & 8.65 \\
\hline Mo L & NA & 0.79 & 1.14 & 5 & 1.03 \\
\hline Co & 7.86 & NA & NA & Bal & 52.56 \\
\hline Other & W - 82.71 & V- 0.78 & V- 1.52 & W - 2 & W - 2.64 \\
\hline
\end{tabular}

Close examination of the edges of the specimens following abrasion testing shows that some material dislodged by breakdown of the grain structure (Figure 4-27). The grain boundaries were found to be tungsten deficient, which may have resulted in a loss of strength that lead to grain removal. Average grain size ranged between 100 to $200 \mu \mathrm{m}$. 
The beveled edges did not show any enhanced wear or rounding. These features are all consistent with the very low SAR value of these materials (SAR=13).
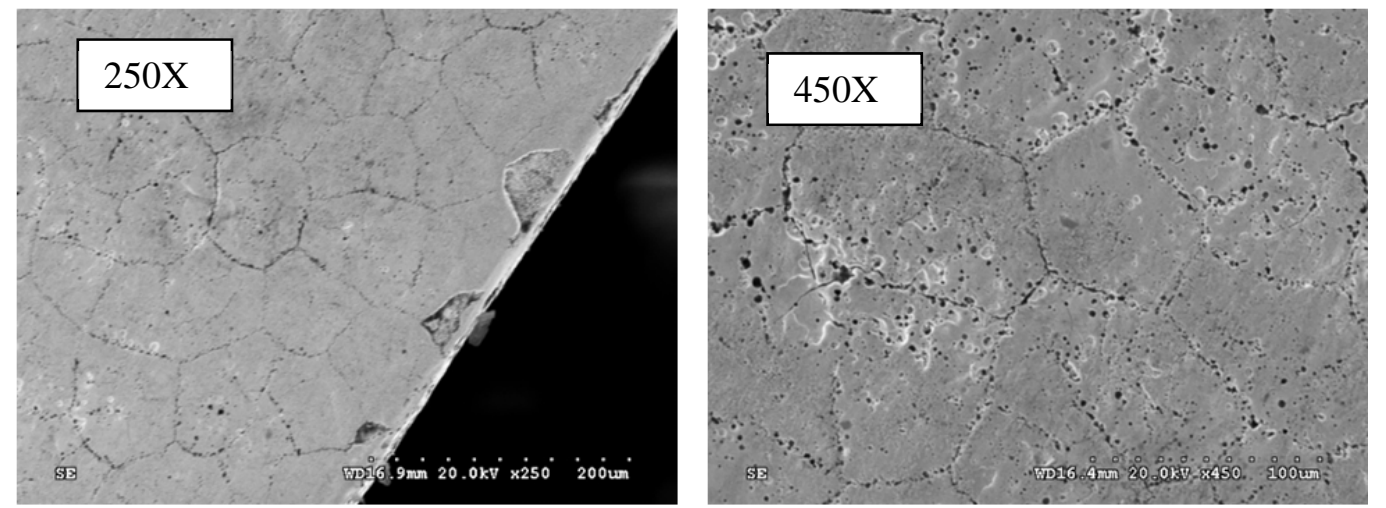

Figure 4-27. SEM micrographs of edge and surface of tungsten carbide samples following wear testing

\subsubsection{D2 Tool Steel}

D2 tool steel wear specimens were procured from Metal Samples, Inc. Surface roughness of the procured specimens was stated as 32RMS or 0.8 Ra. Figure 4-28 shows images of the as-received specimens, which show a grain structure with an average size of $\sim 5 \mu \mathrm{m}$. Some grains appear hollow and a diffuse oxide covers much of the surface. A sum EDS spectrum was obtained over the surface, shown in Figure 4-29. The composition is given in Table 4-5 and is consistent with expected values.
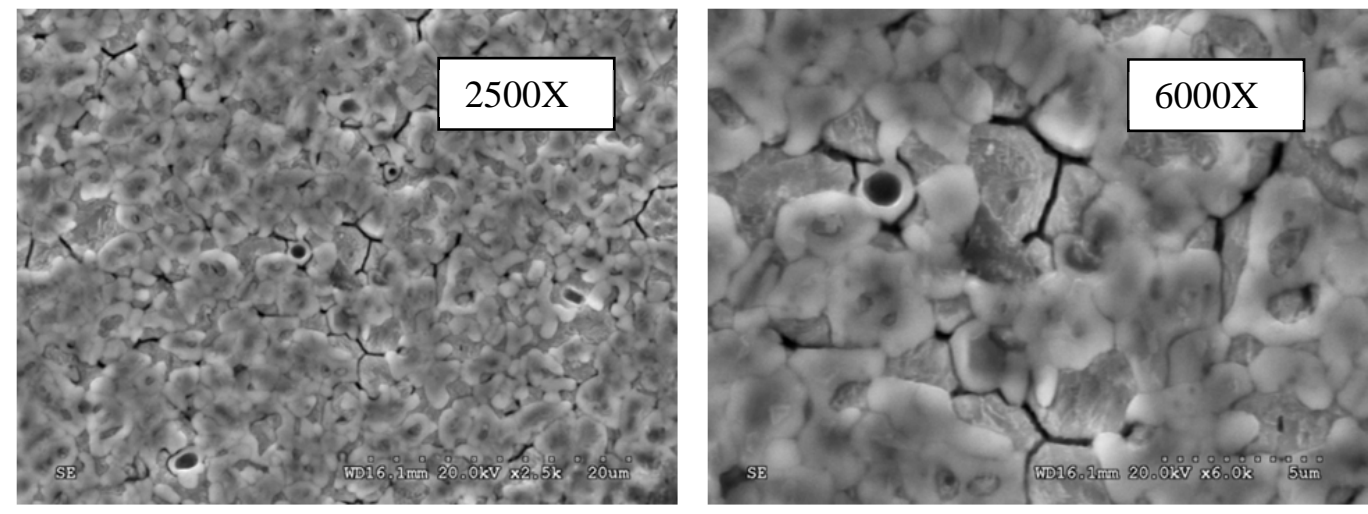

Figure 4-28. SEM micrographs of surface of as-received D2 tool steel wear specimens 


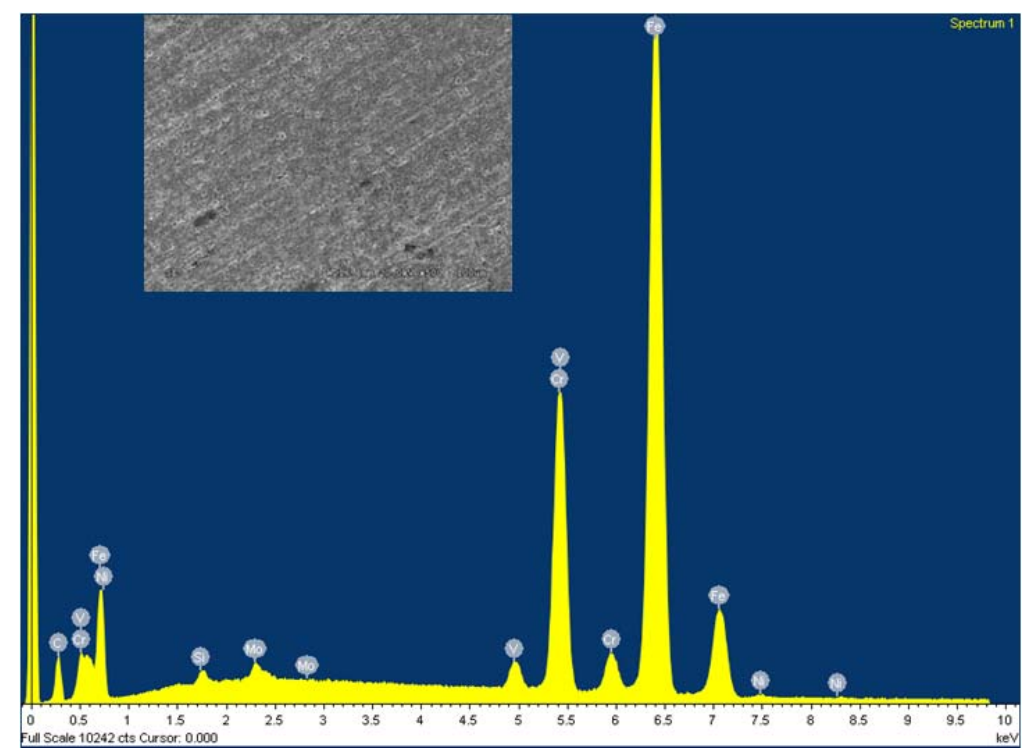

Figure 4-29. SEM micrograph and sum EDS spectrum of surface of as-received D2 tool steel wear specimen

After wear testing in wet slurry, the overall surface of the specimens was primarily unidirectional wear lines in the direction of specimen motion. The grain structure in the initial material could no longer be observed. SEM micrographs showed that the edges of the D2 tool steel specimens remained fairly sharp after the wet slurry abrasion test (Figure 4-30), although some material loss occurred. Some localized corrosion spots were found with visible red corrosion products.

Randomly shaped particles could be seen on the surface, presumably of slurry origin due to the high contrast (charging) inherent in these slurry particles. Additional dark (low secondary electron yield) and light (high yield) spots could also be observed, which were characterized by EDS compositional mapping. The dark features in the surface are carbon rich (Figure 4-31), while the light features appear to be Si and O rich, most likely a resultant of slurry residue (Figure 4-32).
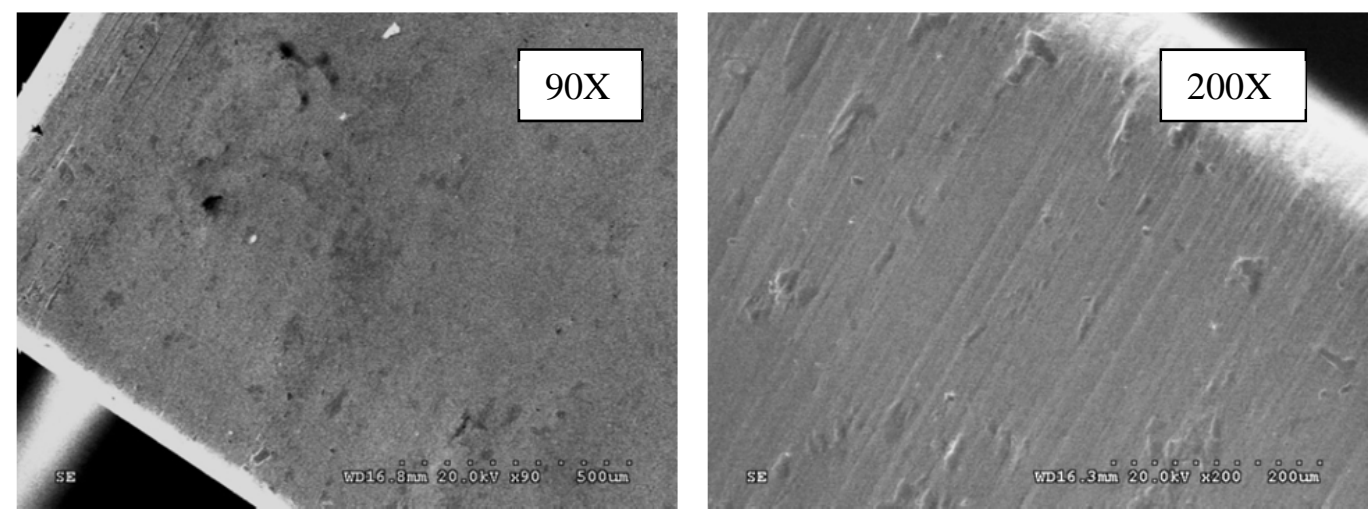

Figure 4-30. SEM micrographs of edges of $D 2$ tool steel samples after wear testing 


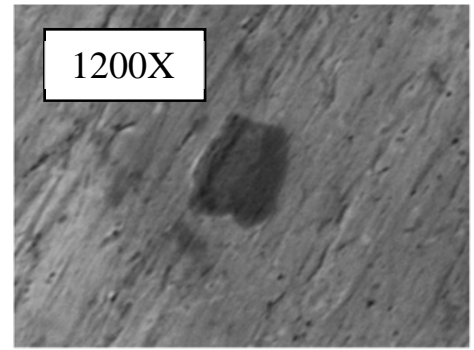

Electron Image 1

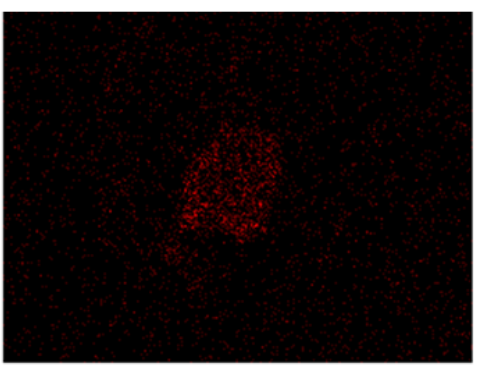

CKa1_2

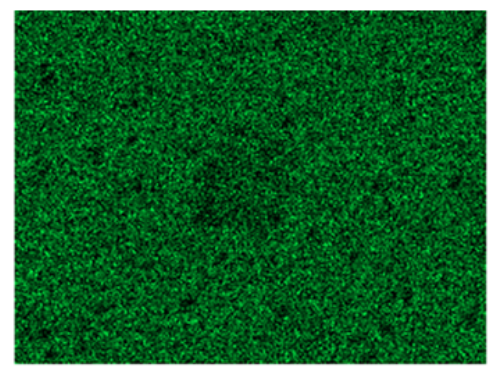

Fe Ka1

Figure 4-31. EDS compositional maps of dark (low secondary electron yield) features in surface of D2 tool steel specimen following wet slurry wear testing

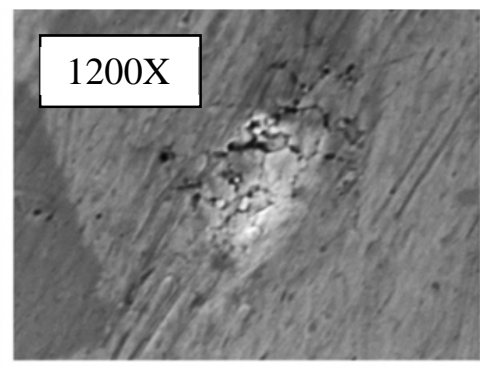

Electron Image 1

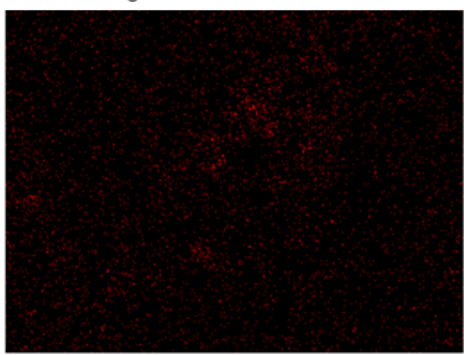

CKa1_2

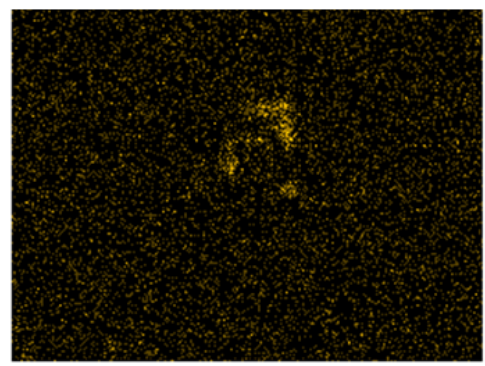

Si Ka1

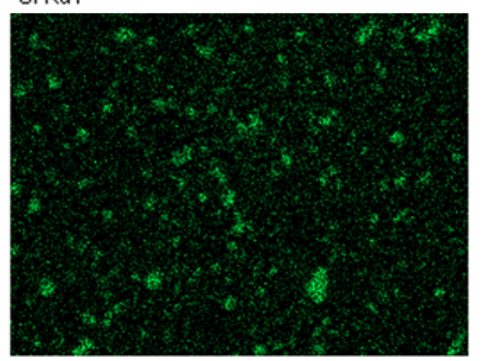

Cr Ka1

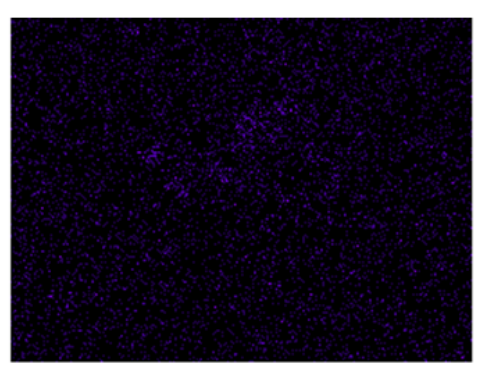

O Ka1

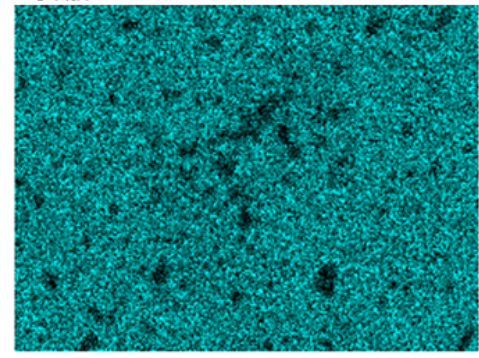

Fe Ka1

Figure 4-32. EDS compositional maps of light (high secondary electron yield) features in surface of D2 tool steel specimen following wear testing

Finally the entire specimen surface exhibited raised block features of varied dimensions, several which were characterized by EDS (Figures 4-33 and 4-34). Compositional mapping indicates that these plates/blocks are chromium and vanadium rich, while iron deficient. Vanadium and chromium form hard carbides in tool steels to improve hardness.

Overall, the minimal gouging and relatively smooth surface combined with the retention of specimen shape are consistent with the low SAR number for these specimens $(\mathrm{SAR}=46)$. 


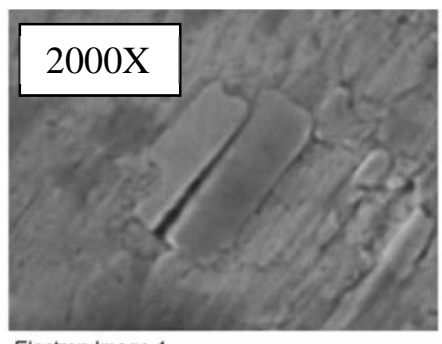

Electron Image 1

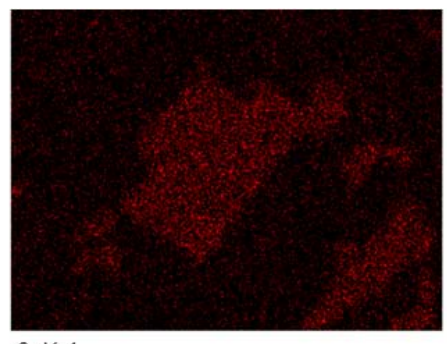

Crka1

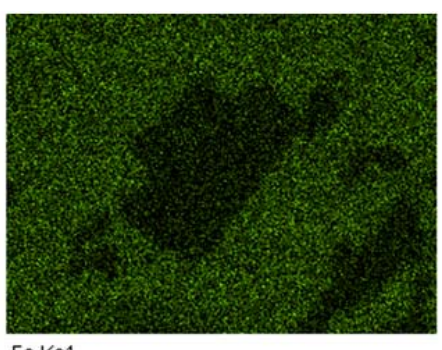

Fe Ka1

Figure 4-33. EDS compositional maps of raised block features in surface of D2 tool steel specimen following wear testing

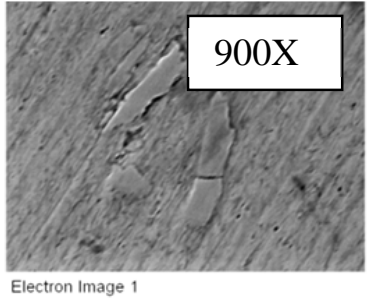

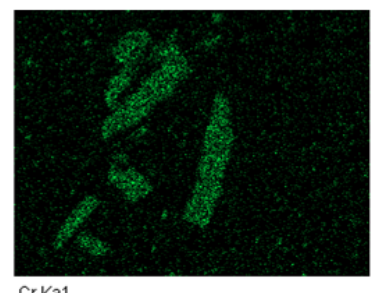

Crka1
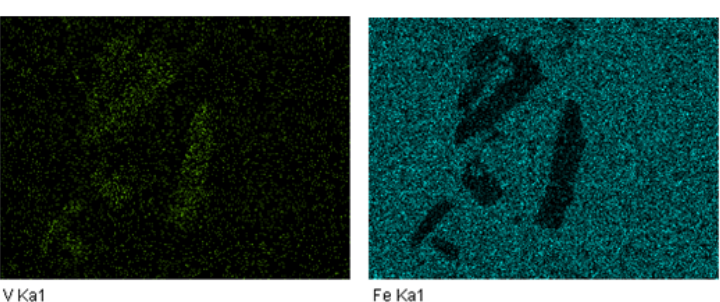

Fe Ka1

Figure 4-34. EDS compositional maps of raised block features in surface of D2 tool steel specimen following wear testing

\subsubsection{Ultimet}

The as-machined Ultimet showed a similar morphology to other samples fabricated by EDM (Figure 4-35). The sum EDS spectrum of the surface shows the presence of the additional elements $\mathrm{Al}, \mathrm{Mn}, \mathrm{Cu}$ and $\mathrm{Zn}$, the latter two resultant from the cutting process. The EDS composition is given in Table 4-5 and was consistent with expected values.

The Ultimet wear specimens showed highly unidirectional lines with few randomly oriented scratches and deep grooves (Figure 4-36). The edges did not appear preferentially worn with material dislodging. The SAR number for these specimens was 100, a mid-range value for the overall test. The minimal gouging in these samples suggests that material loss was relatively uniform, outside of the weld overlay intersections. The wear test revealed the weld overlay structure of the samples. Crevices depicting the intersection and incomplete fusion of the different overlay passes could be observed (Figure 4-36). 


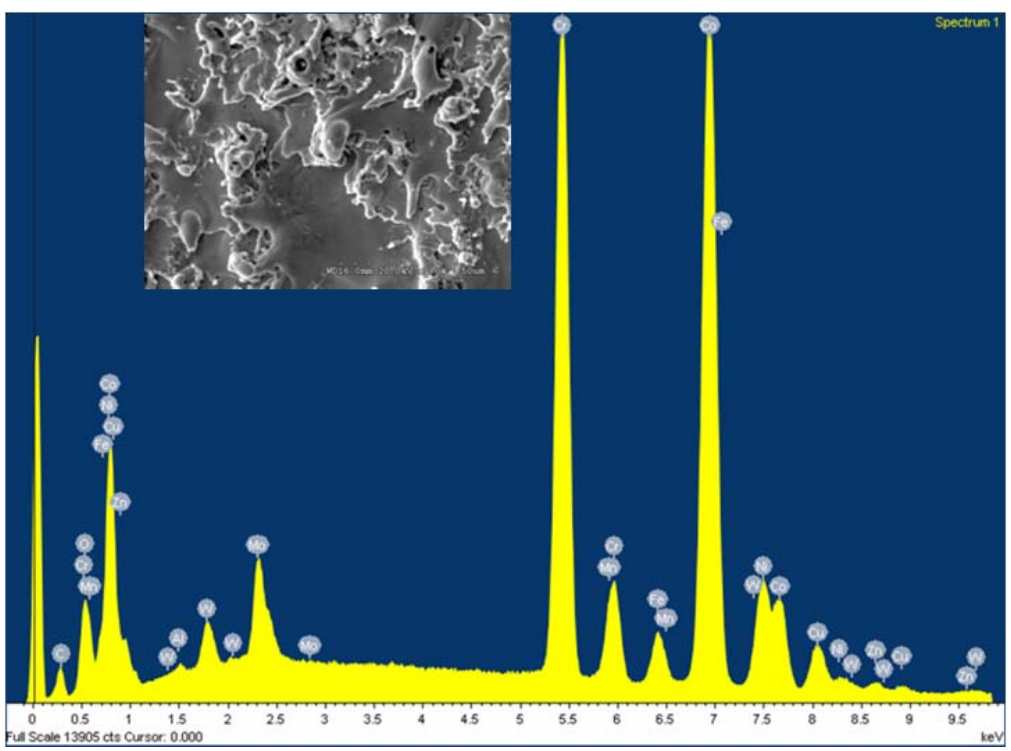

Figure 4-35. SEM micrograph and sum EDS spectrum of surface of as-machined Ultimet wear specimen
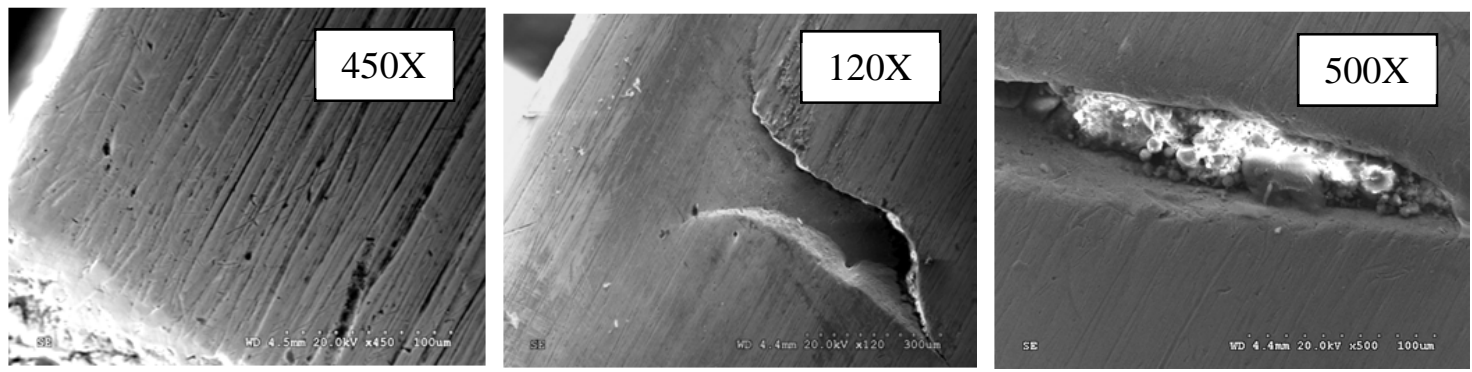

Figure 4-36. SEM micrographs of edge and representative surface of Ultimet steel specimens following wear testing

These crevices resulted in enhanced accumulation of slurry particles. EDS mapping was performed on some of these sections to confirm the composition of the lodged material (Figure 4-37). The spectra confirmed the large accumulation of salts and oxides based on the elements $\mathrm{Ca}, \mathrm{Mg}$, Si, and $\mathrm{Al}$.

\subsubsection{Ultimet - Work Hardened}

Ultimet wear specimens which were work hardened by needle peening were machined by EDM. The SEM micrographs showed no distinct surface characteristics or EDS spectra relative to the non-work-hardened analogues. After wear testing in wet slurry, the workhardened Ultimet specimens also showed similar surface characteristics to the non-workhardened specimens. The edges did not show any significant material removal, and scratch lines appeared unidirectional all throughout the specimen. The samples also exhibited randomly oriented darker spots, presumably carbon rich. These specimens exhibited higher SAR number $(\mathrm{SAR}=184)$ than their non-work-hardened analogues. Since the surface morphologies of both types are almost identical, it appears that the work-hardening accelerates material loss. 

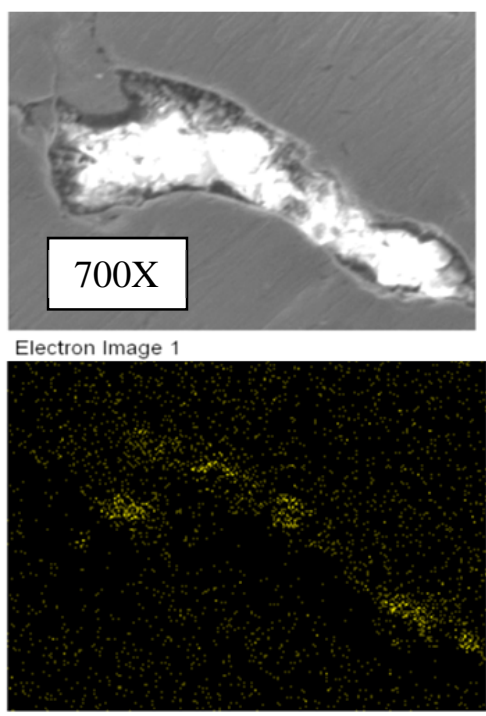

Mg Ka1_2

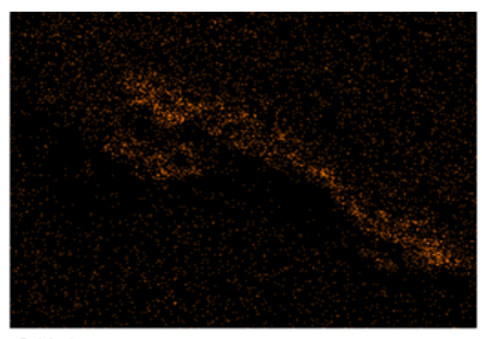

O Ka1

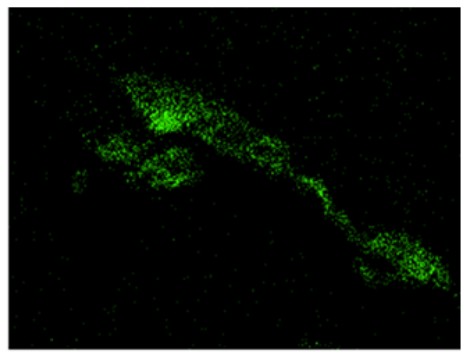

Si Ka1

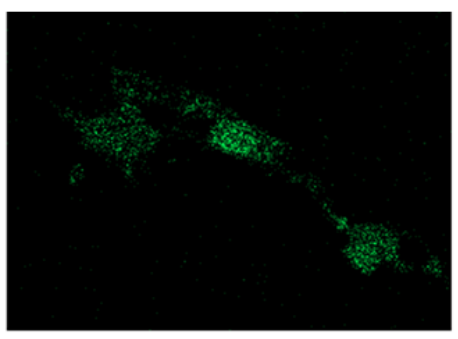

Ca Ka1

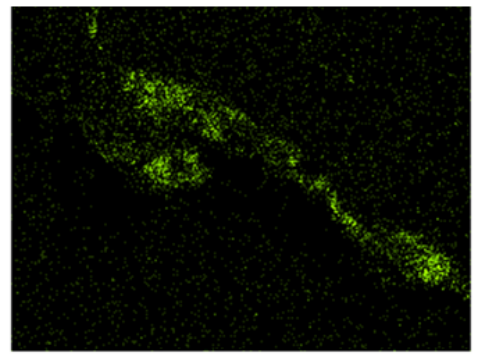

Al Ka1

Figure 4-37. EDS compositional maps of material lodged at intersection of weld overlays in Ultimet steel specimens following wear testing

\subsubsection{Alpha $^{\mathrm{TM}}$ (ZrN-based) Coating}

The ZrN coatings were deposited on 316 stainless steel specimens by Surface Solutions. This coating is a proprietary coating by the company. The coating is a multi-layered structure with $\mathrm{ZrN}$ as the top layer and specified coating thickness of $5 \pm 1 \mu \mathrm{m}$. The coating was tested since the manufacturer claims that the multi-layer structure exhibits increased hardness over its individual components (Figure 4-38), resulting in increased abrasion resistance and lubricity.

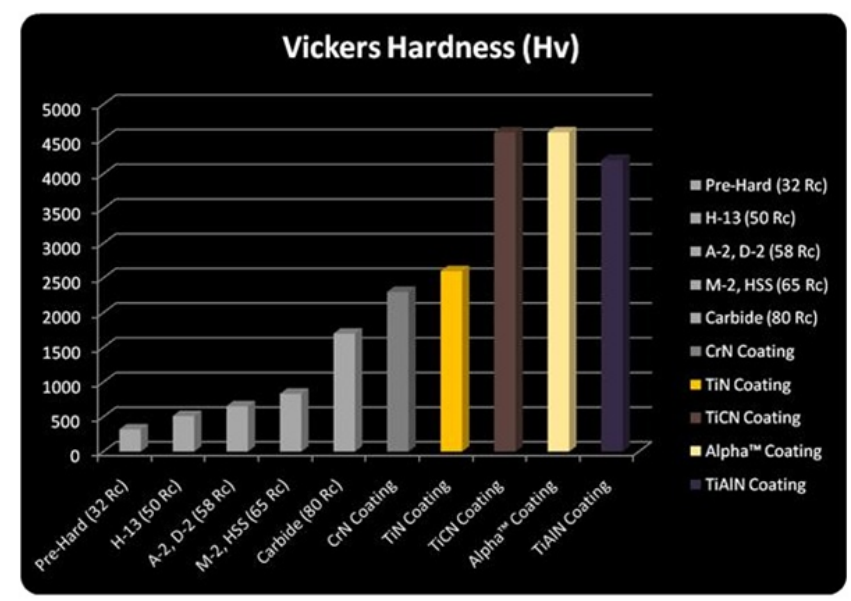

Figure 4-38. Hardness values of common PVD coatings

Figure 4-39 shows an SEM micrograph of the coated surface with a sum surface EDS spectrum. The composition is given in Table 4-6. The semi-quantitative results indicate that for an average interaction volume of $\sim 1-2 \mu \mathrm{m}$, the upper layer is mostly composed of 
$\mathrm{ZrN}$ as stated by the manufacturer. The coating underlying layers appear to be a combination of TiN and TiCN, or possibly only the latter. Most notably, a number of particle features could be observed throughout the surface of the specimens. Localized EDS analysis was performed on one of these particles, which indicated that these are not foreign particles (Table 4-6). These particles have the same elemental composition with a lower $\mathrm{Zr} / \mathrm{Ti}$ ratio (2.6) relative to the sum surface (6.2). These particles may have resulted by explosive ejection or spallation from the source material during physical vapor deposition.

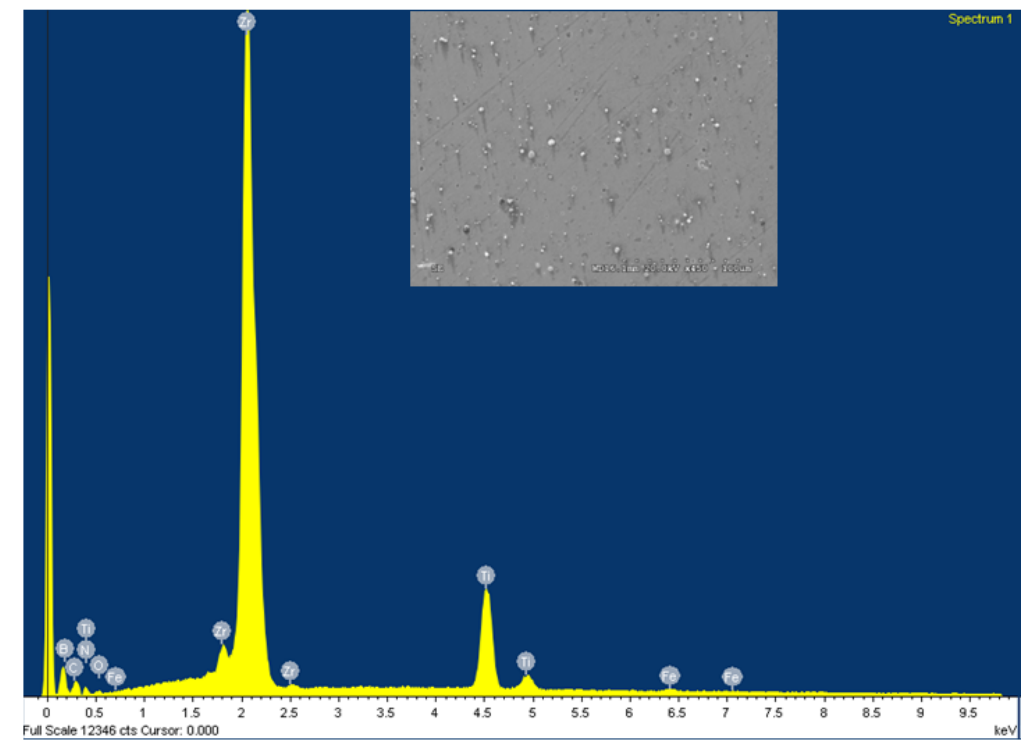

Figure 4-39. Sum EDS spectrum of surface of $\operatorname{Alpha}^{\mathrm{TM}}(\mathrm{ZrN})$ coated wear specimen

Table 4-6. EDS Compositions of PVD Coatings

\begin{tabular}{|c|c|c|c|c|}
\hline & \multicolumn{2}{|c|}{ ZrN } & TiCN & TiN \\
\hline Element & $\begin{array}{c}\text { Measured } \\
\text { Wt \% }\end{array}$ & $\begin{array}{c}\text { Particle } \\
\text { Wt \% }\end{array}$ & $\begin{array}{c}\text { Measured } \\
\text { Wt \% }\end{array}$ & $\begin{array}{c}\text { Measured } \\
\text { Wt \% }\end{array}$ \\
\hline B K & 2.15 & 0.00 & NA & NA \\
\hline C K & 8.64 & 11.62 & 7.67 & 2.46 \\
\hline N K & 4.79 & 8.87 & 7.44 & 12.49 \\
\hline O K & 1.60 & NA & NA & NA \\
\hline Ti K & 11.54 & 21.95 & 84.52 & 84.85 \\
\hline Fe K & 0.34 & NA & 0.37 & 0.21 \\
\hline Zr L & 70.93 & 57.56 & NA & NA \\
\hline
\end{tabular}

The Alpha ${ }^{\mathrm{TM}}$ coated 316 stainless steel specimens were tested with wet slurry per ASTM G75. The SEM micrographs showed extensive abrasion throughout the entire specimens with approximately $50 \%$ of the entire surface area showing complete coating removal. Figure 4-40 shows the EDS compositional maps of a large area $\left(>1 \mathrm{~mm}^{2}\right)$ in the highly worn surface. The maps clearly show that the lighter sections reveal the underlying 316L 
material. Dark (low secondary electron yield) spots could also be observed, which are carbon-rich.

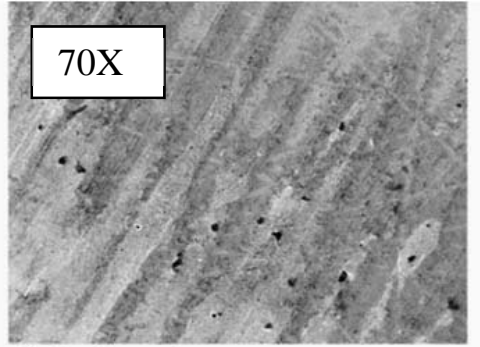

Electron Image 1

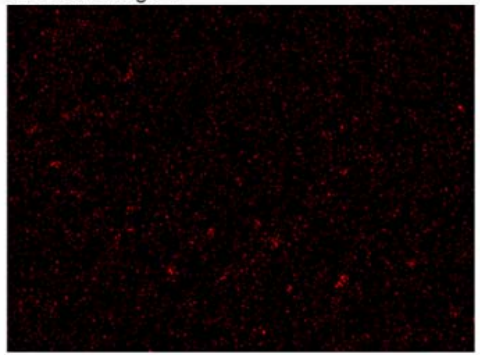

CKa1_2

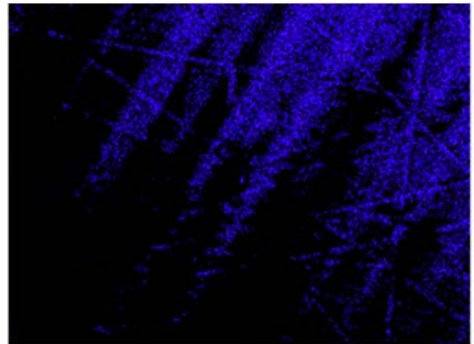

Zr La1

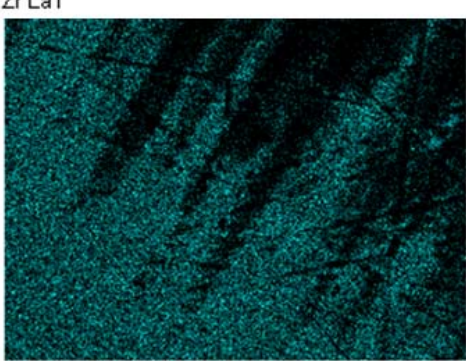

Fe Ka1

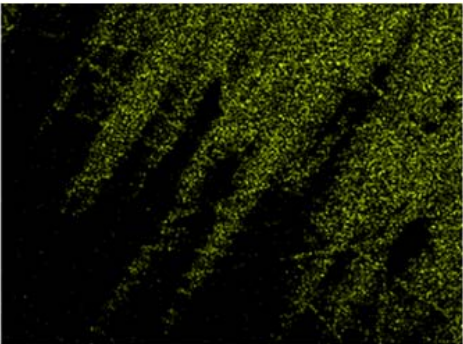

Ti Ka1

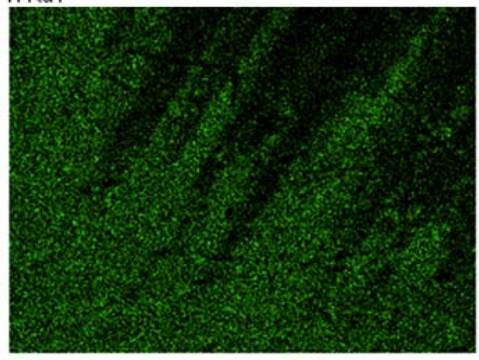

Cr Ka1

Figure 4-40. EDS compositional maps of surface of Alphat ${ }^{\mathrm{TM}}$ coated specimens following wear testing

\subsubsection{TiCN Coating}

Surface Solutions, Inc. coated additional 316 stainless steel specimens with TiCN of nominal thickness $5 \pm 1 \mu \mathrm{m}$. SEM micrographs of the coated specimens showed similar circular and particle features as those observed in the Alpha ${ }^{\mathrm{TM}}$ coated specimens (Figure 4-41 A). Some of these particles could be as large as $100 \mu \mathrm{m}$ (Figure 4-41 B). As mentioned earlier, these features could be the result of a poorly controlled deposition rate resulting in explosive ejection or spallation from the source material during physical vapor deposition.

The sum EDS spectra (Figure 4-42) shows that the composition of ratio of $\mathrm{C}$ to $\mathrm{N}$ is very close, with only Ti and the underlying Fe observed (Table 4-6).

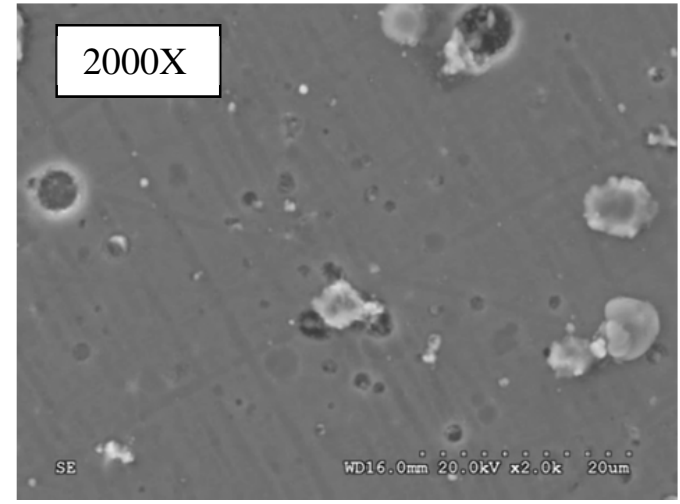

(A)

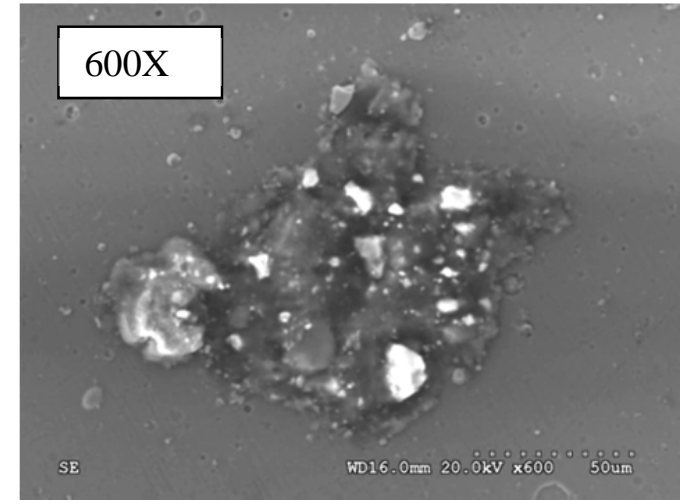

(B)

Figure 4-41. SEM micrographs of surface of TiCN coated wear specimens 


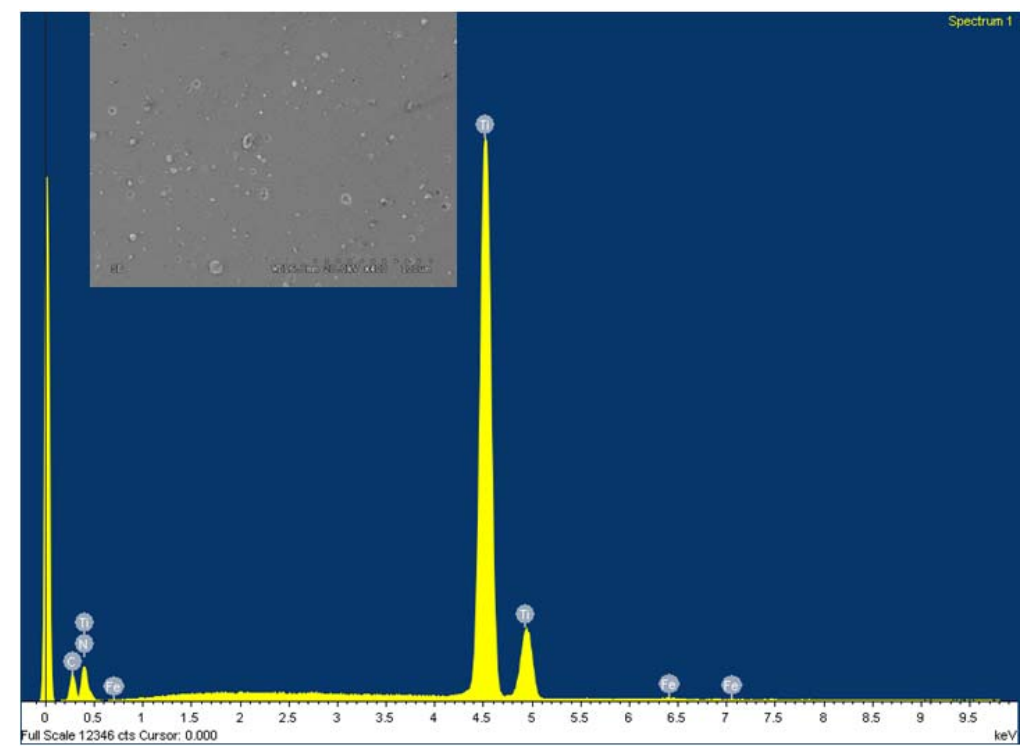

Figure 4-42. Sum EDS spectrum of surface of TiCN coated stainless steel wear specimen

SEM micrographs showed that $\sim 25 \%$ of the coating in these specimens had been removed following testing. Figure 4-43 shows images of the beveled edges and other surfaces areas showing wear (darker regions show coating still present).

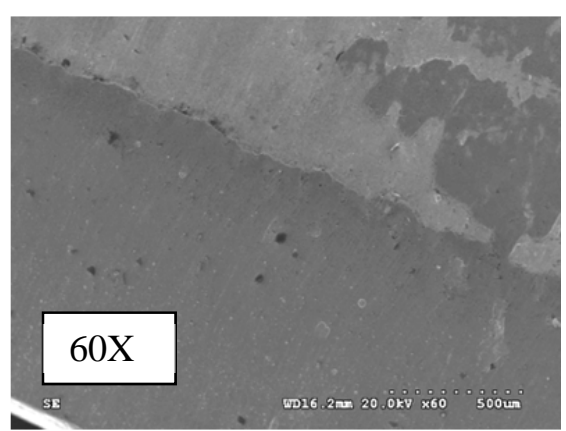

(A)

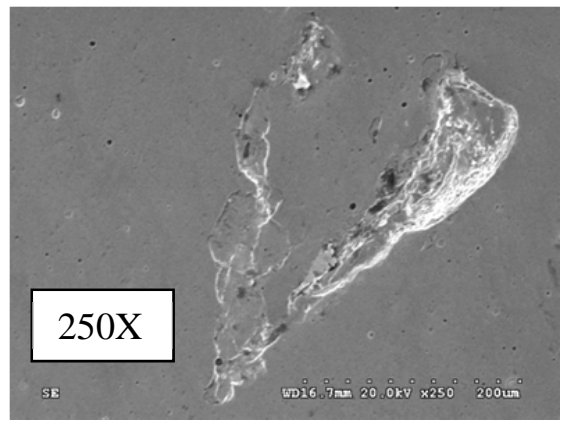

(C)

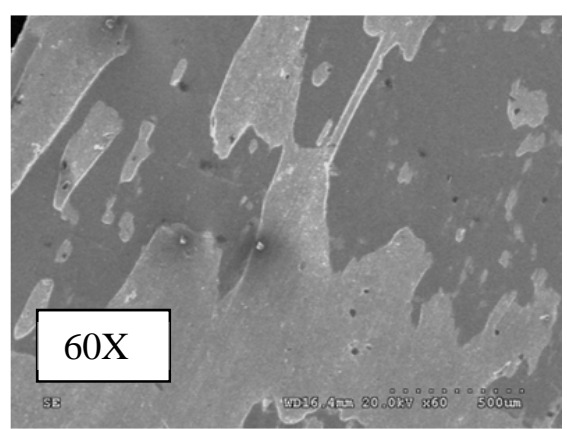

(B)

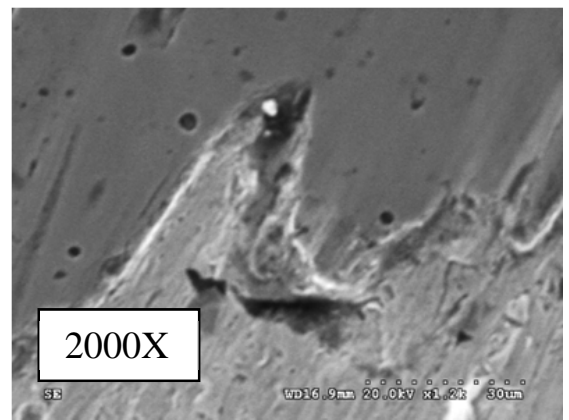

(D)

Figure 4-43. SEM micrographs of TiCN coated stainless steel specimens following wear testing: (A) beveled edge; (B) loss of coating; (C and D) surface gouges 
Other areas showed gouging and material removal revealing the underlying stainless steel. EDS compositional maps were obtained on multiple areas of the sample. Figure 4-44 shows an area clearly depicting the contrast from the removed coating. Dark features could also be observed, which are rich in carbon.
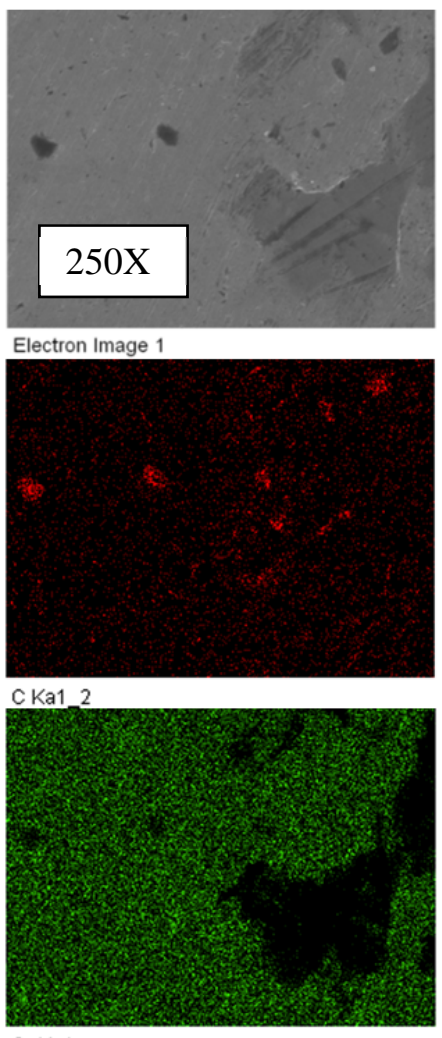

CrKa1
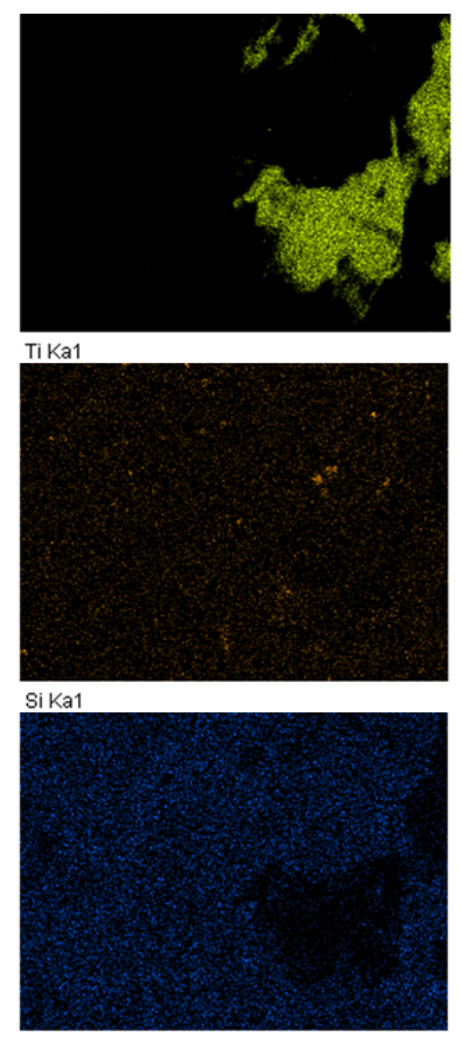

Ni Ka1
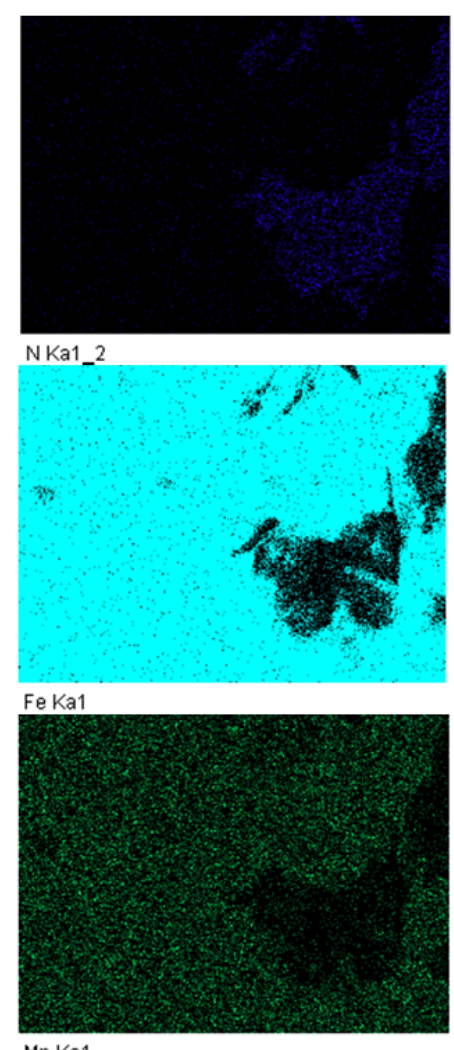

Mn Ka1

Figure 4-44. EDS compositional maps of surface of TiCN coated stainless steel specimens following wear testing

\subsubsection{TiN Coating}

316 stainless steel specimens coated with titanium nitride (TiN) were also procured from Surface Solutions, Inc. The SEM images showed surfaces similar to the other tested coatings, TiCN and Alpha ${ }^{\mathrm{TM}}$ (Figure 4-45). The EDS composition is given in Table 4-6.

SEM micrographs of the TiN wear sample after testing showed that $~ 90 \%$ of the coating remained in these specimens after wear testing (Figure 4-46). Areas where coating was removed (darker areas) are also shown. Significant material loss was observed closer to the edges and bevel ends. The lower SAR number $(\mathrm{SAR}=24)$ for these specimens relative to the other coatings (Alpha ${ }^{\mathrm{TM}}-88, \mathrm{TiCN}-73$ ) is consistent with its relative robustness (more of the coating retained on the surface). 


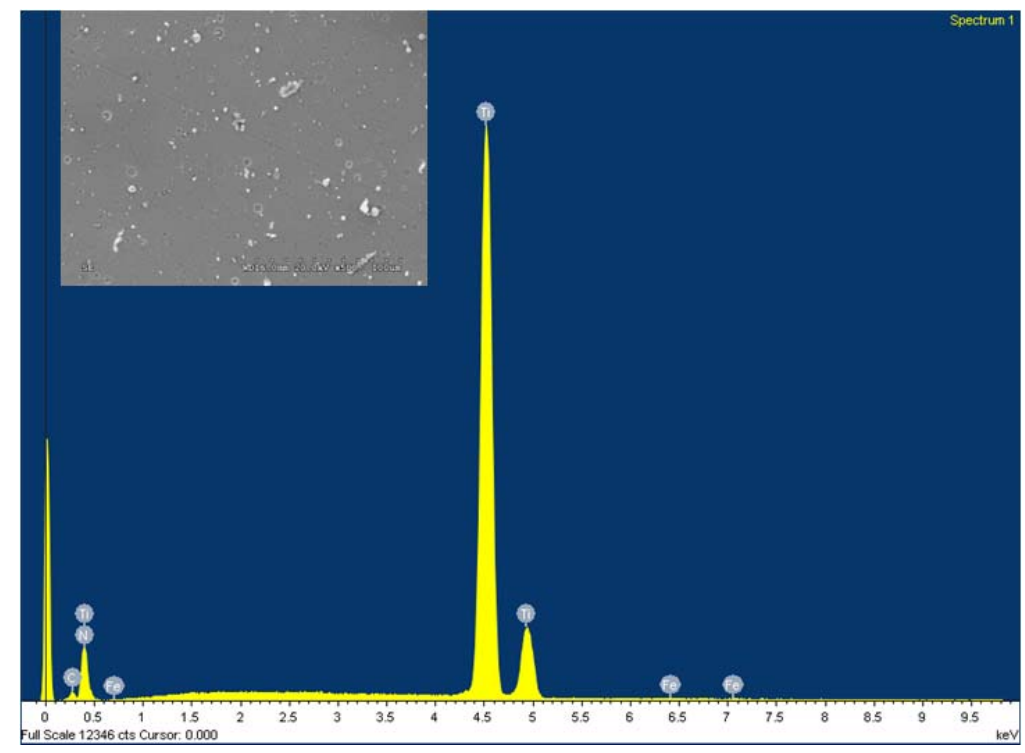

Figure 4-45. SEM micrograph and sum EDS spectrum of surface of TiN coated stainless steel wear specimen

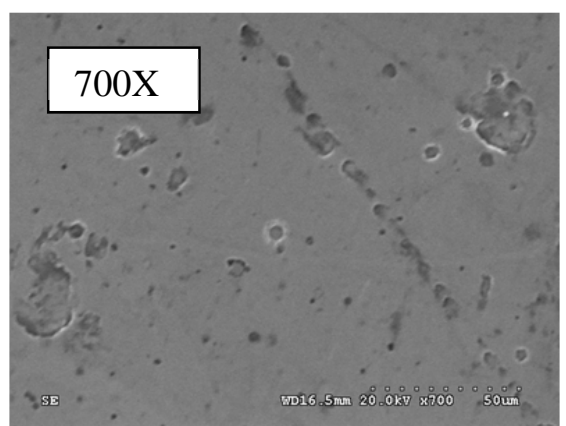

(A)

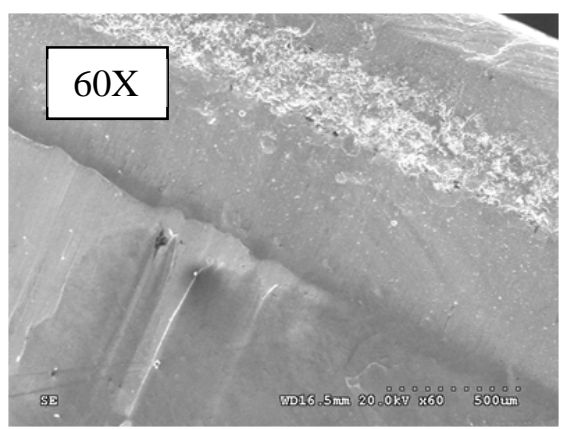

(C)

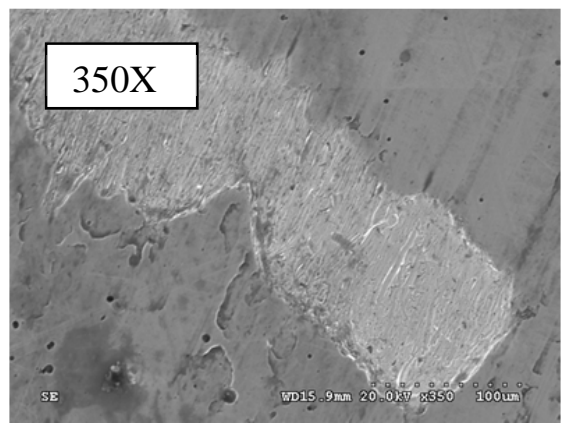

(B)

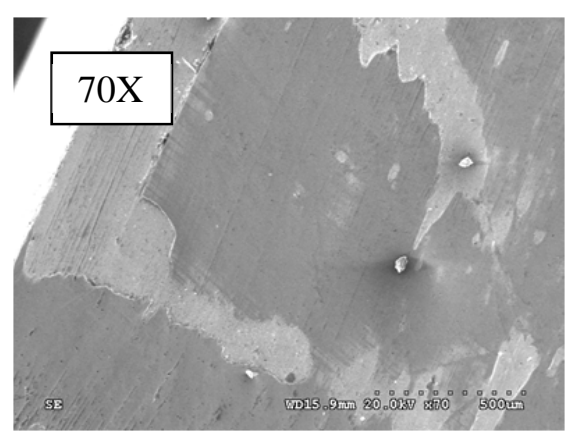

(D)

Figure 4-46. SEM micrographs of TiN coated stainless steel specimens following wear testing: (A) low wear with coating intact; (B) medium wear with some coating removal; $(C$ and $D)$ beveled edge

\subsection{Discussion}

The combined test data showed that corrosion is not a major contributor to degradation of the mixing paddles for the Saltstone mixer. A review of the corrosion data shows 
excellent corrosion rates (Table 4-2) with no susceptibility to localized corrosion (Figures 4-5 to 4-7). Isolated spots of corrosion were identified on the Astralloy and D2 tool steel samples, but these are believed to be a result of post-test handling. . The wear samples after testing as shown in Appendix II generally still show the sharp features of the wear. The ASTM G75 data therefore is not complicated by a synergistic effect between wear and corrosion. The corrosion spots on the steels, however may indicate that any water introduced into the mixer and allowed to sit will lead to corrosion of the paddles

The wear as assessed from the ASTM G75 test showed a reasonable correlation with material hardness as shown by the data summarized in Table 5-1. The data has been divided by test category: slurry, premix and coating. The hardness values are not all on the same scale but the tungsten carbide $\mathrm{HV}$ value is well above the $\mathrm{R}_{\mathrm{C}}$ scale and the 316 $R_{B}$ value is below the $R_{C}$ scale. These two materials were the best and worse in wear testing. The Stellite 12 and Ultimet $\mathrm{WH}$ results from the slurry testing skew the correlation of hardness and relative wear resistance. The PVD coatings are not considered a viable option since the coating integrity was significantly degraded by the wear test and would not be expected to provide extended life in the mixer.

Table 5-1. Comparison of Relative Wear and Average Hardness Values

\begin{tabular}{|l|l|l|l|l|}
\hline \multicolumn{1}{|c|}{ Material } & Test Category & Relative Wear & \multicolumn{1}{|c|}{$\begin{array}{c}\text { Pre-Wear } \\
\text { Hardness }\end{array}$} & \multicolumn{1}{|c|}{$\begin{array}{c}\text { Post-Wear } \\
\text { Hardness }\end{array}$} \\
\hline WC & Slurry & 1.00 & $1783 \mathrm{HV}$ & $1608 \mathrm{HV}$ \\
\hline Stellite 12 & Slurry & 1.69 & $43.1 \mathrm{R}_{\mathrm{C}}$ & $46.6 \mathrm{R}_{\mathrm{C}}$ \\
\hline D2 Tool Steel & Slurry & 3.39 & $60.1 \mathrm{R}_{\mathrm{C}}$ & $60.1 \mathrm{R}_{\mathrm{C}}$ \\
\hline Ultimet & Slurry & 7.45 & $27 \mathrm{R}_{\mathrm{C}}$ & $26 \mathrm{R}_{\mathrm{C}}$ \\
\hline Astralloy & Slurry & 9.43 & $43.5 \mathrm{R}_{\mathrm{C}}$ & $\mathrm{ND}$ \\
\hline Ultimet - WH & Slurry & 13.66 & $45.3 \mathrm{R}_{\mathrm{C}}$ & $28.9 \mathrm{R}_{\mathrm{C}}$ \\
\hline 316 SS & Slurry & 21.67 & $77.7 \mathrm{R}_{\mathrm{B}}$ & $76.8 \mathrm{R}_{\mathrm{B}}$ \\
\hline Stellite 12, Dry & Premix & 4.03 & $49.1 / 43.1 \mathrm{R}_{\mathrm{C}} *$ & $46.8 \mathrm{R}_{\mathrm{C}}{ }^{* *}$ \\
\hline Astralloy, Dry & Premix & 13.91 & $43.5 \mathrm{RC}_{\mathrm{C}}$ & $44.5 \mathrm{R}_{\mathrm{C}}$ \\
\hline TiN & Coating & 1.78 & $1788.3 \mathrm{HK}$ & $\mathrm{ND}$ \\
\hline TiCN & Coating & 5.4 & $1071.7 \mathrm{HK}$ & $\mathrm{ND}$ \\
\hline ZrN & Coating & 6.5 & $1079.1 \mathrm{HK}$ & $\mathrm{ND}$ \\
\hline
\end{tabular}

* The higher hardness is for the Stellite cast plate; the lower value is for the overlay.

** Value for the Stellite plate

Astralloy and 316, the primary current materials of construction of the paddles and augers, respectively, showed wear that was consistent with the measured hardness. These values cannot be directly correlated to the observed mixer wear because of limited information on the worn mixer components. The Astralloy with a moderate hardness appeared to have been sanded by the dry feed as would be expected from dry abrasion by the premix. Recall the Astralloy sample was tested first in wet slurry then followed by the dry premix testing after which the samples were examined. The 316 samples, which have a low hardness, showed plowing of the metal with material pushed up in some cases and shaved in other by the harder premix components. 
Both materials showed possible signs of corrosion on the wear samples. The pits in the 316 samples did not look like corrosion pits and no corrosion products were found. Chlorides and sulfates which are associated with pitting of stainless steels were not components of the slurry, unless they were present as impurities. The pits may have resulted from particles being pushed into the sample and falling out during the wear testing. For Astralloy, the filiform-like corrosion was limited to only a few spots and is not believed to be associated directly with the testing. The corrosion was not deep and is thought to be associated with some residual water from rinsing the samples.

The Stellite 12 which is the overlay on the CF8M auger tips performed very well in this testing. The superior wear resistance results from a distribution of hard complex carbides in the interdendritic regions of the softer Co-rich dendrites. The wear resistance is dependent on the size and distribution of the carbides as well as the interdendritic spacing, which may have caused the slight difference observed in the Stellite overlay sample and the Stellite cast sample in the dry feed testing.

Although the Stellite 12 performed well in this testing, the Stellite 12 overlay on the Saltstone mixer augers were degraded sufficiently that the base material was also worn as shown in Figure 5-1. There may be several reasons for this incongruity in Stellite 12 performance. The location of wear is in the area of waste addition and the flow dynamics may cause varying angle of slurry impingement on the Stellite 12 surface. Literature data shows that Stellite 12 wear performance as measured by volume loss is sensitive to angle of impingement with lower angles leading to greater wear. [22]

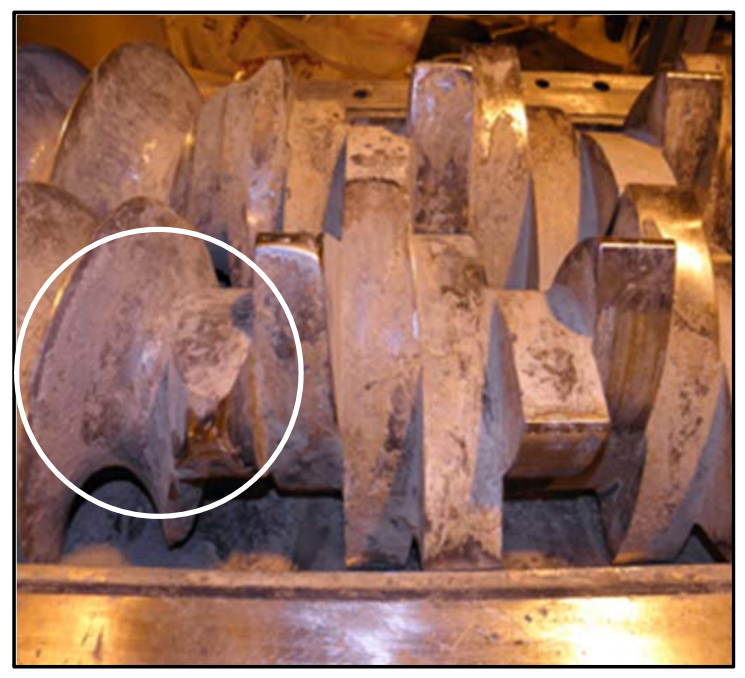

Figure 5-1. Saltstone mixer with worn auger (circled)

Additionally, the mixer manufacturer noted that the Stellite overlay was on the tips of the auger so the coverage on the remaining exposed surface of the auger is uncertain. The current use of the Stellite 12 overlay on the auger should be investigated to optimize the coverage on the auger surface. The use of a Stellite 12 overlay on the paddle tips may be an effective means to extend paddle life. The current Stellite 12 weld overlay procedure 
should be reviewed to determine if a thicker, wider weld overlay should be used to protect the entire CF8M surface.

The Ultimet samples did not perform as expected. From the Ultimet manufacturer's data, Ultimet performance should have been comparable to Stellite alloys.[7] The non-work hardened samples were expected to see a change in hardness over the duration of the test due to work hardeneing from abrasion. Ultimet tested with DWPF frit was work hardened in an ASTM G75 test set up, showing that stress with the frit was sufficient to work harden the sample.[28] The constant hardness value may have been associated with the lack of an impingement in the wear test. The Ultimet samples that were work hardened were expected to perform better than the Ultimet samples without work hardening since hardness is correlated to wear resistance. The data in Table 5-1 shows just the opposite, which may be associated with a change in toughness of the Ultimet WH.

The Ultimet WH samples experienced a decrease in the measured hardness. The wear surfaces of both types of samples were similar as were the post-wear hardness measurements. The initial work hardening may have affected only the outer surface but also compromised mechanical properties, such as toughness, sufficiently that the outer layer was more easily removed by fatigue. The Ultimet WH samples did have a greater mass loss as noted by the higher SAR number.

The D2 tool steel performed very well in the wear test and in corrosion testing. D2 has a higher hardness than Astralloy which contributed to the better wear results. This difference is due in part to the different carbon levels (D2 at 1.5\% and Astralloy at 0.3). Another factor however is the types of carbides that are present in each alloy. The D2 tool steel has vanadium carbides $\left(82 \mathrm{R}_{\mathrm{C}}\right)$ which have a higher hardness than chromium carbides $\left(66 \mathrm{R}_{\mathrm{C}}\right.$ ) or molybdenum carbides $\left(75 \mathrm{R}_{\mathrm{C}}\right.$ ), which would form in Astralloy. The distribution of these carbides will also affect the wear performance. The carbides are clearly observable and uniformly distributed in the D2 tool steel compared to the more random distribution in the Astralloy (Figures 4-10 and Figure 4-34). Vanadium carbides because of their high hardness are particularly beneficial.

Material processing factors were not considered with certain materials in this testing. A way to increase wear resistance is to obtain a more uniform distribution of fine hard carbides. Steels made via powders would be able to provide this improvement but at a higher cost. Steels can also be heat treated to optimize specific properties. The D2 samples were not heat treated to maximize hardness so further investigation can be done on choosing the optimal heat treatments as well as considering additional compositions. These selections must be made with any considerations necessary in the manufacture of the mixer. Further testing would be required on the final selection or choices. Optimally final testing would be performed on paddles for the 2-in mixer at SRNL.

D2 and WC both have lower toughness than Astralloy which would not play a factor in the ASTM G5 testing, but may possibly be a factor in the actual mixer. A material of construction with low toughness may have chips or chunks dislodge during operation that 
could cause problems downstream of the paddle. Testing a desired paddle in the 2-inch mixer is recommended to assess the occurrence and impact of these dislodged chips.

\subsection{Conclusion and Recommendations}

Wear and corrosion testing were conducted to evaluate new options of materials of construction for the Saltstone mixer auger and paddles. These components have been degraded by wear from the slurry processed in the mixer. Material test options included PVD coatings (TiN, TiCN, and ZrN), weld overlays (Stellite 12 and Ultimet) and higher hardness steels and carbides (D2 and tungsten carbide). The corrosion testing demonstrated that the slurry is not detrimental to the current materials of construction or the new options. The ASTM G75 Miller wear test showed that the high hardness materials and the Stellite 12 weld overlay provide superior wear relative to the Astralloy and 316 stainless steel, the current materials of construction, as well as the PVD coatings and Ultimet. However, the higher hardness materials have lower toughness than the Astralloy and would have to be tested in service to determine if their performance in the mixer.

The following recommendations were made for selecting new material options and improving the overall wear resistance of the Saltstone mixer components:

- A Stellite 12 weld overlay or higher hardness steel (with toughness equivalent to Astralloy) be used to improve the wear resistance of the Saltstone mixer paddles; other manufacturing specifications for the mixer need to be considered in this selection and Readco, the mixer manufacturer, should be consulted.

- The current use of the Stellite 12 weld overlay be evaluated so that coverage of the 316 auger can be optimized for improved wear resistance of the auger.

- The wear surfaces of the Saltstone mixer auger and paddles be evaluated so that laboratory data can be better correlated to actual service.

- The 2-inch Saltstone mixer prototype be used to verify material performance. 


\subsection{References}

1 Drew Carter et al, "Engineering Pathforward: Saltstone Mixer Troubleshooting," SRR-WSE-2011-000141, Revision 0, July 25,

2 2011Task Technical Request: Evaluate/Recommend Saltstone Mixer Auger/Paddles Material of Construction for Improved Wear Resistance, HLW-SSF-TTR-201200001, Revision 0, October 12, 2012

3 ASTM G75, "Determination of Slurry Abrasivity (Miller Number) andSlurry Abrasion Response of Materials (SAR Number)," ASTM International, West Conshohoken, PA, 2007.

4 Material Safety Data Sheet 34240, Revision 1, Ground granulated blast-furnace slag

5. Material Safety Data Sheet 37526, Revision 1, Class F fly ash from bituminous coal

6. Material Safety Data Sheet 39522, Revision 1, Portland cement

7 A. R. Lansdown and A. L. Price, Materials to Resist Wear: A Guide to their Selection and Use, Pergamon Press Inc.: Elmsford, NY, 1986, p 58

8 Ultimet Alloy Brochure, Haynes International , H-2082C, 2004

9 J. R. Harbour et al, "Characterization of Slag, Fly Ash and Portland Cement for Saltstone,” WSRC-TR-2006-00067, Rev 0, February 2006

10 ASTM Standards for Wear Testing, ASTM International, West Chohocken, PA, 2012

11 Personal communication Ricardo Torres with Jim Miller, White Rock Engineering Services, December, 2011

12 M. Reigel, “Tables Containing Results for the Second Quarter 2011 Tank 50 WAC Slurry Sample: Chemical and Radionuclide Contaminant Results,” SRNL-L31002011-00115, Rev 0, June 27, 2011

13 G. Bellanger and J. J. Rameau, "Corrosion of Titanium Nitride Deposits 630 on AISI Stainless Steel Used in Radioactive Water With and Without Chloride at $\mathrm{pH}$ 11,” Electrochimica Acta, Vol 40 (15), 1995, pp 2519-32

14 P. Jemmely et al, "Tribocorrosion Behavior of Fe-17Cr Stainless Steel in Acid and Alkaline Solutions,” Tribology International, Vol 32, 1999, pp 295-303

15 A. R. Trueman et al, "A study of the effect of cobalt additions on the corrosion of tungsten carbide:carbon steel metal matrix composites,” Corrosion Science, Vol 41, 1999 1377-1389

16 M. Sanchez et al, "Electrochemical impedance spectroscopy for studying passive layers on steel rebars immersed in alkaline solutions simulating concrete pores,” Electrochimica Acta, Vol 52, 2007, 7634-41

17 L. Friere et al, "The passive behaviour of AISI 316 in alkaline media and the effect of pH: A combined electrochemical and analytical study,” Electrochimica Acta, Vol 55, 2010, pp 61746181

18 Stellite 12 Alloy Technical Data Brochure, Deloro Stellite

19 Yan Wang et al, "Electrochemical Reactions on Some Cemented Metal Carbides," Journal of Power Sources, Vol. 191, 2009, pp 483-488 
20 J. C. Caicedo et al, "Effec of applies bias voltage on corrosion resistance for TiCN and TiNbCN Coatings,” Applied Surface Science, Vol 256, 2010, pp 2876-2883

21 H. Deng et al, "Influence of coating thickness and temperature on mechanical properties of steel deposited with Co-based alloy hardfacing coating," Surface and Coatings Technology, Vol 204 (23), 2010, 3927-3924

22 M. X. Yao, "Wear, corrosion and cracking resistance of some W- or Mocontaining Stellite hardfacing alloys,” Materials Science and Engineering A, Vol 407, 2005, pp 234-44

23 W. Wu et al, “The Wear Behavior Between Hardfacing Materials,”: Metallurgical and Materials Transactions A, Vol 27A, 1996, pp 3639-3648

24 H. Deng et al, "Influence of coating thickness and temperature on the mechanical properties of stell deposited with Co-based alloy hardfacing coating,” Surface and Coating Technology, Vol 204, 2010, pp 3927-3934

25 W. S. da Silva, "Room Temperature Mechanical Properties and Tribology of Nicralc and Stellite as Cast Alloys,” Wear, Vol 271 (9-10), 2011, 1819-1827

26 M. A. M Irahim et al, "Corrosion of stainless steel coated with TiN, (TiAl)N and $\mathrm{CrN}$ in aqueous environments " Corrosion Science, Vol. 44, 2002, 815-823

27 G. R. Desale et al, "Slurry erosion of ductile materals under normal impact condition,” Wear, Vol 264, 2008, pp 322-330

28 K. J. Imrich et al, "Corrosion/Erosion Resistance of Ultimet ${ }^{\circledR}$ R31233 in a Simulated Feed for a Radioactive Vitrification Facility,” WSRC-MS-98-00665, 1998

29 Astalloy V steel literature at www. astralloy.infomedia.net/pdf/ms_astralloy_v.pdf

30 S. Zhang and W. Zhu, "TiN coating of tool steels: a review," Journal of Materials Processing Technology,” Vol 39, 1993, pp 165-77

31 C. A. Suski and C.A. S. de Oliveira, "Ciencia \&Technologia dos Materials, Vol. 20, 2008, pp 2-9 


\section{APPENDIX I ASTM Standard Wear Protocols Reviewed for Saltstone Mixer Wear Testing}

\begin{tabular}{|c|c|c|c|}
\hline ASTM Standard & Description & $\begin{array}{c}\text { Outcome/Result of } \\
\text { Test }\end{array}$ & $\begin{array}{c}\text { Representative } \\
\text { of Mixer }\end{array}$ \\
\hline $\begin{array}{l}\text { ASTM D 2714: } \\
\text { Calibration and } \\
\text { Operation of the } \\
\text { Falex Block-on- } \\
\text { Ring } \\
\text { Friction and Wear } \\
\text { Testing Machine }\end{array}$ & $\begin{array}{l}\text { A steel test ring } \\
\text { rotates against a } \\
\text { steel test block, the } \\
\text { specimen assembly } \\
\text { being partially } \\
\text { immersed in the } \\
\text { lubricant sample. }\end{array}$ & $\begin{array}{l}\text { Three determinations } \\
\text { are made: (1) The } \\
\text { friction force } \\
\text { after a certain number } \\
\text { of revolutions, (2) the } \\
\text { average width of the } \\
\text { wear scar on the } \\
\text { stationary block at the } \\
\text { end of the test, and (3) } \\
\text { the weight loss for the } \\
\text { stationary block at the } \\
\text { end of the test. }\end{array}$ & $\begin{array}{l}\text { No, addresses } \\
\text { steel to steel } \\
\text { interaction }\end{array}$ \\
\hline $\begin{array}{l}\text { ASTM D 3702: } \\
\text { Wear Rate and } \\
\text { Coefficient of } \\
\text { Friction of Materials } \\
\text { in Self-Lubricated } \\
\text { Rubbing Contact } \\
\text { Using a Thrust } \\
\text { Washer Testing } \\
\text { Machine }\end{array}$ & $\begin{array}{l}\text { This test method } \\
\text { covers the } \\
\text { determination of } \\
\text { wear rate and } \\
\text { coefficient of } \\
\text { friction for self- } \\
\text { lubricated materials } \\
\text { in rubbing contact } \\
\text { by a testing machine } \\
\text { using a thrust } \\
\text { washer specimen } \\
\text { configuration. }\end{array}$ & $\begin{array}{l}\text { The method is used to } \\
\text { determine the } \\
\text { equilibrium } \\
\text { rate of wear and } \\
\text { coefficient of friction } \\
\text { of materials in rubbing } \\
\text { contact under } \\
\text { combinations of } \\
\text { pressure and velocity } \\
\text { that fall below the PV } \\
\text { limit of the test } \\
\text { material. }\end{array}$ & $\begin{array}{l}\text { No, addresses } \\
\text { lubricated } \\
\text { rubbing contact } \\
\text { with steel }\end{array}$ \\
\hline $\begin{array}{l}\text { ASTM G32: } \\
\text { Cavitation Erosion } \\
\text { Using Vibratory } \\
\text { Apparatus }\end{array}$ & $\begin{array}{l}\text { This test method } \\
\text { covers the } \\
\text { production of } \\
\text { cavitation damage } \\
\text { on the face of a } \\
\text { specimen vibrated at } \\
\text { high frequency } \\
\text { while immersed in a } \\
\text { liquid. }\end{array}$ & $\begin{array}{l}\text { This method may be } \\
\text { used to estimate the } \\
\text { relative resistance of } \\
\text { materials to cavitation } \\
\text { erosion as may be } \\
\text { encountered in pumps, } \\
\text { hydraulic turbines, } \\
\text { hydraulic } \\
\text { dynamometers, valves, } \\
\text { and others. }\end{array}$ & $\begin{array}{l}\text { No, addresses } \\
\text { only liquid } \\
\text { cavitation } \\
\text { damage }\end{array}$ \\
\hline
\end{tabular}




\begin{tabular}{|c|c|c|c|}
\hline ASTM Standard & Description & $\begin{array}{c}\text { Outcome/Result of } \\
\text { Test }\end{array}$ & $\begin{array}{l}\text { Representative } \\
\text { of Mixer }\end{array}$ \\
\hline $\begin{array}{l}\text { ASTM G65: } \\
\text { Measuring Abrasion } \\
\text { Using the Dry } \\
\text { Sand/Rubber Wheel } \\
\text { Apparatus }\end{array}$ & $\begin{array}{l}\text { This test method } \\
\text { covers laboratory } \\
\text { procedures for } \\
\text { determining the } \\
\text { resistance of } \\
\text { metallic materials to } \\
\text { scratching abrasion } \\
\text { by means of the dry } \\
\text { sand/rubber wheel } \\
\text { test. }\end{array}$ & $\begin{array}{l}\text { Rank materials in their } \\
\text { resistance to scratching } \\
\text { abrasion under } \\
\text { a specified set of } \\
\text { conditions. }\end{array}$ & $\begin{array}{l}\text { Yes, but wear } \\
\text { rate is driven by } \\
\text { combination of } \\
\text { abrasion from } \\
\text { sand and a rubber } \\
\text { wheel, not unique } \\
\text { action from the } \\
\text { slurry }\end{array}$ \\
\hline $\begin{array}{l}\text { ASTM G73: Liquid } \\
\text { Impingement } \\
\text { Erosion Using } \\
\text { Rotating Apparatus }\end{array}$ & $\begin{array}{l}\text { This test method } \\
\text { covers tests in which } \\
\text { solid specimens are } \\
\text { eroded or otherwise } \\
\text { damaged by } \\
\text { repeated discrete } \\
\text { impacts } \\
\text { of liquid drops or } \\
\text { jets. }\end{array}$ & $\begin{array}{l}\text { This test method may } \\
\text { be used } \\
\text { for evaluating the } \\
\text { erosion resistance of } \\
\text { materials for service } \\
\text { environments where } \\
\text { solid surfaces are } \\
\text { subjected to repeated } \\
\text { impacts by liquid } \\
\text { drops or jets. }\end{array}$ & $\begin{array}{l}\text { No, only } \\
\text { addresses liquid } \\
\text { impingement } \\
\text { wear, not } \\
\text { expected } \\
\text { significant in } \\
\text { mixer }\end{array}$ \\
\hline $\begin{array}{l}\text { ASTM G75: } \\
\text { Determination of } \\
\text { Slurry Abrasivity } \\
\text { (Miller Number) } \\
\text { and Slurry } \\
\text { Abrasion Response } \\
\text { of Materials (SAR } \\
\text { Number) }\end{array}$ & $\begin{array}{l}\text { This test method is } \\
\text { used to calculate a } \\
\text { number related to } \\
\text { the rate of mass loss } \\
\text { (converted to } \\
\text { volume loss) of } \\
\text { duplicate standard- } \\
\text { shaped wear } \\
\text { specimens of any } \\
\text { material of interest } \\
\text { when run for a } \\
\text { period of time in } \\
\text { any slurry of interest } \\
\text { (SAR Number). }\end{array}$ & $\begin{array}{l}\text { The SAR Number is } \\
\text { an index of the relative } \\
\text { abrasion } \\
\text { response of materials } \\
\text { as tested in any } \\
\text { particular slurry of } \\
\text { interest. A major } \\
\text { purpose is to rank } \\
\text { construction materials } \\
\text { for use in a system for } \\
\text { pumping and fluid } \\
\text { handling equipment } \\
\text { for a particular slurry. } \\
\text { Materials with a SAR } \\
\text { Number of <50 can be } \\
\text { pumped with minor } \\
\text { abrasive damage to the } \\
\text { system. }\end{array}$ & $\begin{array}{l}\text { Yes, test is } \\
\text { representative } \\
\text { of Saltstone } \\
\text { mixer operation }\end{array}$ \\
\hline
\end{tabular}




\begin{tabular}{|c|c|c|c|}
\hline ASTM Standard & Description & $\begin{array}{c}\text { Outcome/Result of } \\
\text { Test }\end{array}$ & $\begin{array}{c}\text { Representative } \\
\text { of Mixer }\end{array}$ \\
\hline $\begin{array}{l}\text { ASTM G76: } \\
\text { Conducting Erosion } \\
\text { Tests by Solid } \\
\text { Particle } \\
\text { Impingement } \\
\text { Using Gas Jets }\end{array}$ & $\begin{array}{l}\text { This test method } \\
\text { covers the } \\
\text { determination of } \\
\text { material loss by gas- } \\
\text { entrained solid } \\
\text { particle } \\
\text { impingement } \\
\text { erosion with } \\
\text { jet-nozzle type } \\
\text { erosion equipment. }\end{array}$ & $\begin{array}{l}\text { This test method may } \\
\text { be } \\
\text { used in the laboratory } \\
\text { to measure the solid } \\
\text { particle erosion of } \\
\text { different materials and } \\
\text { has been used as a } \\
\text { screening test for } \\
\text { ranking solid particle } \\
\text { erosion rates of } \\
\text { materials in simulated } \\
\text { service environments }\end{array}$ & $\begin{array}{l}\text { No, addresses } \\
\text { wear from high } \\
\text { velocity particle } \\
\text { impingement } \\
\text { from a gas stream }\end{array}$ \\
\hline $\begin{array}{l}\text { ASTM G77: } \\
\text { Ranking Resistance } \\
\text { of Materials to } \\
\text { Sliding Wear Using } \\
\text { Block-on-Ring Wear } \\
\text { Test }\end{array}$ & $\begin{array}{l}\text { This test method } \\
\text { covers laboratory } \\
\text { procedures for } \\
\text { determining the } \\
\text { resistance of } \\
\text { materials to sliding } \\
\text { wear. The test } \\
\text { utilizes a block-on- } \\
\text { ring friction and } \\
\text { wear testing } \\
\text { machine to } \\
\text { rank pairs of } \\
\text { materials according } \\
\text { to their sliding wear } \\
\text { characteristics } \\
\text { under various } \\
\text { conditions. }\end{array}$ & $\begin{array}{l}\text { A test block is loaded } \\
\text { against a test ring that } \\
\text { rotates at a } \\
\text { given speed for a given } \\
\text { number of revolutions. } \\
\text { Block scar and ring } \\
\text { volumes, the friction } \\
\text { force required to keep } \\
\text { the block in place I } \\
\text { and the normal force } \\
\text { data are converted to } \\
\text { coefficient of friction } \\
\text { values and reported. }\end{array}$ & $\begin{array}{l}\text { No, addresses } \\
\text { abrasion from a } \\
\text { solid ring, not } \\
\text { from a } \\
\text { representative } \\
\text { slurry }\end{array}$ \\
\hline $\begin{array}{l}\text { ASTM G81: Jaw } \\
\text { Crusher Gouging } \\
\text { Abrasion Test }\end{array}$ & $\begin{array}{l}\text { This test method } \\
\text { covers a laboratory } \\
\text { procedure to } \\
\text { determine the } \\
\text { relative gouging } \\
\text { abrasion resistance } \\
\text { of materials. }\end{array}$ & $\begin{array}{l}\text { This test method ranks } \\
\text { materials and provides } \\
\text { wear life information } \\
\text { for application of } \\
\text { heavy gouging } \\
\text { abrasion, as is found in } \\
\text { crushing equipment } \\
\text { and in many mining } \\
\text { and earthmoving } \\
\text { applications. }\end{array}$ & $\begin{array}{l}\text { No, addresses } \\
\text { highly aggressive } \\
\text { gouging and jaw } \\
\text { crushing }\end{array}$ \\
\hline
\end{tabular}




\begin{tabular}{|c|c|c|c|}
\hline ASTM Standard & Description & $\begin{array}{c}\text { Outcome/Result of } \\
\text { Test }\end{array}$ & $\begin{array}{c}\text { Representative } \\
\text { of Mixer }\end{array}$ \\
\hline $\begin{array}{l}\text { ASTM G83: Wear } \\
\text { Testing with a } \\
\text { Crossed-Cylinder } \\
\text { Apparatus }\end{array}$ & $\begin{array}{l}\text { This test method } \\
\text { covers a laboratory } \\
\text { test for ranking } \\
\text { metallic couples in } \\
\text { their resistance to } \\
\text { sliding wear using } \\
\text { the crossed-cylinder } \\
\text { apparatus. During } \\
\text { the test, wear occurs } \\
\text { at a contact between } \\
\text { a rotating cyclinder } \\
\text { and a stationary } \\
\text { cylinder which have } \\
\text { their long axes } \\
\text { oriented normal to } \\
\text { each other. }\end{array}$ & $\begin{array}{l}\text { The method predicts } \\
\text { the relative ranking of } \\
\text { various materials } \\
\text { where metal-to-metal } \\
\text { contact takes place. }\end{array}$ & $\begin{array}{l}\text { No, addresses } \\
\text { cross-abrasion in } \\
\text { metallic couples }\end{array}$ \\
\hline $\begin{array}{l}\text { ASTM G98: Galling } \\
\text { Resistance of } \\
\text { Materials }\end{array}$ & $\begin{array}{l}\text { This test method } \\
\text { covers a laboratory } \\
\text { test which ranks } \\
\text { the galling } \\
\text { resistance of } \\
\text { material couples. }\end{array}$ & $\begin{array}{l}\text { This test method is } \\
\text { designed to rank } \\
\text { material couples in } \\
\text { their resistance to the } \\
\text { failure mode caused by } \\
\text { galling and not merely } \\
\text { to classify the surface } \\
\text { appearance of sliding } \\
\text { surfaces. This test } \\
\text { method should be } \\
\text { considered when } \\
\text { damaged (galled) } \\
\text { surfaces render } \\
\text { components non- } \\
\text { serviceable. }\end{array}$ & $\begin{array}{l}\text { No, addresses } \\
\text { galling in } \\
\text { metallic couples }\end{array}$ \\
\hline $\begin{array}{l}\text { ASTM G99: Wear } \\
\text { Testing with a Pin- } \\
\text { on-Disk Apparatus }\end{array}$ & $\begin{array}{l}\text { This test method } \\
\text { covers a laboratory } \\
\text { procedure for } \\
\text { determining the } \\
\text { wear of materials } \\
\text { during sliding using } \\
\text { a pin-on-disk } \\
\text { apparatus. }\end{array}$ & $\begin{array}{l}\text { The pin-on-disk test } \\
\text { method provides a } \\
\text { relative ranking of of } \\
\text { wear rate. }\end{array}$ & $\begin{array}{l}\text { No, abrasion is } \\
\text { due to applied } \\
\text { load of a cylinder } \\
\text { on a disk }\end{array}$ \\
\hline
\end{tabular}




\begin{tabular}{|c|c|c|c|}
\hline ASTM Standard & Description & $\begin{array}{c}\text { Outcome/Result of } \\
\text { Test }\end{array}$ & $\begin{array}{c}\text { Representative } \\
\text { of Mixer }\end{array}$ \\
\hline $\begin{array}{l}\text { ASTM G105: } \\
\text { Conducting Wet } \\
\text { Sand/Rubber Wheel } \\
\text { Abrasion Tests }\end{array}$ & $\begin{array}{l}\text { This test method } \\
\text { covers laboratory } \\
\text { procedures for } \\
\text { determining the } \\
\text { resistance of } \\
\text { metallic materials to } \\
\text { scratching abrasion } \\
\text { by means of the wet } \\
\text { sand/rubber wheel } \\
\text { test }\end{array}$ & $\begin{array}{l}\text { In this test method } \\
\text { conditions are } \\
\text { standardized to } \\
\text { develop a uniform } \\
\text { condition of wear } \\
\text { referred to as } \\
\text { scratching abrasion. }\end{array}$ & $\begin{array}{l}\text { Yes, but wear } \\
\text { rate is driven by } \\
\text { combination of } \\
\text { abrasion from } \\
\text { sand and a rubber } \\
\text { wheel, not unique } \\
\text { action from the } \\
\text { slurry. }\end{array}$ \\
\hline $\begin{array}{l}\text { ASTM G132: Pin } \\
\text { Abrasion Testing }\end{array}$ & $\begin{array}{l}\text { This test method } \\
\text { covers a laboratory } \\
\text { procedure for } \\
\text { determining the } \\
\text { wear resistance of a } \\
\text { material when } \\
\text { relative motion is } \\
\text { caused between an } \\
\text { abrasive cloth, } \\
\text { paper, or plastic film } \\
\text { and a contacting pin } \\
\text { of the test material. }\end{array}$ & $\begin{array}{l}\text { This test method } \\
\text { imposes conditions } \\
\text { that cause } \\
\text { measurable mass } \\
\text { losses and it is } \\
\text { intended to rank } \\
\text { materials for } \\
\text { applications in which } \\
\text { moderate to severe } \\
\text { abrasion occurs. }\end{array}$ & $\begin{array}{l}\text { No, abrasion is } \\
\text { due to applied } \\
\text { load of a cylinder } \\
\text { on an abrasive } \\
\text { paper }\end{array}$ \\
\hline $\begin{array}{l}\text { ASTM G133: } \\
\text { Linearly } \\
\text { Reciprocating Ball- } \\
\text { on-Flat Sliding Wear }\end{array}$ & $\begin{array}{l}\text { This test method } \\
\text { covers laboratory } \\
\text { procedures for } \\
\text { determining the } \\
\text { sliding wear of } \\
\text { ceramics, metals, } \\
\text { and other candidate } \\
\text { wear-resistant } \\
\text { materials using a } \\
\text { linear, reciprocating } \\
\text { ball-on-flat plane } \\
\text { geometry. }\end{array}$ & $\begin{array}{l}\text { This test method is } \\
\text { designed to simulate } \\
\text { the geometry } \\
\text { and motions that are } \\
\text { experienced in many } \\
\text { types of rubbing } \\
\text { components whose } \\
\text { normal operation } \\
\text { results in periodic } \\
\text { reversals in the } \\
\text { direction of relative } \\
\text { sliding. }\end{array}$ & $\begin{array}{l}\text { No, abrasion } \\
\text { from ball sliding } \\
\text { on a flat } \\
\text { specimen }\end{array}$ \\
\hline
\end{tabular}




\begin{tabular}{|c|c|c|c|}
\hline ASTM Standard & Description & $\begin{array}{c}\text { Outcome/Result of } \\
\text { Test }\end{array}$ & $\begin{array}{c}\text { Representative } \\
\text { of Mixer }\end{array}$ \\
\hline $\begin{array}{l}\text { ASTM G134: } \\
\text { Erosion of Solid } \\
\text { Materials by } \\
\text { Cavitating Liquid Jet }\end{array}$ & $\begin{array}{l}\text { This test method } \\
\text { covers a test that can } \\
\text { be used to } \\
\text { compare the } \\
\text { cavitation erosion } \\
\text { resistance of solid } \\
\text { materials. A } \\
\text { submerged } \\
\text { cavitating jet, } \\
\text { issuing from a } \\
\text { nozzle, impinges on } \\
\text { a } \\
\text { test specimen placed } \\
\text { in its path so that } \\
\text { cavities collapse on } \\
\text { it, thereby causing } \\
\text { erosion. }\end{array}$ & $\begin{array}{l}\text { This test method may } \\
\text { be used to estimate the } \\
\text { relative } \\
\text { resistances of materials } \\
\text { to cavitation erosion, } \\
\text { as may be } \\
\text { encountered for } \\
\text { instance in pumps, } \\
\text { hydraulic turbines, } \\
\text { valves, hydraulic } \\
\text { dynamometers and } \\
\text { couplings, bearings, } \\
\text { etc. }\end{array}$ & $\begin{array}{l}\text { No, only } \\
\text { addresses liquid } \\
\text { cavitation } \\
\text { damage, not } \\
\text { expected in } \\
\text { mixer }\end{array}$ \\
\hline $\begin{array}{l}\text { ASTM G171: } \\
\text { Scratch Hardness of } \\
\text { Materials Using a } \\
\text { Diamond Stylus }\end{array}$ & $\begin{array}{l}\text { This test method } \\
\text { covers laboratory } \\
\text { procedures for } \\
\text { determining the } \\
\text { scratch hardness of } \\
\text { the surfaces of solid } \\
\text { materials. }\end{array}$ & $\begin{array}{l}\text { This test method is } \\
\text { intended to measure } \\
\text { the resistance of } \\
\text { solid surfaces to } \\
\text { permanent } \\
\text { deformation under the } \\
\text { action of a single point } \\
\text { (stylus tip). }\end{array}$ & $\begin{array}{l}\text { No, measures } \\
\text { single scratch } \\
\text { resistance }\end{array}$ \\
\hline $\begin{array}{l}\text { ASTM G174: } \\
\text { Measuring Abrasion } \\
\text { Resistance of } \\
\text { Materials by } \\
\text { Abrasive } \\
\text { Loop Contact }\end{array}$ & $\begin{array}{l}\text { This test method } \\
\text { covers ranking rigid } \\
\text { engineering } \\
\text { materials for } \\
\text { abrasion resistance } \\
\text { in rubbing against } \\
\text { aluminum } \\
\text { oxide abrasive } \\
\text { finishing tape. }\end{array}$ & $\begin{array}{l}\text { This test is useful for } \\
\text { screening materials for } \\
\text { use in tools that are } \\
\text { subjected to abrasion } \\
\text { from the material that } \\
\text { is being machined, } \\
\text { worked, or formed. It } \\
\text { has been used to } \\
\text { screen tool } \\
\text { steels for punch press } \\
\text { dies, hardfacings for } \\
\text { earth-moving } \\
\text { machinery, and wear } \\
\text { coatings. }\end{array}$ & $\begin{array}{l}\text { No, abrasion is } \\
\text { against a set } \\
\text { aluminum oxide } \\
\text { ribbon }\end{array}$ \\
\hline
\end{tabular}


APPENDIX II Photographs of Saltstone Mixer Candidate Materials of Construction Wear Samples Before and After Testing

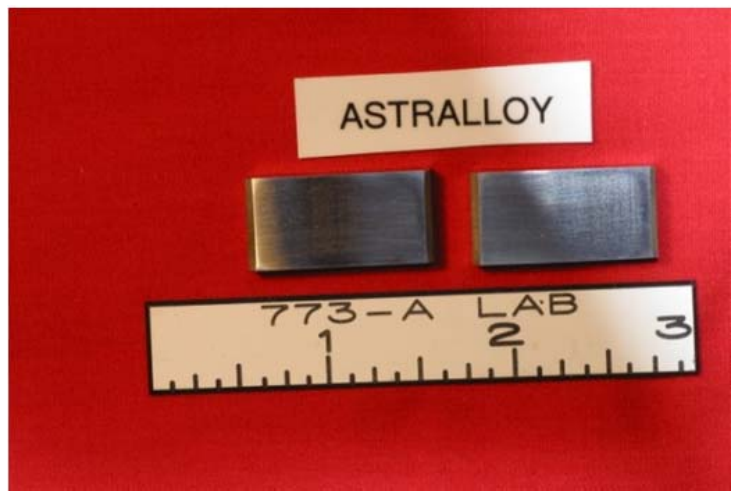

Before

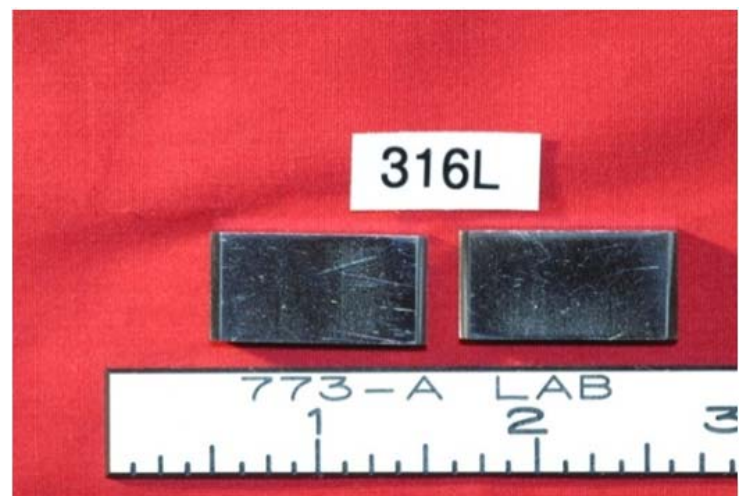

Before

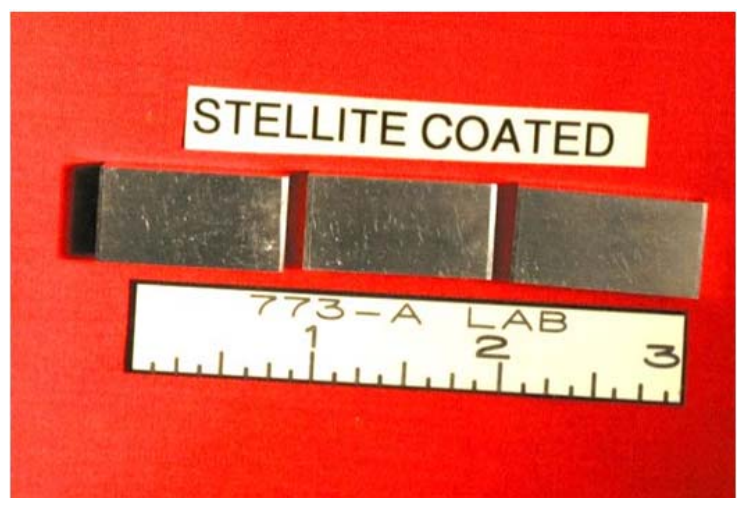

Before

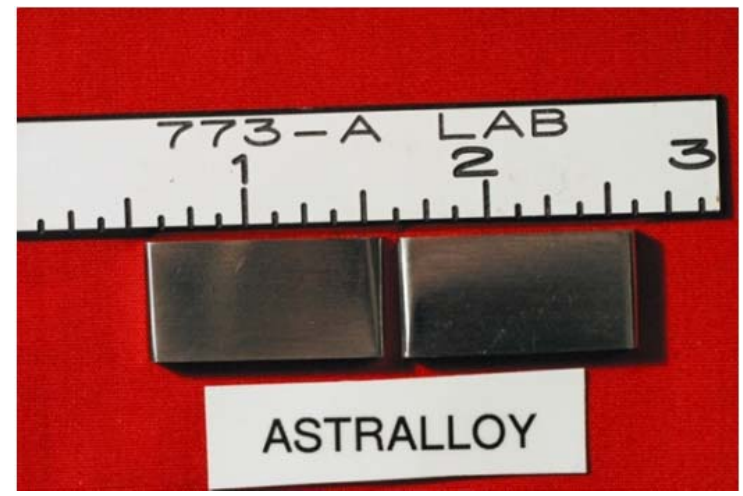

After

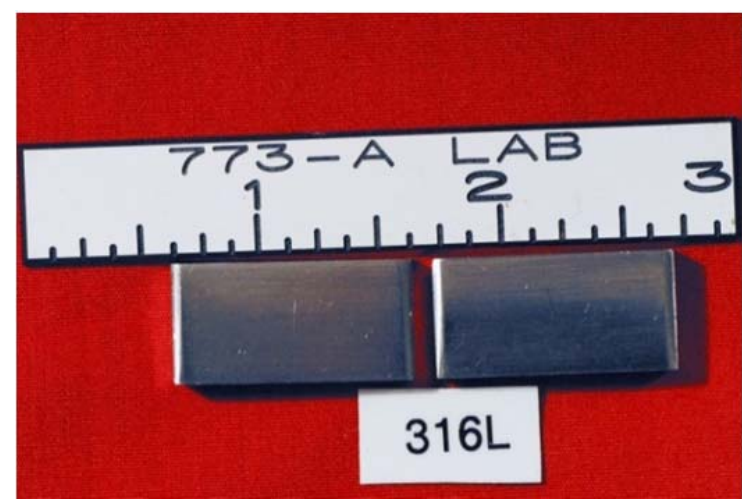

After

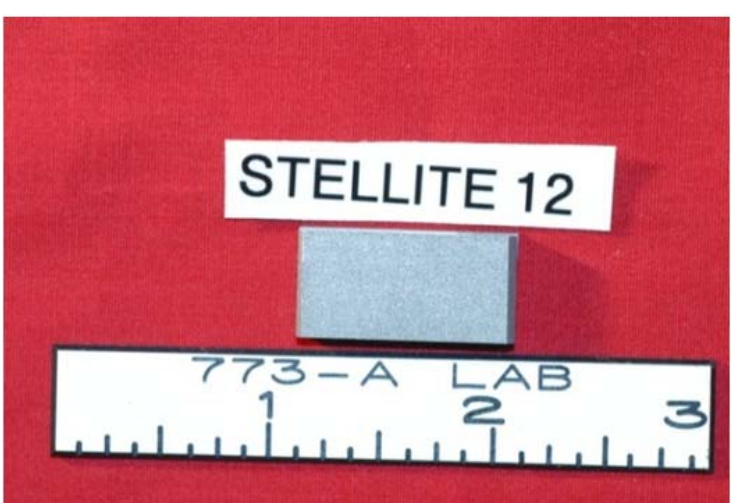

Before 


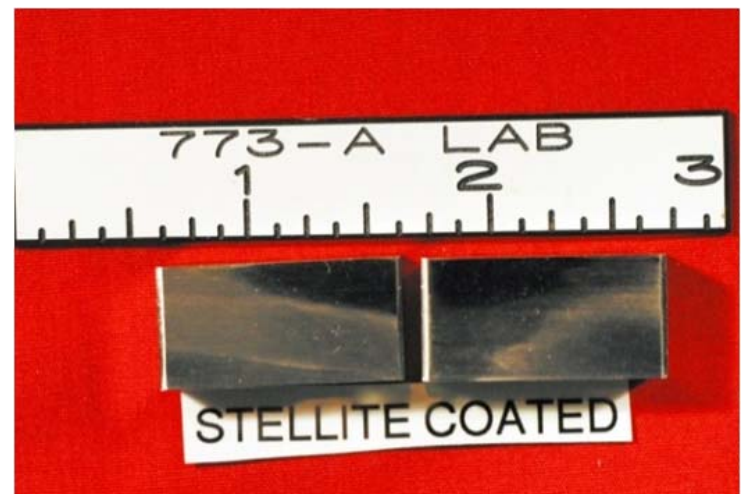

After

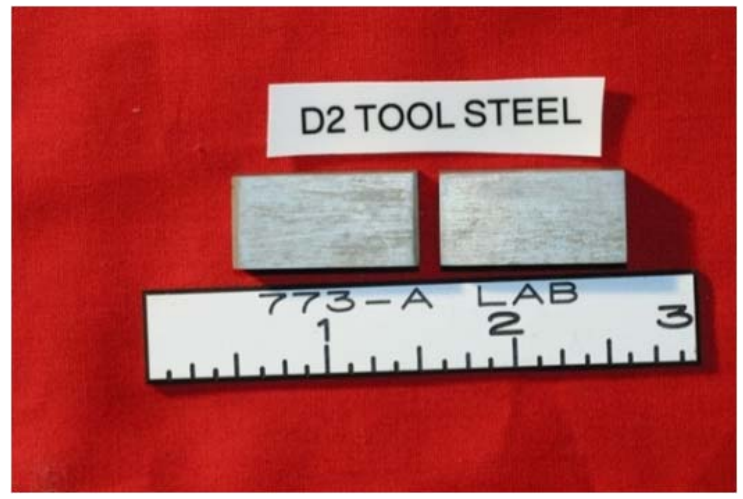

Before

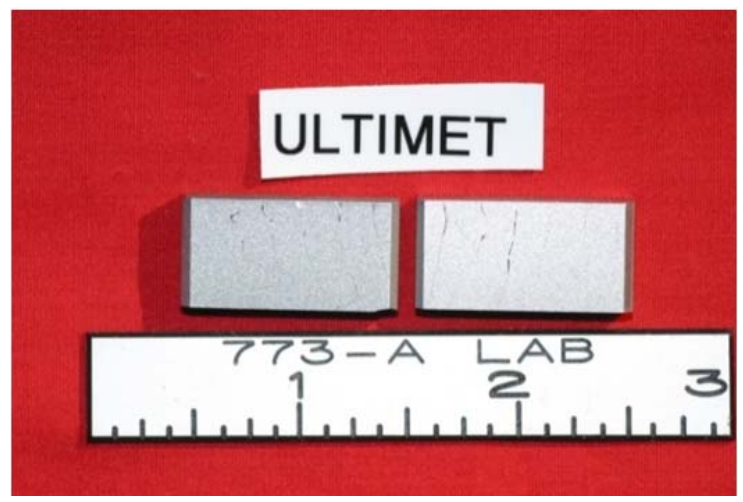

Before

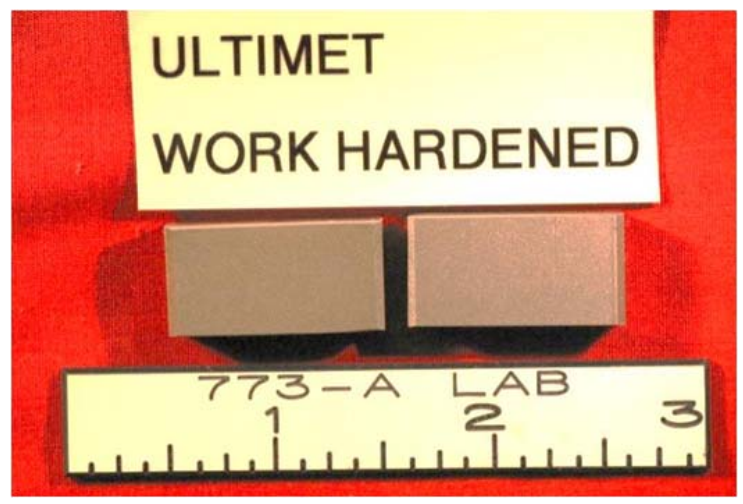

Before

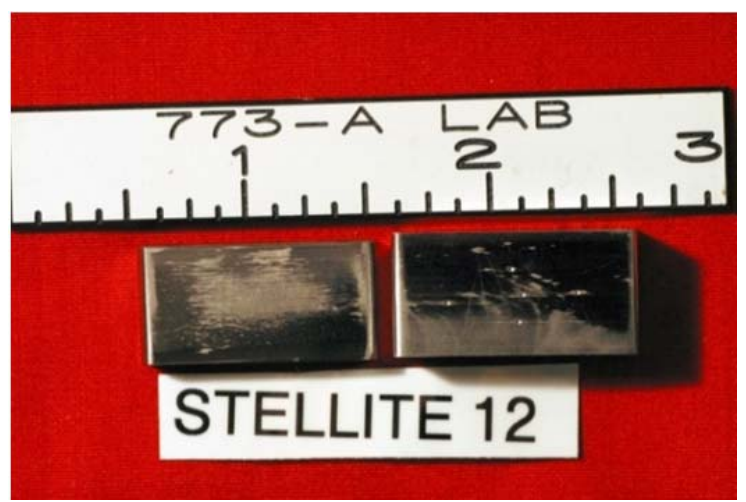

After

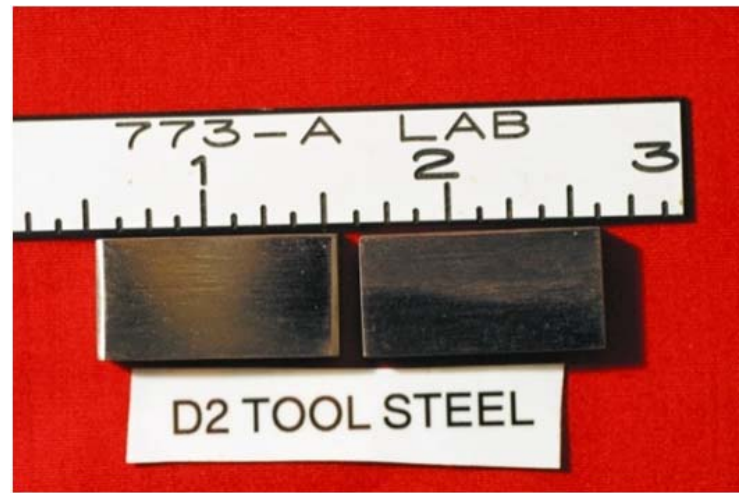

After

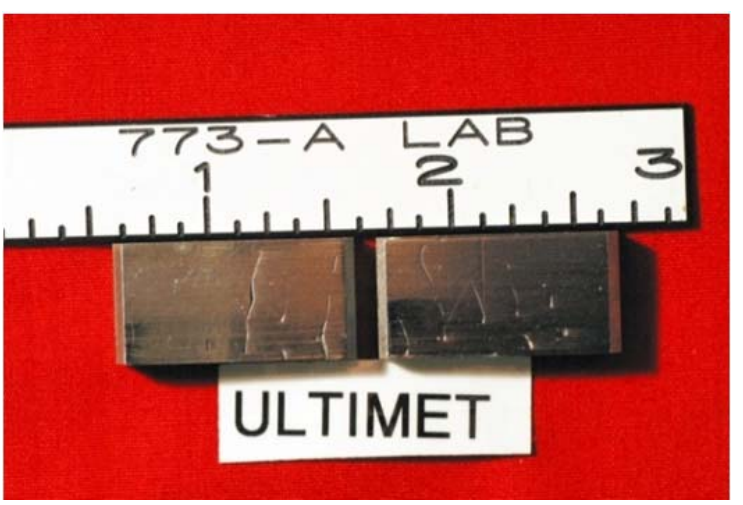

After

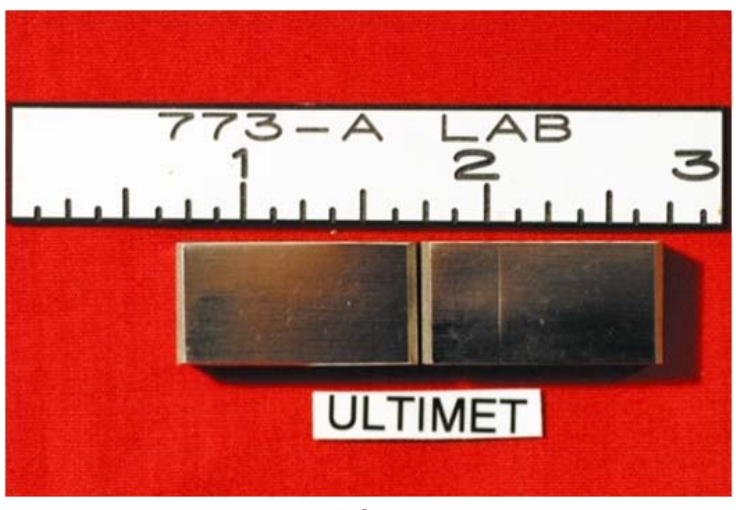

After 


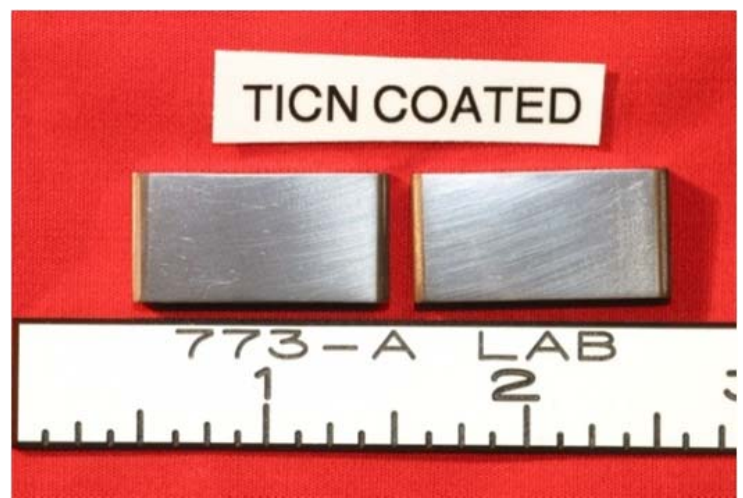

Before

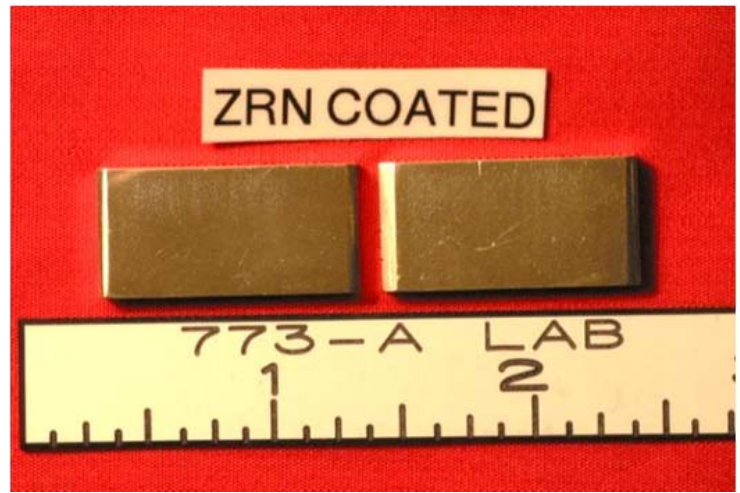

Before

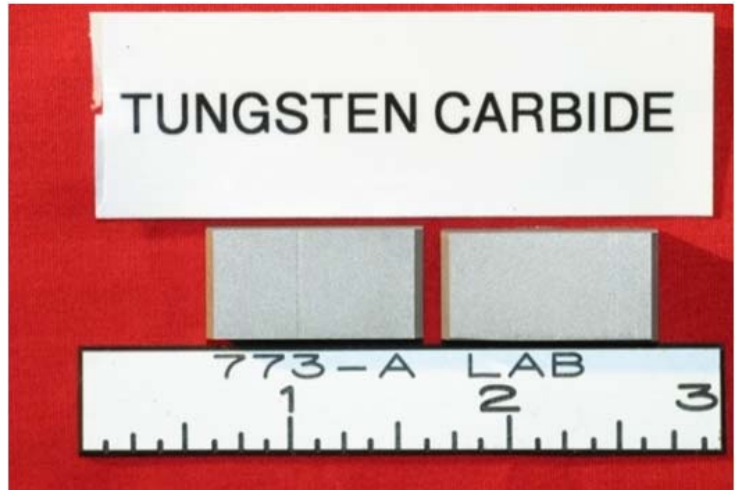

Before

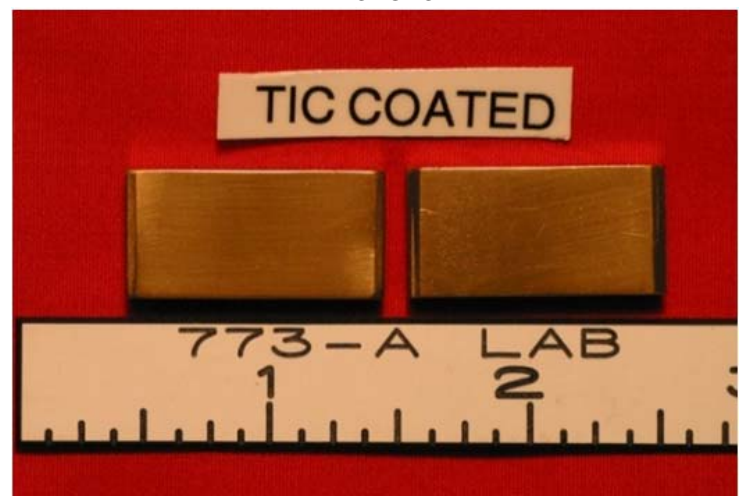

Before (mislabeled)

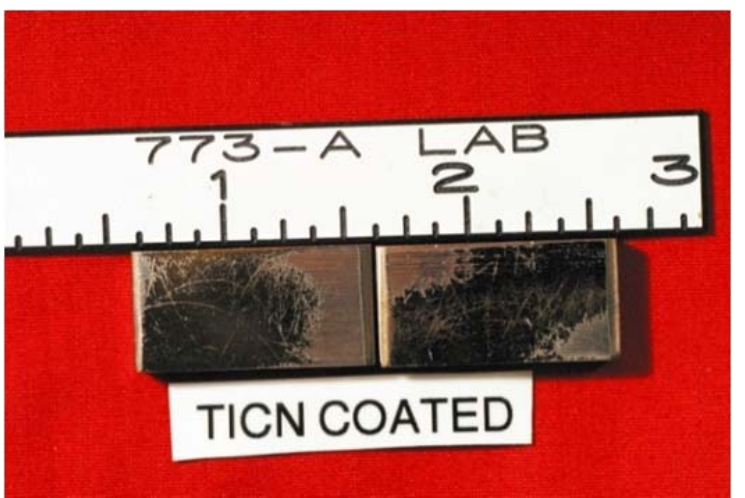

After

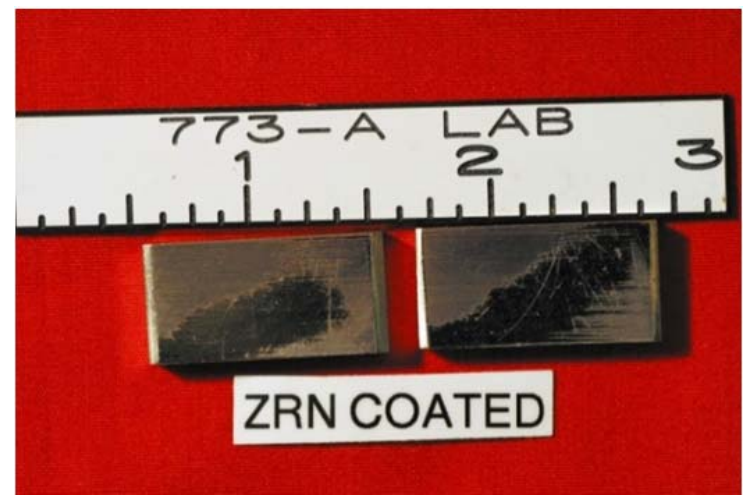

After

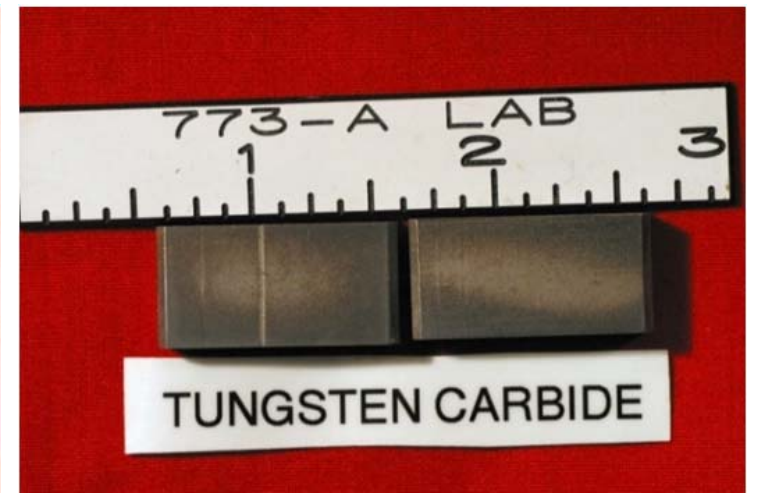

After

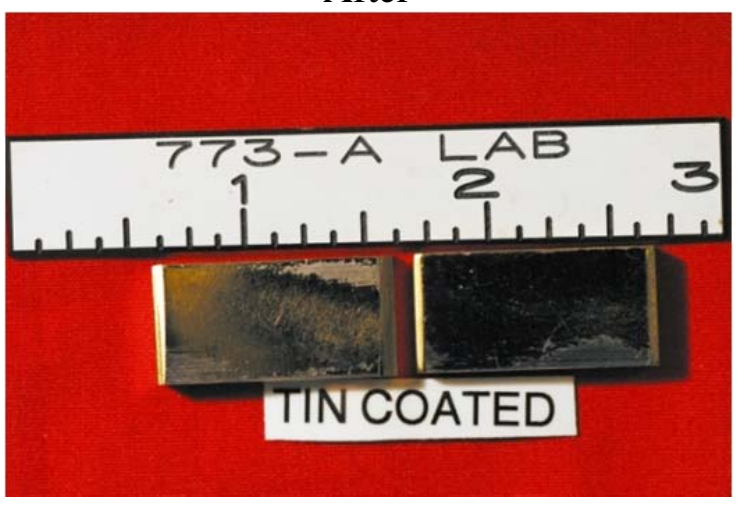

After 


\section{Distribution:}

\begin{tabular}{|c|c|}
\hline S. L. Marra & 773-A \\
\hline S. D. Fink & 773-A \\
\hline K. M. Fox & 999-W \\
\hline B. J. Giddings & $786-5 A$ \\
\hline C. C. Herman & 999-W \\
\hline F. M. Pennebake & $773-42 A$ \\
\hline P. M. Almond & 773-43A \\
\hline A. D. Cozzi & 999-W \\
\hline R. E. Eibling & 999-W \\
\hline E. K. Hansen & 999-W \\
\hline C. A. Langton & $773-43 A$ \\
\hline D. H. Miller & 999-W \\
\hline B. R. Pickenheir & 999-W \\
\hline M. M. Reigel & 999-W \\
\hline M. G. Serrato & $773-42 \mathrm{~A}$ \\
\hline D. B. Stefanko & 773-43A \\
\hline P. R. Jackson & $703-46 A$ \\
\hline K. H. Subraman & hian $\quad 249-8 H$ \\
\hline J. M. Bricker & $704-27 S$ \\
\hline K. D. Dixon & $704-14 Z$ \\
\hline J. N. Leita & $704-Z$ \\
\hline K. R. Liner & $704-S$ \\
\hline P. D. Mason & $704-14 Z$ \\
\hline P. W. Norris & $704-29 S$ \\
\hline J.E. Occhipinti & $704-S$ \\
\hline J. W. Ray & $704-S$ \\
\hline S. C. Shah & $704-14 Z$ \\
\hline \multicolumn{2}{|c|}{ D. C. Sherburne704-S } \\
\hline A. V. Staub & 704-27S \\
\hline J. R. Tihey & $704-Z$ \\
\hline
\end{tabular}

